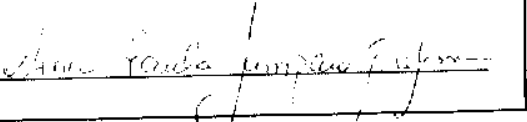

\title{
Investigando abordagens para a criação automática de ligações entre repositórios web $^{1}$
}

\author{
José Antonio Camacho Guerrero
}

Orientadora: Profa. Dra. Maria da Graça Campos Pimentel

Disscrtação apresentada ao Instituto de Ciências Matemáticas e de Computação - ICMC-USP, como parte dos requisitos para obtenção do título de Mestre em Ciências de Computação e Matemática Computacional.

USP - São Carlos

Dezembro/2002

${ }_{1}$ Trabalho realizado com o apoio tinanceiro da FAPLSP $(00 / 14103-6)$ 


\section{A Comissão Julgadora:}

Profa. Dra. Maria da Graça Campos Pimentel Profa. Dra. Maria das Graças Volpe Nunes

Prof. Dr. Wagner Meira Junior

$$
\text { Lagne mpis pinon }
$$




\section{Dedicatória}

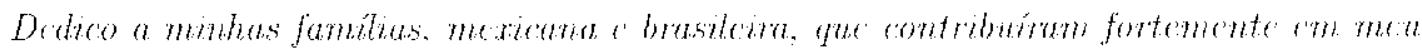

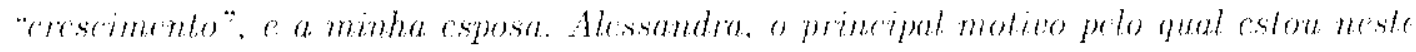
ponto da minha vida. 


\section{Agradecimentos}

Inicialmonte ayradeco a Detus, por loda proteça c forca.

A minha orientadora, Graca Pimentel, por scus cosinamentos, criticas r sugestoes que muito me ajudaram no desenulvimento do trabalho.

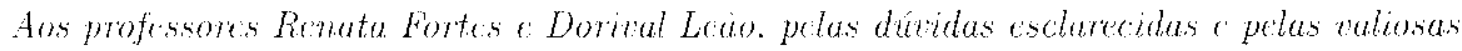
sugesticess.

A FAPESP (00/14103-6) pelo apoio finunceiro.

Aqueles que participaram dos expermentos de Reletance fextback:

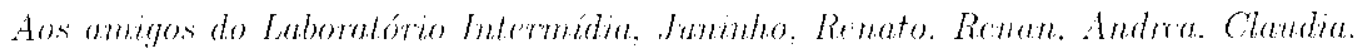

Lacreio. Diluan, Débora e Elaine.

As secretárias da Pós-Gruduaço, Belh. Lanra t Ana P'aula. e. Tatiana. do Departamente Finanution.

A minhos famnias pelo apoio, cartibo e amor etemos.

Agradeço a minha esposa o amor. a confiança a compronsào, a ajudn e a infinita

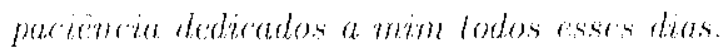




\section{Resumo}

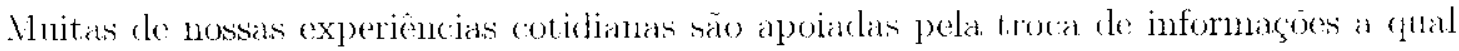
pode ser capturada de modo a suportar a geragăo autonátic de hiperdocumentos cule: correspondem às expcricncias capturdas. () l'rojeto eClass do Georgio Institute of Tech-

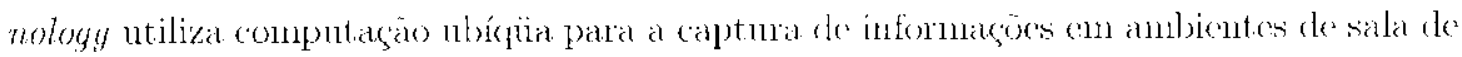

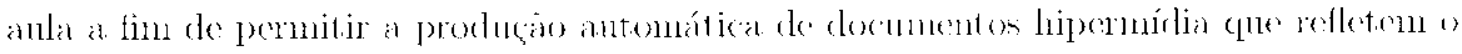
conterído capturado. Anbiestes como os do Projeto eClass pormitem a antoria ant omática de ligacoen hipertexto a partir da interagäo do uslário com o anbiente mbíqüo. Servigess

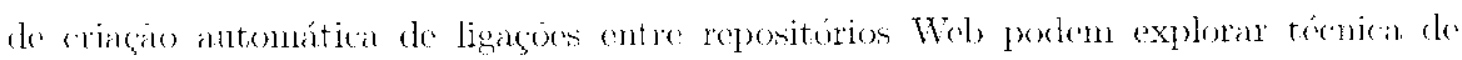
Recuperaçäe de Informaçăo, cono demonstram trabalhos que véen semde desenvolvides pelo grupo de pescuisa no qual este trabalho cstá inserido. No cutanto, taic técnicas

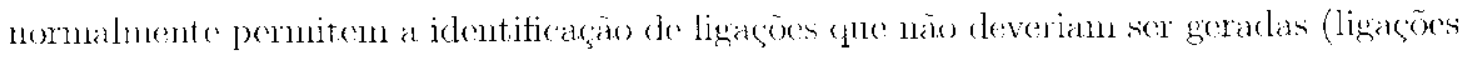

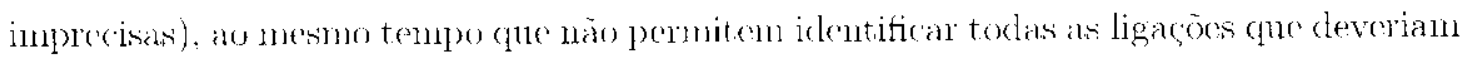
tor sido geradas (ligaços relevantes). Esses faros notivaran o thabaltho apresentado.

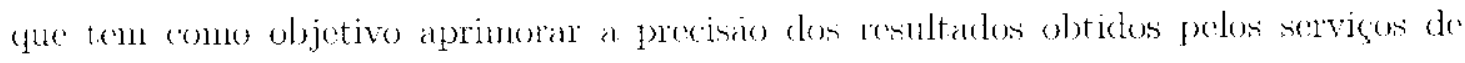

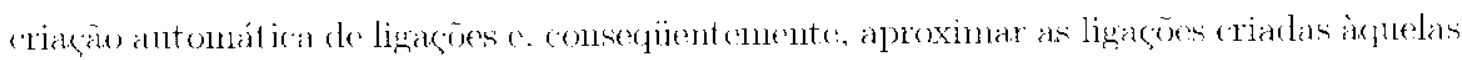
exporadas pelos usuários. Para alcançar esse objetivo. foram utilizadas abordagens de

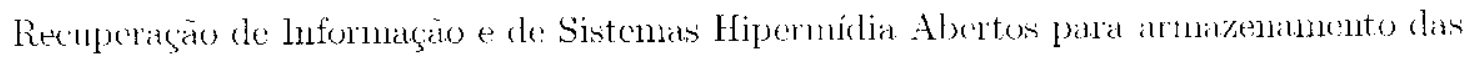

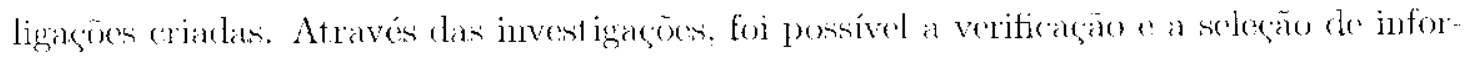

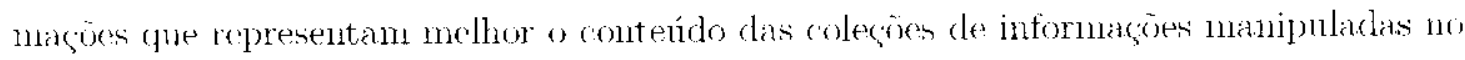
sentido de prover ligagoes mais precinas. Como resultado. foram definides procedinentos,

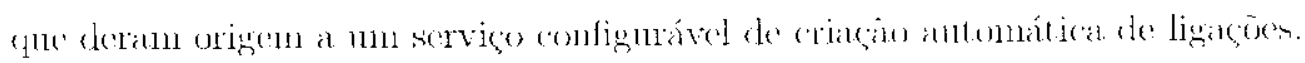




\begin{abstract}
Nany everyday experiences are based on the exchange of information which can be (al)tured to support the aut onatic generation of multimedia lyperdoments corroponding to those experiences. The eClass Project, developed at the Georgin Institute of Tech-

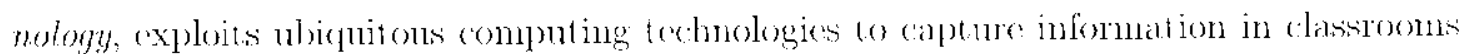
lowarde allowing the antomatio gencrat jon of hypernedia documents comesponding to live lectures. Such environments allow the automatic gemeration of hypertext links from

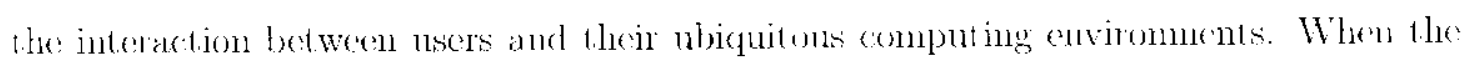

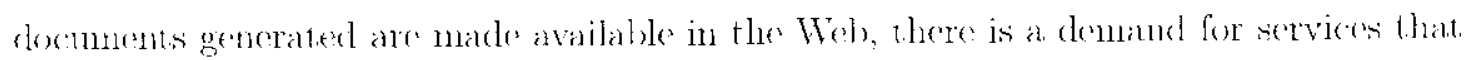
support the automatic indentification of hypertext links annong the documents thenselves or anong those docments and other web-based material: such services can malko use of Intormation Retrieval techinines. However. Information Retrieval techniques ustally leak to the identification of relationships that shoukl not have heen generated (gemerating non-relevant links) at the same time that lail to identify all relevant relationships (poor recall). The aim of this work is to builel upon antomatice linking servieces in order to furthes investigate information retrieval techniques towarels innproving the quality of the relationships identified. The investigations lave used a collection of docunents

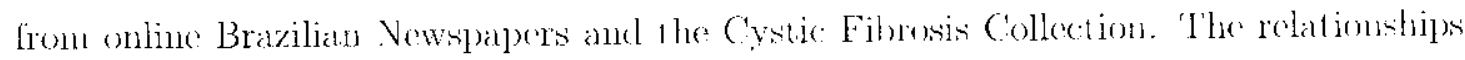
identified lave bern used to generate links anweng the repesitories investigated. while the links have been stored in an open hypemedia linklase to allow their use by any applications. The positive results of the investigations latve defined the requirements for

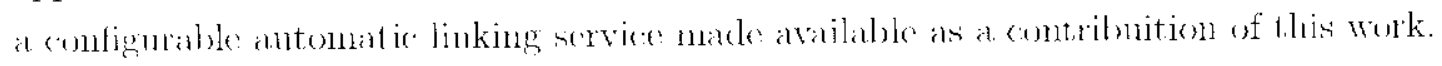




\section{Conteúdo}

1 Introduçāo 1

1.1 Consideracoss Iniciais . . . . . . . . . . . . . . . . . . . . . 1

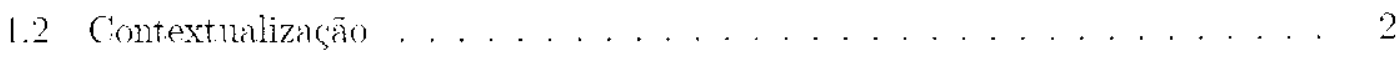

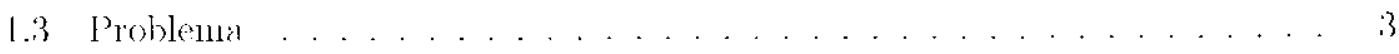

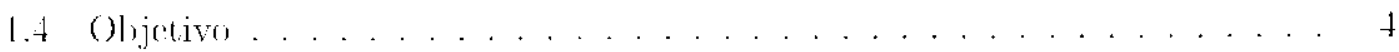

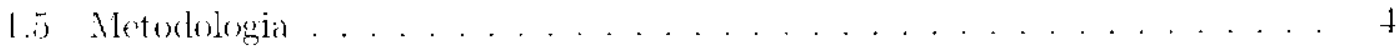

1.6 Restutades. . . . . . . . . . . . . . . . . . . . 4

1.7 Estrutura do Toxto . . . . . . . . . . . . . . . . . 5

2 Recuperação de Informação $\quad 6$

2.1 Consideracoes Iniciats . . . . . . . . . . . . . . . . . . . . . . c;

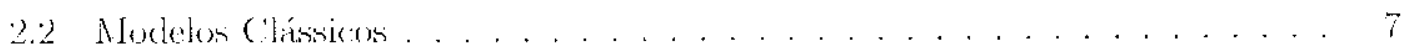

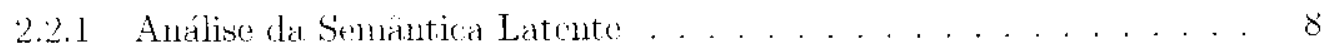

2.3 Escuenas Clássicos de Atribuiça de Pesos . . . . . . . . . . . . 11

2.4 consultas . . . . . . . . . . . . . . . . . . . . 13

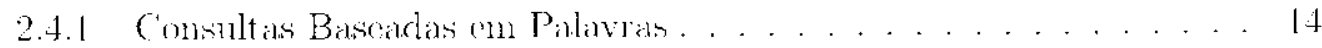

2.4 Expansine de Consultais . . . . . . . . . . . . . 15 


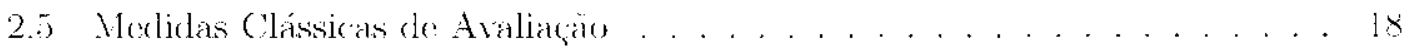

2.6 Consideraçoes Finais . . . . . . . . . . . . . . . . . . 19

3 Sistemas Hipermídia Abertos 20

3.1 Consideraçoes Iniciais . . . . . . . . . . . . . . . . . . 20

3.2 Características de Sistemas Ilipermidia Abertos . . . . . . . . 21

3.3 Requisitus de Sistenas Hipermídia Abertos . . . . . . . . . . . . . 22

3.4 Protoculo Hipernídia Aberto e o Padrão XML . . . . . . . . . . . . 23

3.5 Estude de Caso de SHA: Wel, Linkibase Servicer . . . . . . . . . . 25

3.5 .1 Requisites do WLS . . . . . . . . . . . . . 25

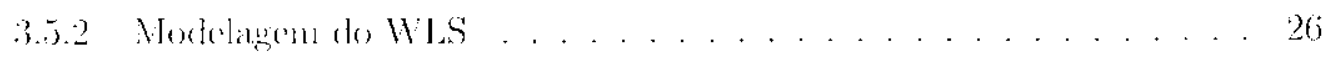

3.5 .3 A Arquitetura do WLS . . . . . . . . . . . . . 27

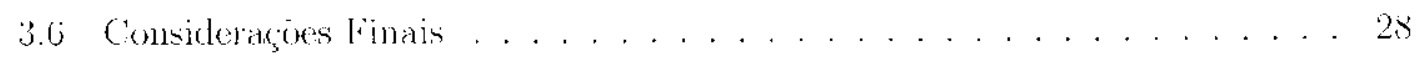

4 Criação Automática de Ligaçōes $\quad 29$

4.1 consideracos Iniciais. . . . . . . . . . . . . . . . . . . . 29

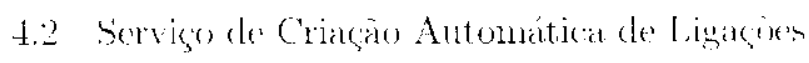

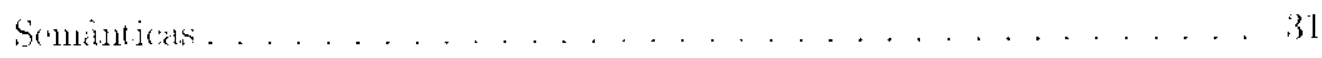

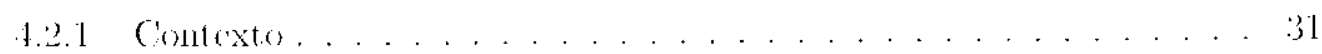

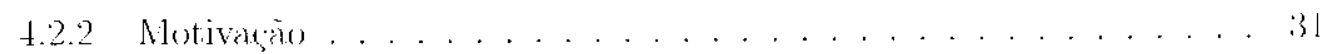

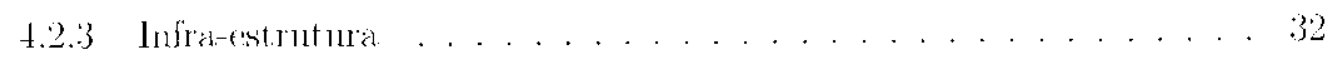

4.2 .4 Implenentaçào $\ldots \ldots \ldots \ldots \ldots \ldots \ldots$

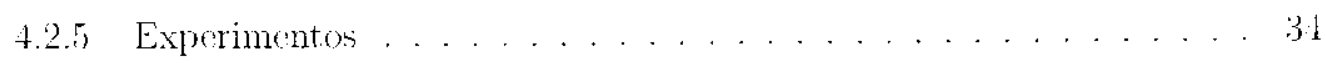


4.3 Serviço Aberto de Criação Automáticia de

Ligagoes sominticas . . . . . . . . . . . . . . . . . 36

4.3 .1 Notivatgio . . . . . . . . . . . . . . . . . . . . . . . . . . .

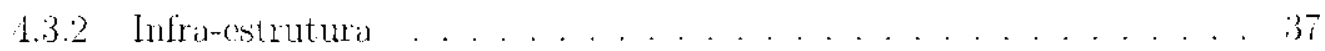

4.3 .3 Implementacăo . . . . . . . . . . . . . . . . 38

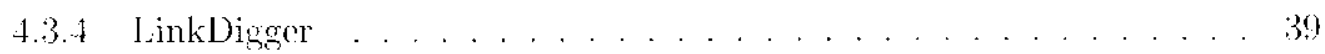

$4.3 .5 \quad$ Experimento. . . . . . . . . . . . . . . . . 10

1.4 Consideragies Finais . . . . . . . . . . . . . . . . . 41

5 Investigando abordagens de IR para a criação automática de ligações $\begin{array}{ll}\text { entre repositórios } & 42\end{array}$

5.1 Consideraçies Iniciais . . . . . . . . . . . . . . . . 12

5.2 Delinican dos Experinentos . . . . . . . . . . . . . . . . .

5.2 .1 Anbiente operacional. . . . . . . . . . . . . . . . .

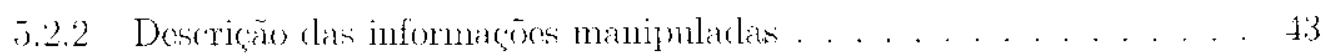

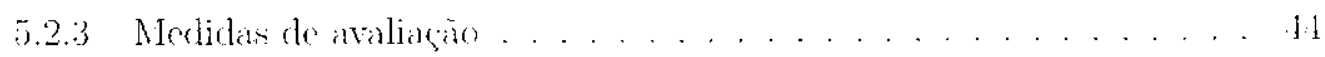

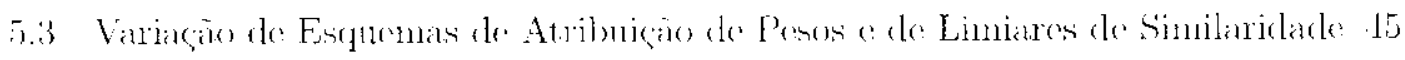

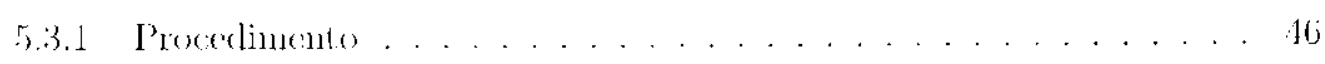

5.3 .2 Resultados . . . . . . . . . . . . . . . 47

5.4 Reduça Baseadla eln Distribuiçoes Matenuáticas . . . . . . . . . . . . 49

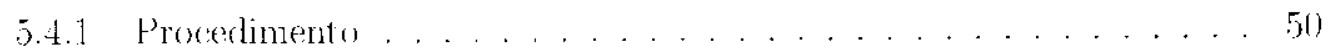

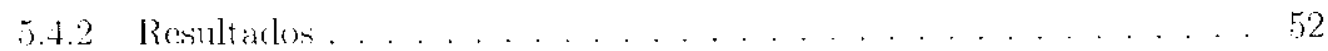

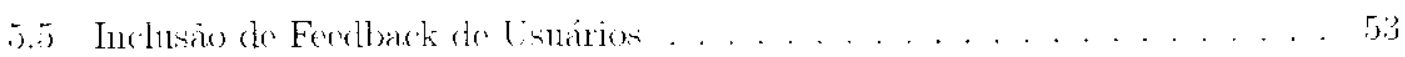

$5 . \bar{s} 1$ Procedinnemos . . . . . . . . . . . . . . . . . . . . . 
5.5 .2 Resultados. . . . . . . . . . . . . . . . . 57

5.6 Detinigàn de un Sorvico Configurárel . . . . . . . . . . . . . . 58

5.6 .1 Procedinento . . . . . . . . . . . . . . . . 6 60

j. $\bar{i}$ Consideracoes Finain . . . . . . . . . . . . . . . . . 62

6 Conclusões $\quad 64$ 


\section{Lista de Figuras}

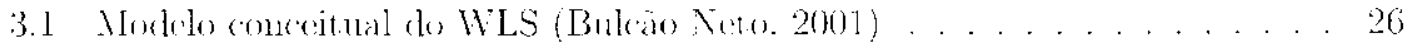

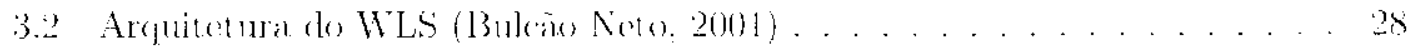

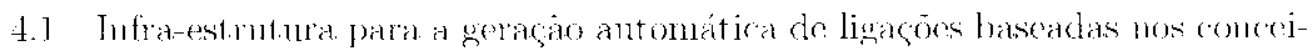

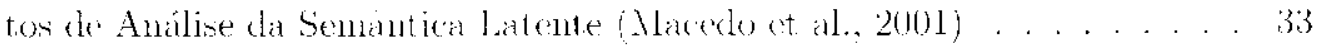

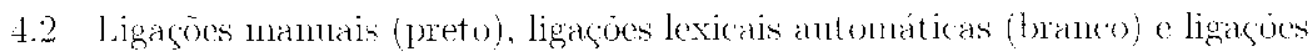

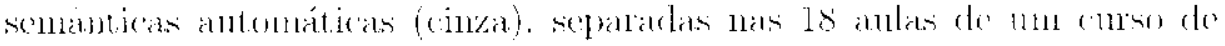

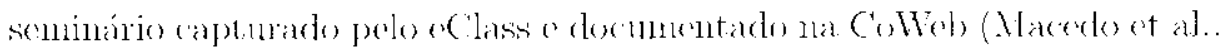

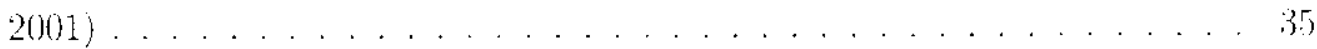

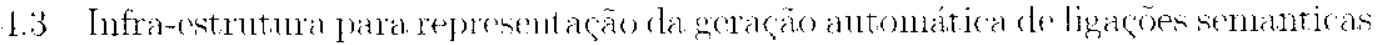

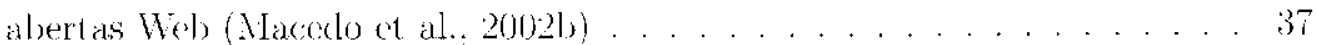

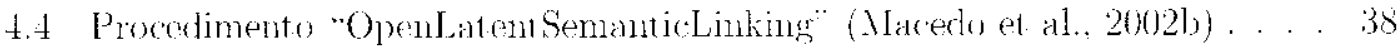

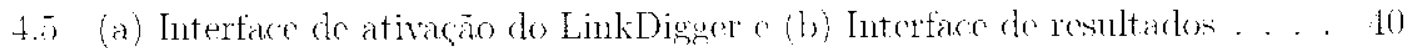

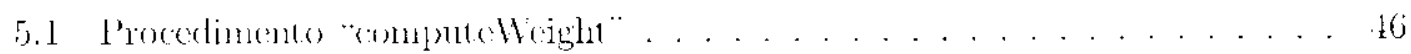

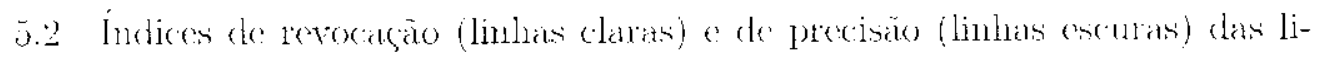

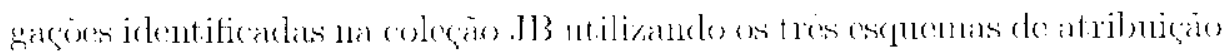

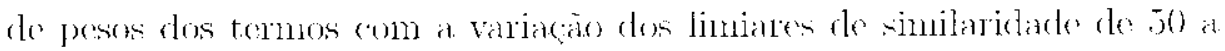

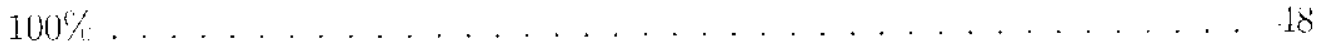




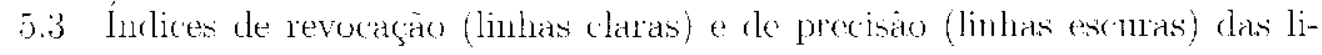

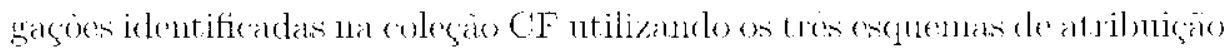

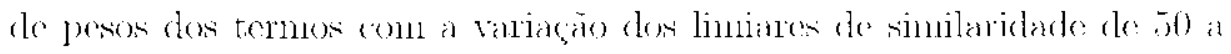
$100 \% \ldots \ldots \ldots \ldots \ldots \ldots \ldots \ldots$

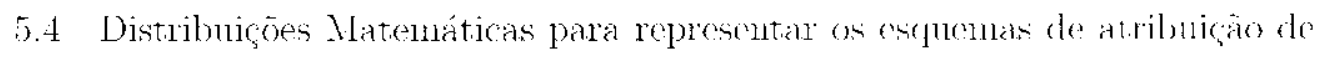

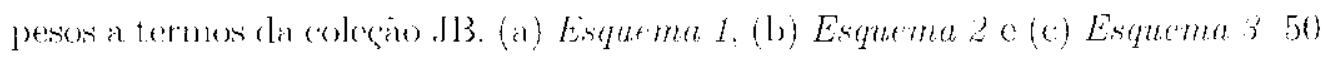

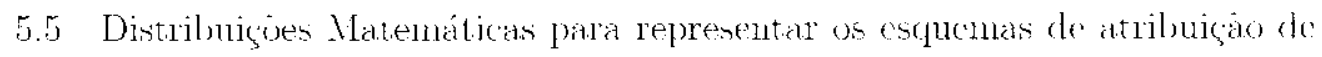

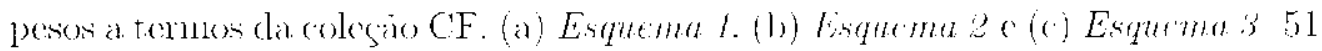

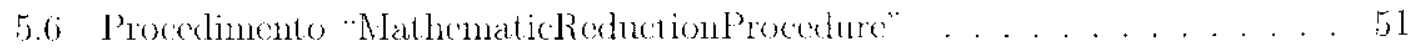

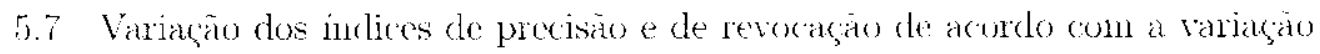

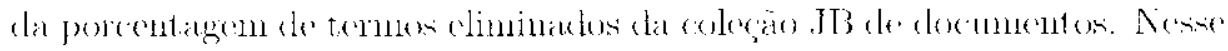

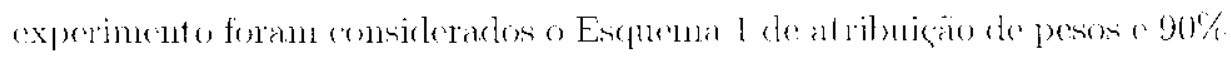
de limiar de similaridade . . . . . . . . . . . . . . . . 5.3

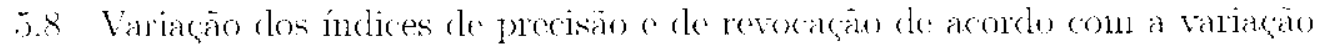

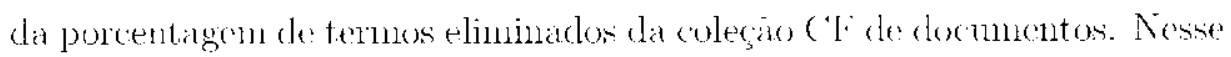

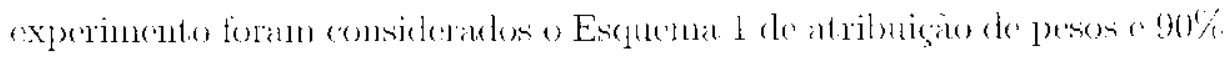
de liniar de sinnilariefade

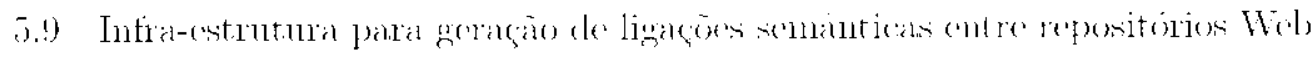

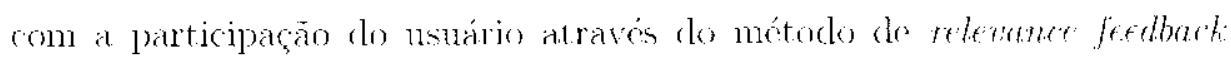

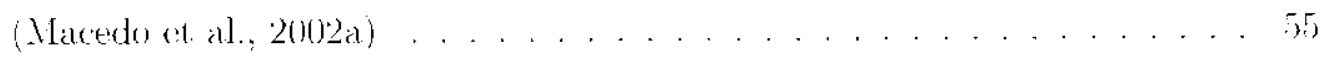

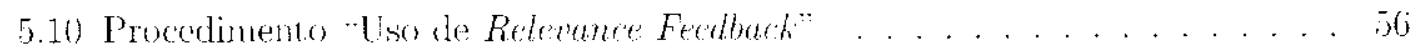

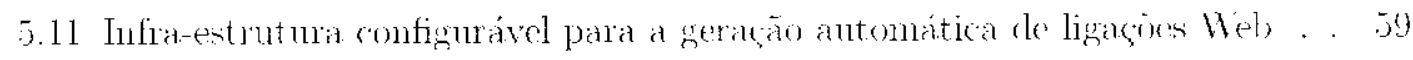

5.12 Procedimento "FlexibleservireLinkine" . . . . . . . . . . . 61

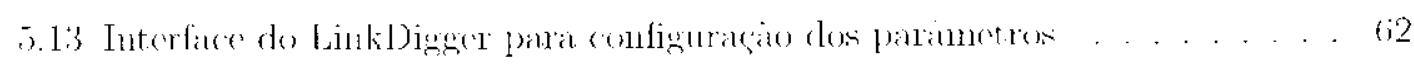




\section{Lista de Tabelas}

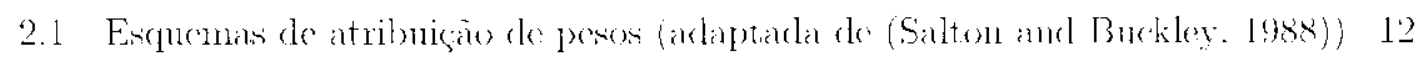

3.1 Paranetros das nensagens do OHP (Gronlozk ct al., 1999) . . . . . . . 24

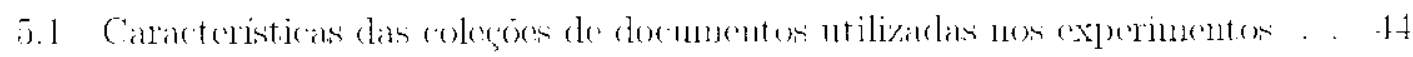

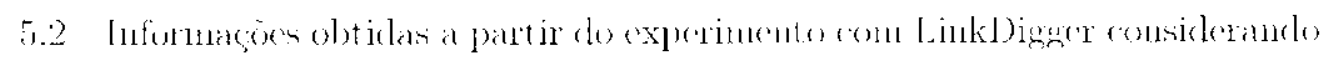

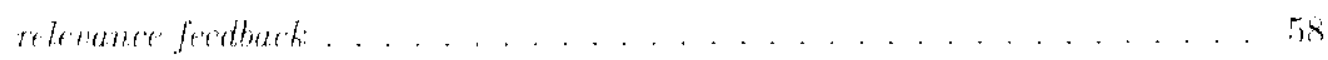




\section{Capítulo 1}

\section{Introdução}

\subsection{Considerações Iniciais}

Nossas experiencias diárias sá apoiadas pela troca de informagoes cule se capturadas,

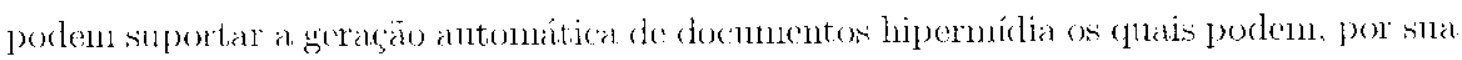

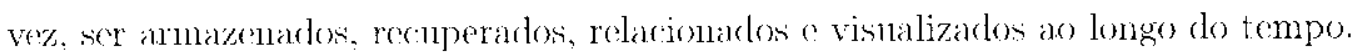

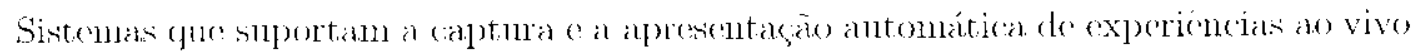
clinininm o trabalho humano nas atividades de registro dessas experiências e, conser qüentemente, elininann a sobrecargad connitiva despendida para tal tarefa. Vários traballoss

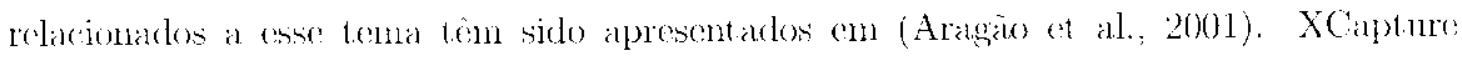
(Hindus and Schmandt, 1992) captura inlomaçós do áudio de onversaçós telefonicast e prove um meio de acessar sell conteúdo. Os sistemas Tivoli (Pedersen et al., 1993) o

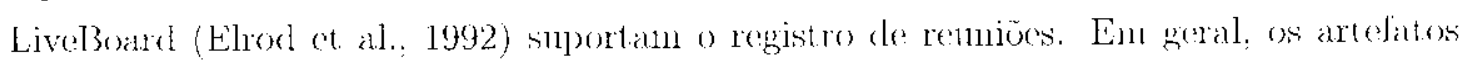

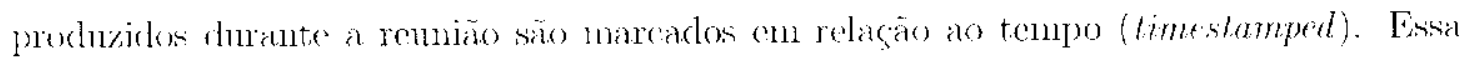
marcagano tenponal é utilizada posteriormente à captura para indexar os registros de áudio

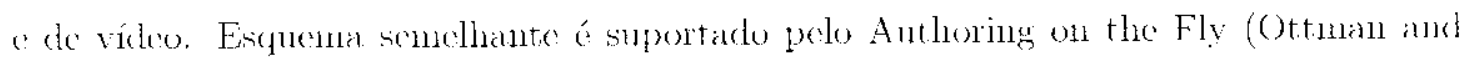
Berher, 1995) " pelo Lecture Browser (Mnkhoparllya and Snith. 1999). Já o XLibris (Price ot al., 1998) ó $1 \mathrm{~m}$ ambiente que apresenta infurmaçoes utilizando a metáfora de

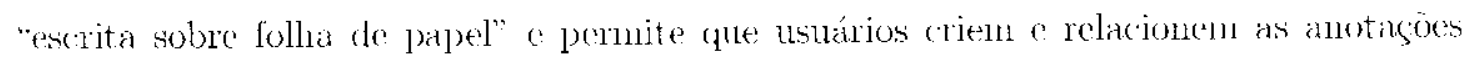

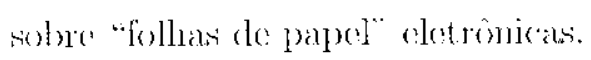

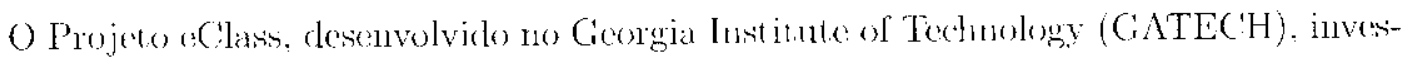

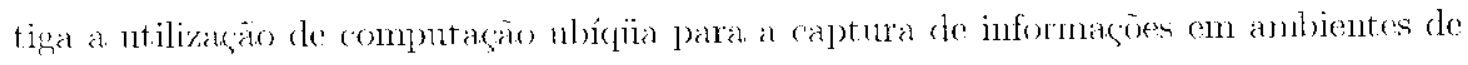


sala de aula convencionais, de modo a permitir a produção automática de docunentes

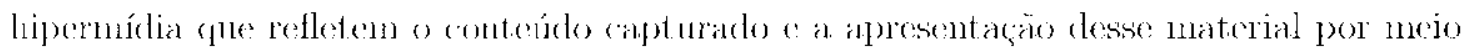
da. Wol, (Abowd, 1999) (Abowd ot al. 1998i) (Abowd et. al., 1998b) (Brotherton and Abowd, 1998) (Brotherton et al., 1998). Esses hiperdocumentos sào baseados en ligaçōes

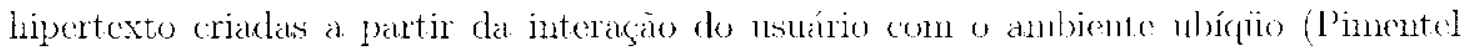
(1) al., $2(0)(0)$.

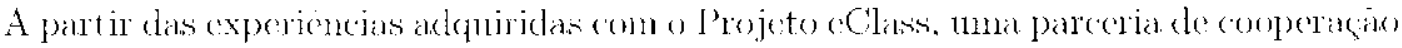

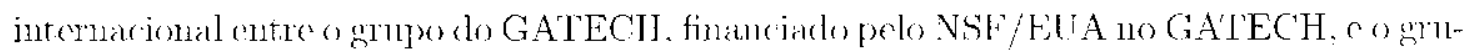
po de pesquisa da orientadora desta dissertaçào. financiado pelo Próle-l-CC/CNPq/Brasil. tem como objetivos:

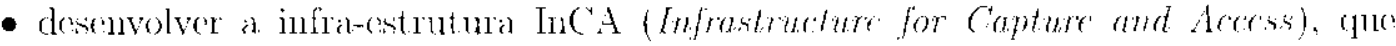

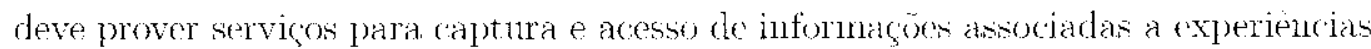

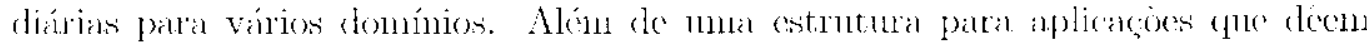

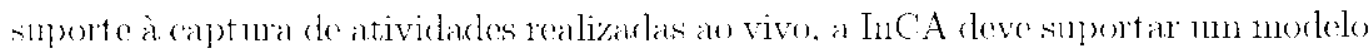
de informaça extensivel para a captura de experiencias que podem ser utilizadas para integrar as atividades que ocorrem fore da sestian de captura;

- desenvolver a inlra-estrutura SERVE (Infrastructure for Store. Extend, Retrent

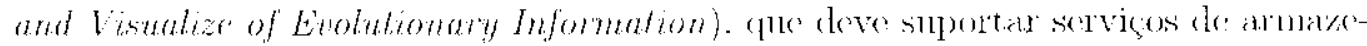

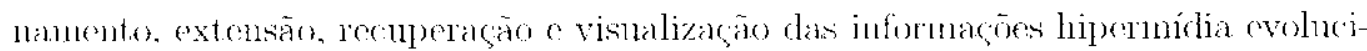
onćrias capturadas pela $\ln (\mathrm{A} A$ :

- utilizar as infra-estruturas InCA-SERVF na construgáo de aplicacoes de suporte a atividades de ensino nos anbintes do IC MC LSP o do CATECII.

O presente trabalbo se insere no projeto do desenvolvineme das inlra-estmuturas lnCA-SERVE (Pinentel and Abowd. 19999).

\subsection{Contextualização}

Os ambientes XCapture, Tivoli, LiveBonde, Authoring on the Fly, Lexture Browser,

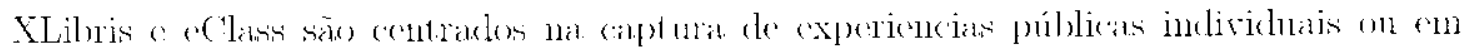

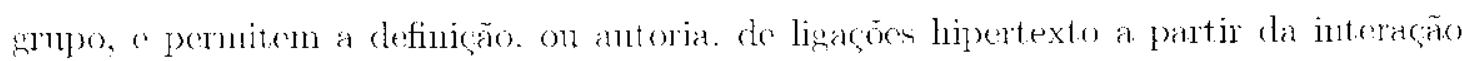

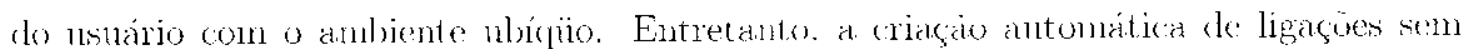


qualquer intervençäo de usuário dinninui a sobrecarga cognitiva despendida nossa tarefa e por isso, toma-se una importante fermonenta de anxílio à antoria de hiperdocumentos.

Servicos de criaçäo automática de ligaçoes entre repowitórios Wel contrndo informaçös homogêneas foram trabalhos desenvolvides en conjunto pelo antor junto ao grupo de pescuisa no qual cstá inscrido (Pimontel et al., 200 lb) (Nacedo et al., 2001) (Macedo ('t al.. 2002b).

A primeira abordagm investigada polo grupo foi a de comparaçies lexicais para integrar dois repositórios conplementares de informaçós associadas a mun mesmo curso de pós-graduaçào (Pinentel et al.. 2001b). Contudo, essaśs comparações lexicais ocasionavam problemas para relacionar, por excmplo, palavras sinônimas com grafial distintas. Una

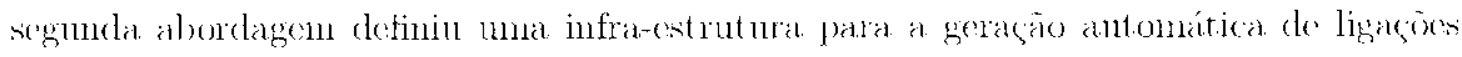
baseadas em entruturas semanticas cxtraídas de repowitórios Web (Macedo ot al.. 2001). A necessidade de inchusáo de marcaçós (tags) em documentos para a definiçăo de ligagós pode ser um olstáculo para os servicos antomáticos. Na tontativa de explorar an contribuiçós do Sistomas Hipernúrdia Abertos sobre repesitórios Web, foi proposta uma infra-strutura aborta para a criação de ligaçoes hipermídia a partir de estruturas semanticas implícitas entre repositórios honogeness Webs (Macedo et al., 20021).

Para veriticar a utilidade das infra-estruturas propostas, foram readizados experinem-

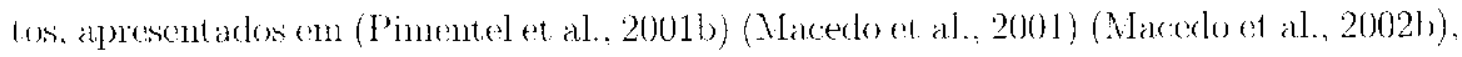
que demonstranu grandes variaçoes de precinão na definiçăo antonática de ligacócs.

\subsection{Problema}

Através da utilização de serviços que antomaticanente crian ligaçoes, usuários săo capar-

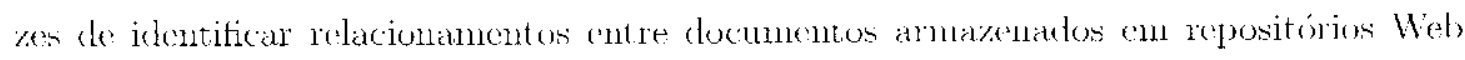

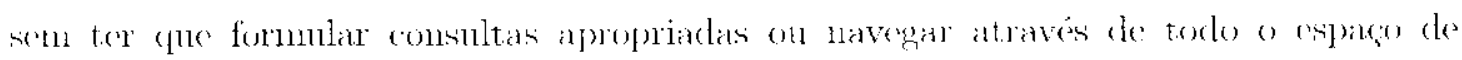

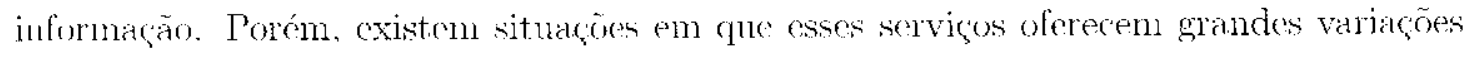
de precisán na definiça dos relacionanentos. Por csse motivo toma-se importante a investiganga de alowdagens que permitam aprinorar a precisado dos resultados obtidos por serviços de criaçầ antomática de ligacóes. 


\subsection{Objetivo}

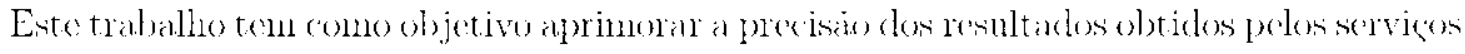
de criaçăo antomática de ligaçoes desenvolvidos pelo grupo e criar manciras de adechur esses serviços às necessidades dos usuários.

\subsection{Metodologia}

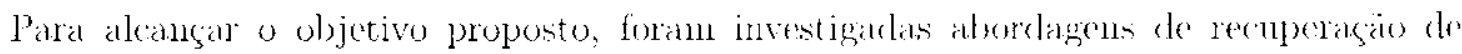

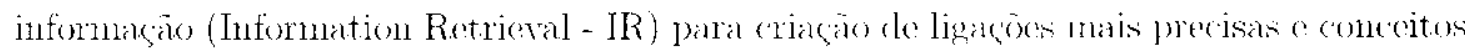
de Sistemas Hipermídia $M$ bertos para armazenamento des ligagoes r riadas. As abordagens de: IR investigatlas formun:

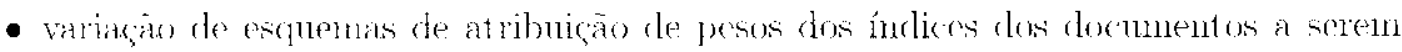
relaciomados;

- variaçăo de liniares de sinilaridade dumate verificaçoes de similaridades entre documentos candidatos a definiçare de ligasues hijertexto;

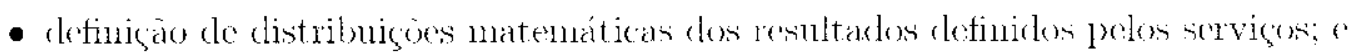

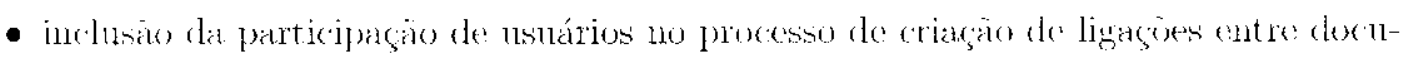

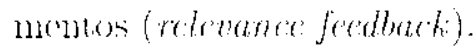

Para a roalizaça das investigasios citadas e para comparaçoes de resultades, formu

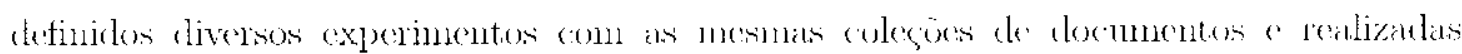

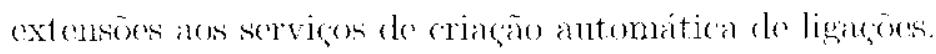

\subsection{Resultados}

A partir da investigacäo das abordagens de IR citadas, foi possivel verificar um apri-

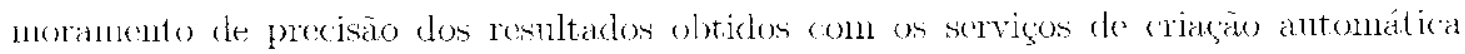

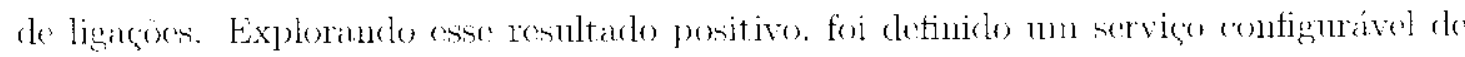

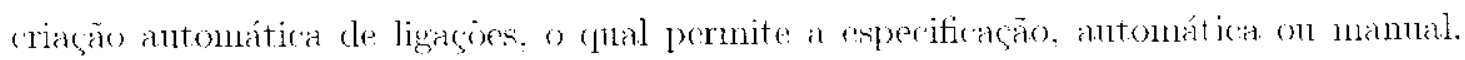
de parametros a serem utilizados pelos scrviços de criekào autumática de ligacoes. Os 
paranetros configurados autoniaticannente sán anlequados no contexto no qual o serviço

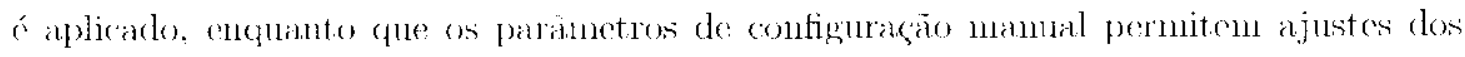
resultados segundor is expectialivas dos usuários.

Os resultados obtirłos com este trabalho têm contribuído para a avanço das pesquisas do projeto InCA-SERVE, principalnente em relação à infra-estrutura SERVE, sendo

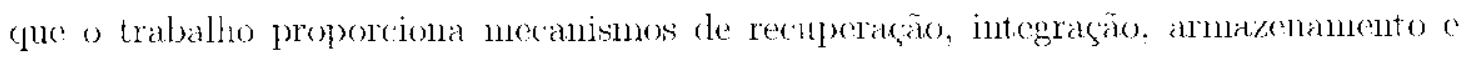
visualizaça de informacoues contidas em repositórios Well.

\subsection{Estrutura do Texto}

Esite (apíf ulo apresenton o contexto no qual se insere este traballho, a motivaçà para sen desenvolvinento, os objetivos propostos e us resultados alcangados. No Capítulo '2 séto

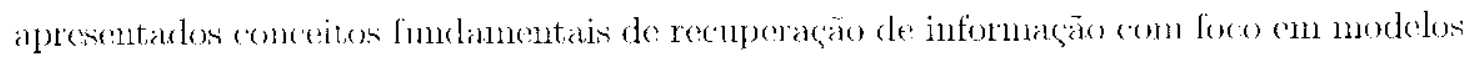

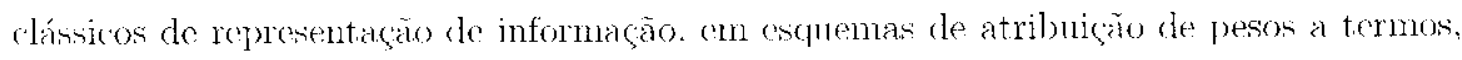
en consultas e en medidas de avaliação. Jo Capítulo 3 são aprescentados características,

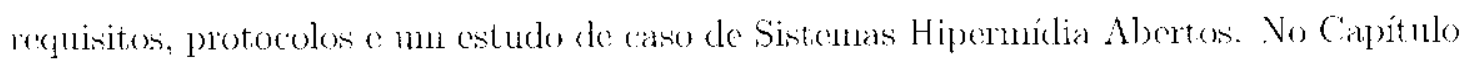

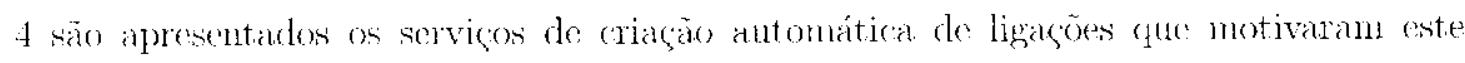
trabalho e, no Capítulo j, sào apresentados os experimentos realizados para suportar as

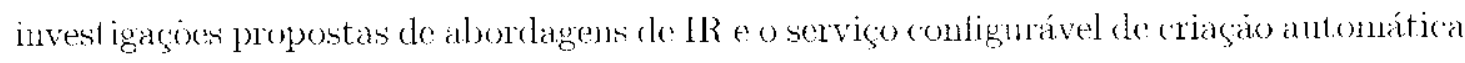
de ligacoes criaklo durante as investigaçoes. Por finn, no Capitulo 6 sano apresentades as conchuoses, as contribuiçoes e os trabalhos futuros. 


\section{Capítulo 2}

\section{Recuperação de Informação}

\subsection{Considerações Iniciais}

Com o crescinmento da Web o a conseqüente dispmibilidade de colegós de docuemntos cmline, tornou-se fundamential a investigagà do mocanismos rápidos e eficientes para

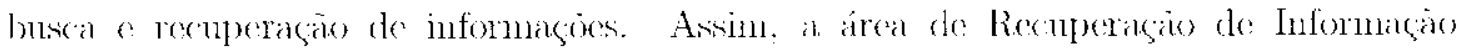
(Information Retrievaj - IR), que há tempos vem realizando estuclos de técnicas o de

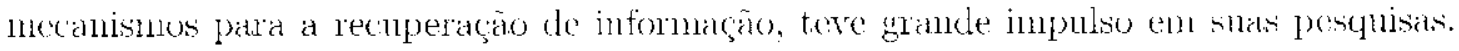

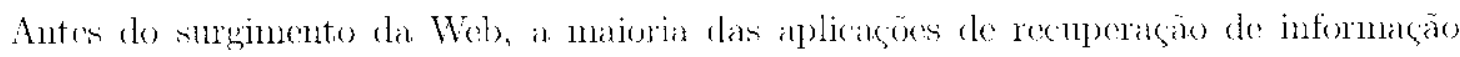

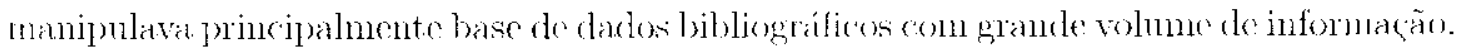
Essas aplicaçoen gerahmente utilizavan lógica booleana para a realizagăo de consultas en seres repusitónion.

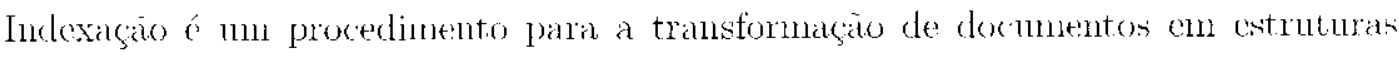
de dactos digitalizadas, que representan conceitos logicos dos docnunentess. Porém, "

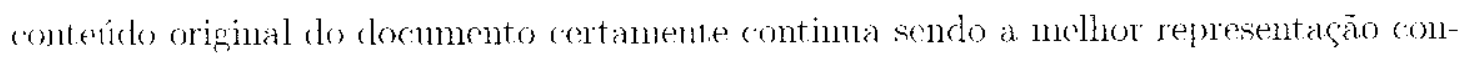

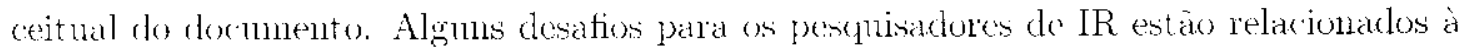

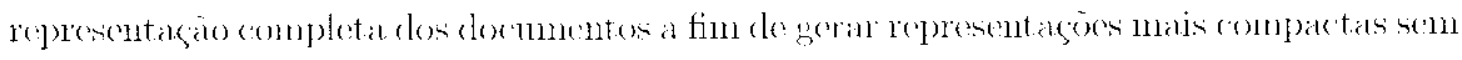

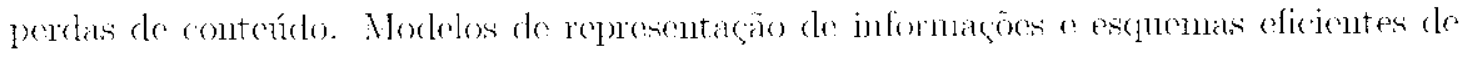
atribuiçăo de pesos procuram aprimorar o procosso de indexaça facilitando a res:uperaçăo

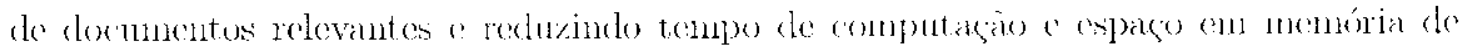

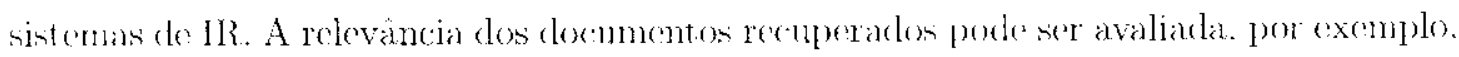
por un conjunto de medidas dássinas denominadas judices de precisão e de revocaçäo.

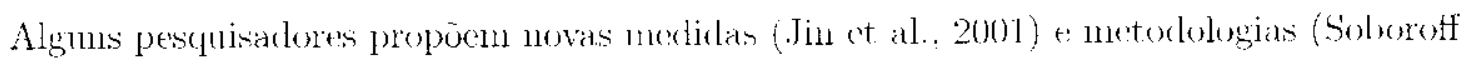


et al., 2001) para avaliar o desempenho de sistemas de IR, contundo índices de precisáo e de revocagào continudun sendo os mais utilizades (Bacza-Yates and Ribeiro-Neto, 1999).

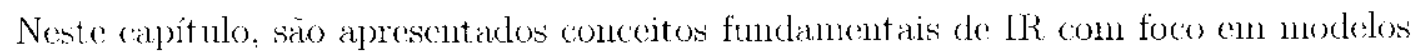

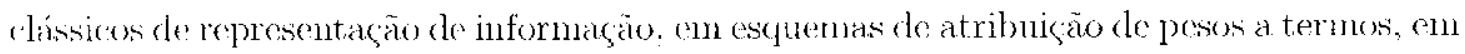
consultas e en medidas de avaliação. Abordagens de IR motivaram o trabalho apresentado nesta dissertação no sentido de buscar soluçöes na literatura e de explorá-las para mellorar o desempenho de serviçs de riagno automática de ligacoes entre repositórios Wob. Pretende-se utilizar esses serviços sobre informaçés de captura de experiencias de salas de aulas suportadas pelo P'rojeto InCA-SERVE e informaģoes distribuídas pela Web com material didático dacpueles curses capturados.

\subsection{Modelos Clássicos}

(os modelos clássicos em IR consideran que cada docmuncuto é descrito por mun comjunto do palavras-chave chamadas índices. Existem tres modelos clássicos -- booleano, probabilístico o vetorial. On quais utilizann csses indices para calcular o gran de comelanga (nntre os documentos (Bac\%a-Yates and Ribeiro-Nets). 1999).

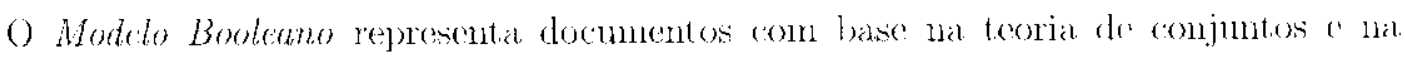

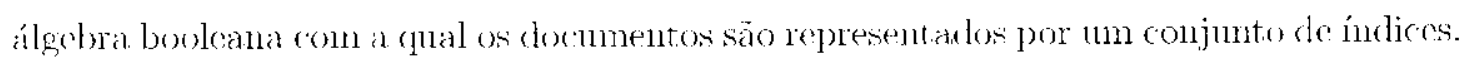
A esses indices podem ser atribuidos pesos binários: isto é. "l" se o índice existir no contéde do documento on "()" (aso contrário.

O Moddo Probabilistico é baseado na estinativa das probabilidades que numários tem

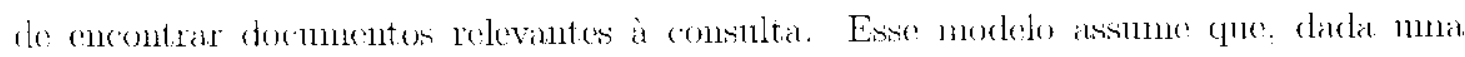
(onsultac existe un comjunto resposta ideal co oprocesso de buscat está bascado na tentativa de encontrar as propriedades desse conjunto (Robertson and Jones, 1976).

Utilizando esse modclo, usuários interagen con interfaces de buscat para indicas os

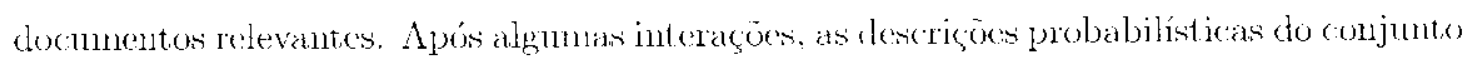

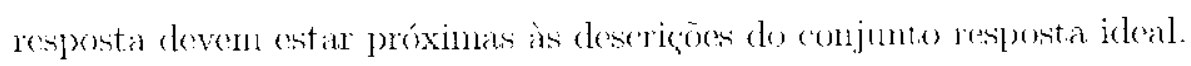

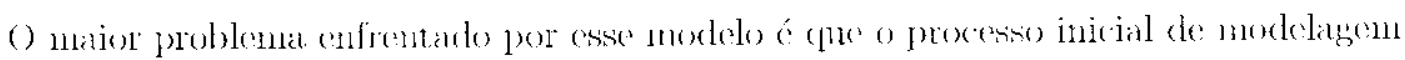

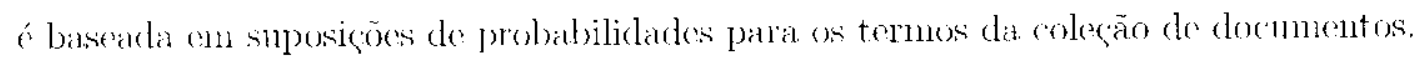

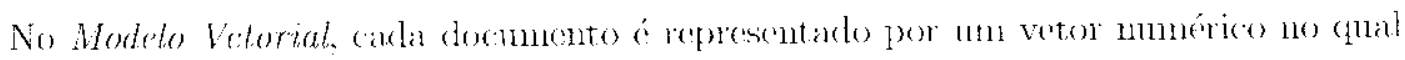


cada clomento representa um termo, e para cada un desses temos são atribuídos pesos

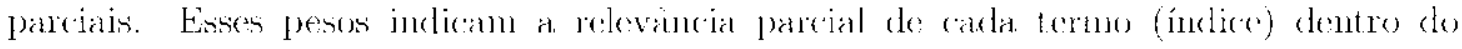
documento (Salton and tesk, 1968), a sano ntilizades para calcular o gran de similaridade?

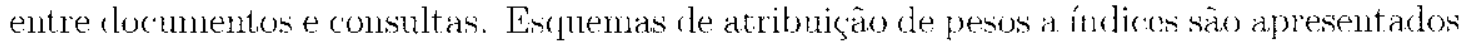

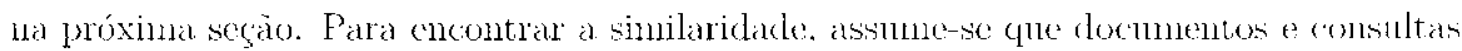

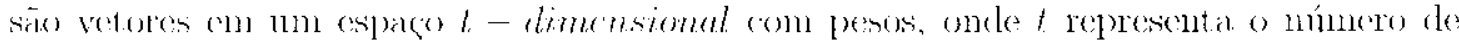
trmos de cada doc umento. Assim, documentus e consultas podem ser comparados através do cálculo da distancia entre os vetores que os representam.

Os principais problemas encontrarlos nesse modelo säo a independencia linear do conjunto de indices es nato-casamento des termos (term mismateh). Essé áltimo problema

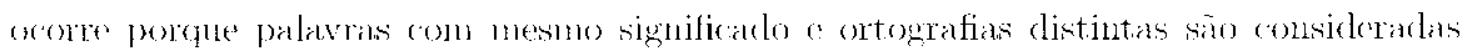
diferentes. () problenda do nào-casanento de termos pole ser tratado por tócnicas de

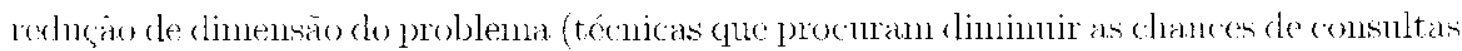

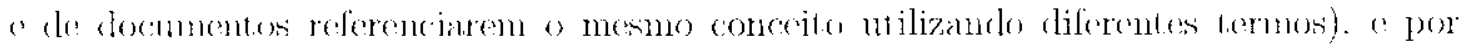
téconicas de expansäo de comsultas (Crestani, 20)(10).

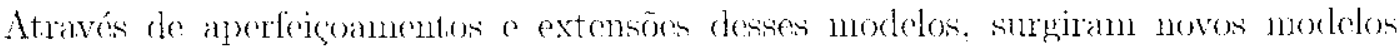

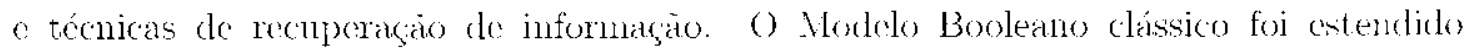

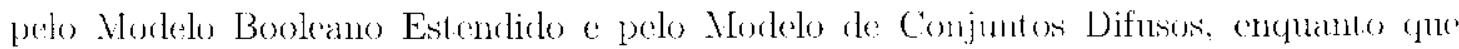

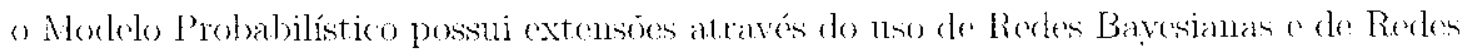
de Iniferência. O Modelo Vetorial foi estendido pelo Morlelo Vetorial Generalizado. pela

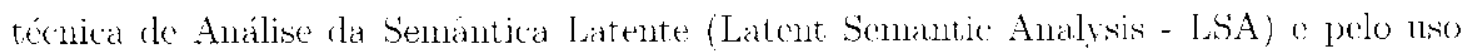

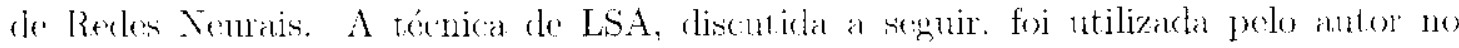
descuvolvinemo dos trabalhos reportados nesta disivertaciào.

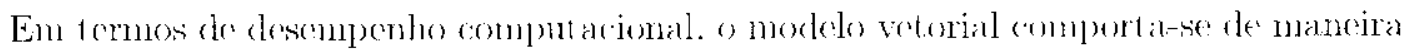
linear em relação ao número de documentos da colegáo. Sula complexidade é de $O(t N)$

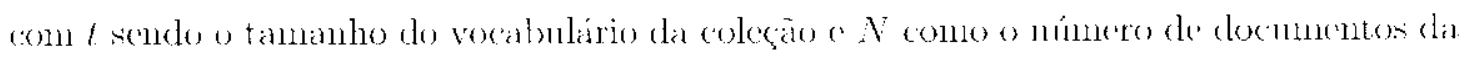
(colecinit).

\subsubsection{Análise da Semântica Latente}

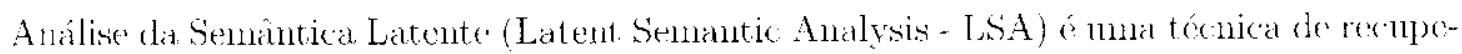

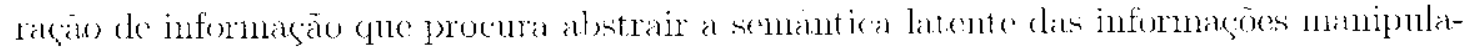
das utilizando conceitos do ádgelma linear a fin de provel um nexanismo para organizaça de infornaçoos textuais em estruturas semantical (Furnas el al., 1988). Essia técnica porde 
ser utilizada para recuperaçäo de infornaçoes e para navegação.

O modelo algébrico de Decomposiçäo de Valores Singulares (Singular Valuc Decomposition - SVD) é utilizado para representaçăo da estrutura semantica manipulada pela trécilca de LSA.

\section{Decomposiçāo de Valores Singulares}

O modelo algébrico de Deromposição de Valores Singulares, SVD, é mun técuica populan e poderosa ntilizada para decompor uma matriz om suas matrizes componentes as quais extraem propriedades importantes da matriz original (Goluls and Loan. 1983). Essa

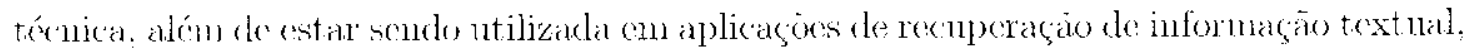

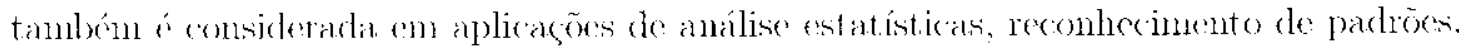
de modo geral. e reconhecinento de faces. em particular.

Ao considerar um grupo de pontos representados en mula matriz $X$ de tamanho $m \times n$, usia natriz pode ser representada da segunte forma:

$$
X=T \times S \times D^{l}
$$

orkte $T$ é uma matriz ortogonal $m \times n$. D é mana matriz orlogonal $n \times n$ e $S$ é l.ma malriz diagonal $n \times n$. Os valores da matriz $S$ sào chamados valores singulares (singula

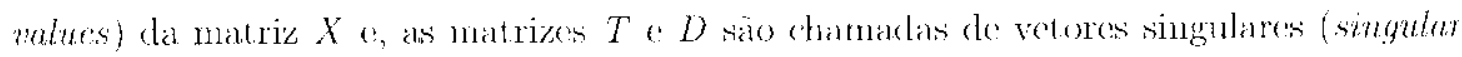
pectors) da direita o da esenerda respextivamente.

Por exemplo, da matriz:

\begin{tabular}{|c|c|c|c|c|}
\hline 1.180 & 11011 & :..1111 & $(0,0) t$ & (1) 116 \\
\hline 2.64 & 200 & 2.HH & 0.000 & (0.10t? \\
\hline 1.100 & : int & $1 \mathrm{iHl}$ & (1).ite & 0.000 \\
\hline D.. $[1, i]$ & $\therefore 014$ & $\therefore 130$ & 11.2111 & 10.1111 \\
\hline i). & קטJ.תי & 19.00 & Z::Hi & 2.39 \\
\hline$\therefore(1,1 \mathrm{w}$ & $\therefore$ :1.01 & 1) & $3: n 1$ & 3. $\mathrm{HII}$ \\
\hline$: 6: 1$ & (1.18) & 0 & 1, 1, & 1.NHI \\
\hline
\end{tabular}

porle-se extrair, atraves do merdelo SVD, as mattrizes connponentes:

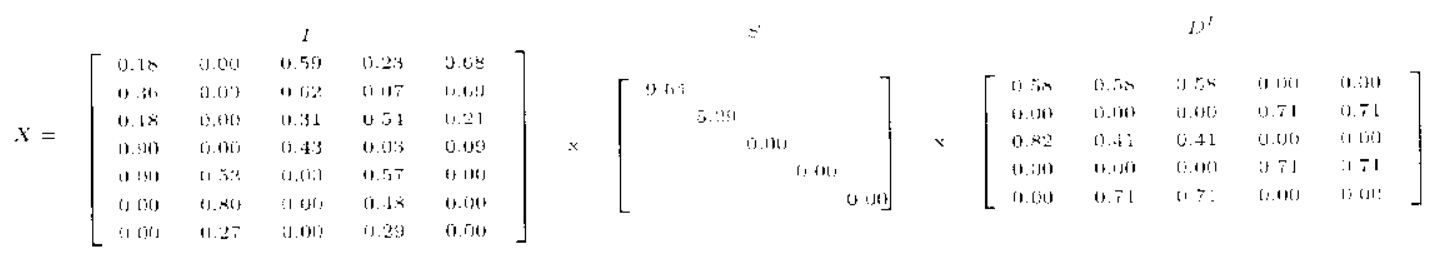


Pode-se observar lia matri\% $S$ que os valores dat diagonal são mamagenados en ordem

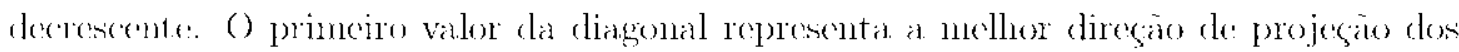
poutes da matriz, o segundo representar a segunda melhor diregão e assim por diante.

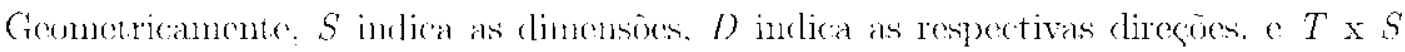
indica as localizaçóes dos pontos nessas dimensóes.

A matriz $S$ possui valores pequenos phe porkm ser considerados múdos. portanto. enses valores porlem ser desconsiderados. Ao considerar apenas us $k$ maiores valores singulares da natriz $S$ a as correspondentes colunas das mal rizes $T$ o $D$. é obthicla a matriz mais próxima à matriz original gue contém wo us $k$ marores componomes lineamente indepenententes da matriz original. A matriz $\hat{X}$. apresentada a segnir. captura a maior

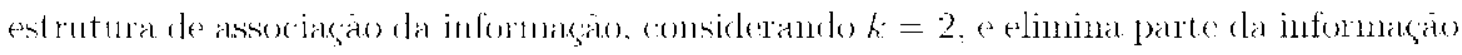
imclevante referente an exemplo apresent ato interiomente.

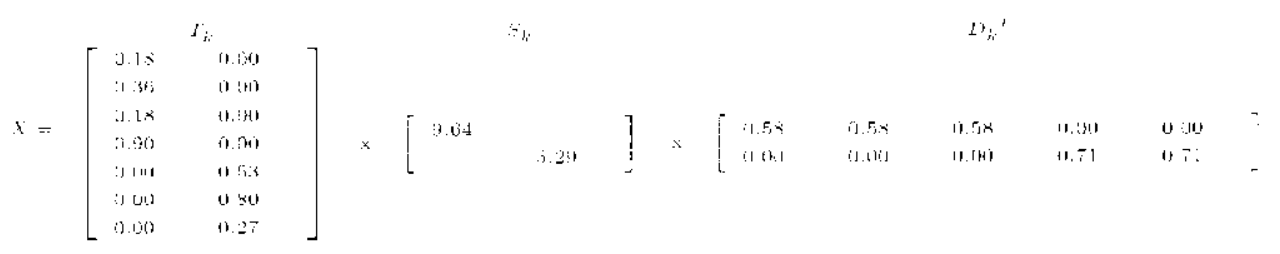

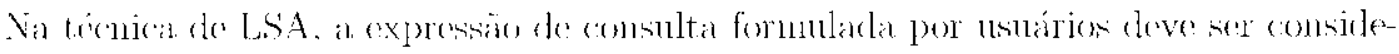

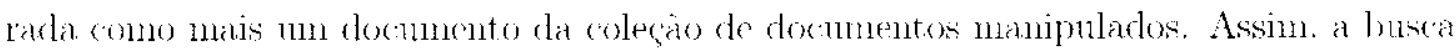
f transformada no vetor $V_{g}$ que contém a freqüencia dos tremos da consulta de acorto

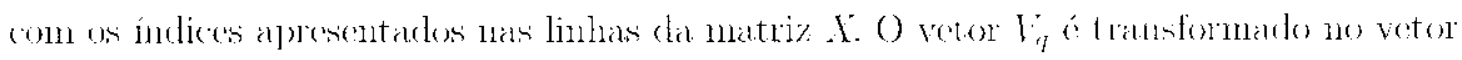

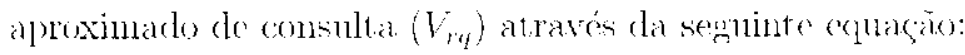

$$
V_{r q}=T_{k} T_{k}^{T} V_{i}
$$

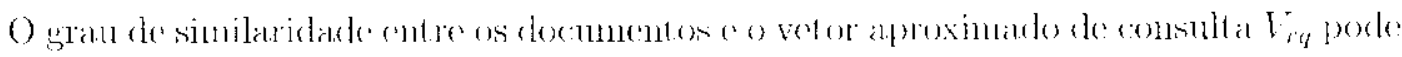

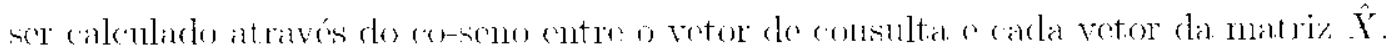

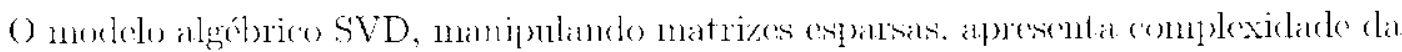
orden de $O(m m)$ sendo $m$ e $n$ as dimensoes da matriz de termos por docmentos a c 0 núnero de elenenent os diferentes de zero eme cada linhla da matriz. 


\subsection{Esquemas Clássicos de Atribuição de Pesos}

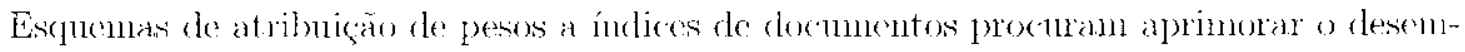
penho da recuporagão de informagào auxiliando na distinçäo dos termos que representem melhor o conteído dos docimentos.

Em 1968. escuemas simples de atribuigäo de pesos a termos modelados en vetores

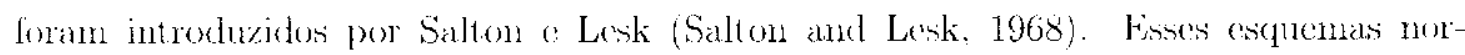

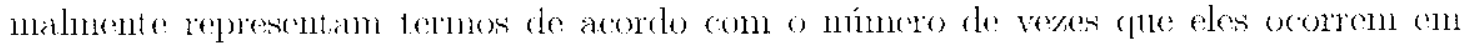
$1 \mathrm{~m}$ dado documento - o fator 4 . P'osteriomente om 1972, Sparck Jones introduziu num nowo elemento aus esquemas de atribuição de pesos, o fator idf, que desfavorece

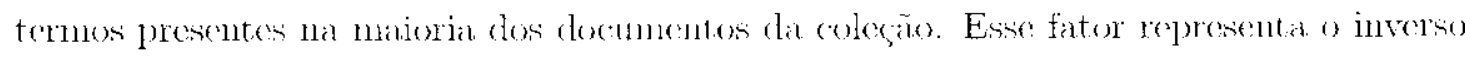

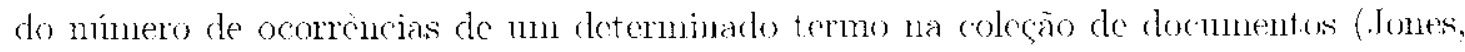
1972). Assin, idf varia inversamonte com o núnero de documentos $n$ para o clabl um

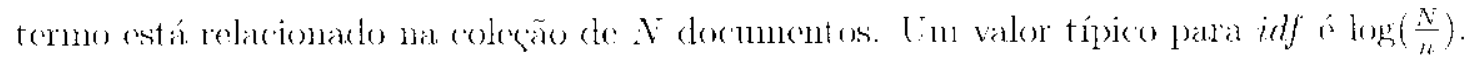

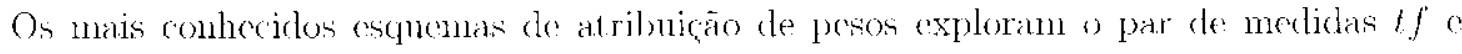
idf para cada termo de um documento. En 1973, alguns pesquisadores em (Salkon and

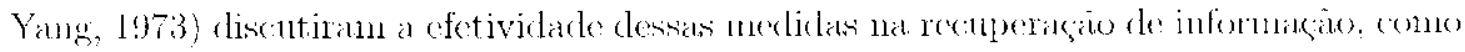
discutijdo a seguir.

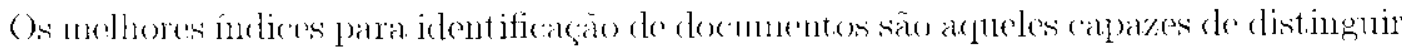
documentos individualmente da coleção de documentos. Isso implica que termos discriminantes devem ter alta freqüuncia no docmuento, $t$ f o baixa freqüencia na coleção. $i d f$.

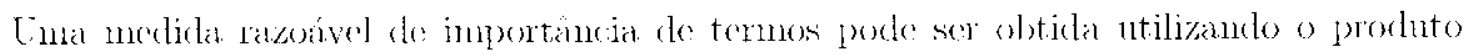

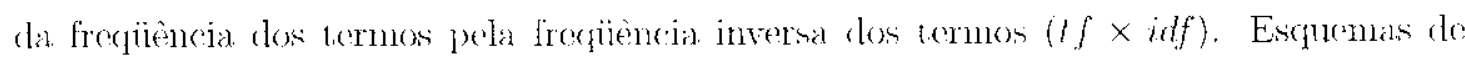
atribuiçăo baseados on $t f \times$ idf solrem críticas devido ato fato do näo serem sustentados

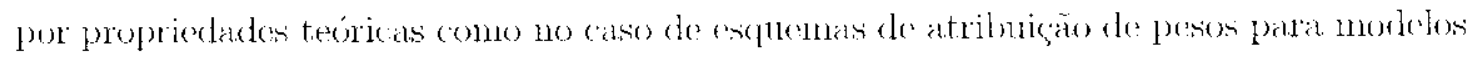

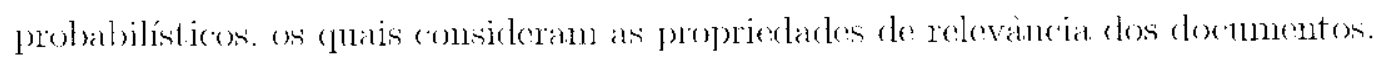

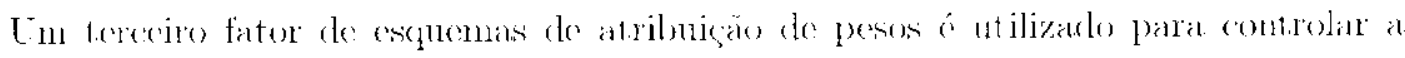

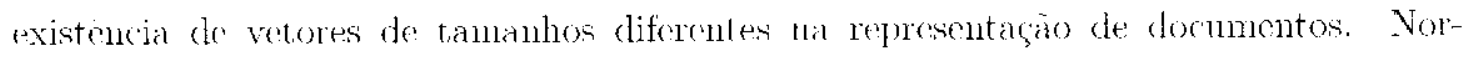
malmente, documentos com poucas palavras tendem a ser representartos por vetores

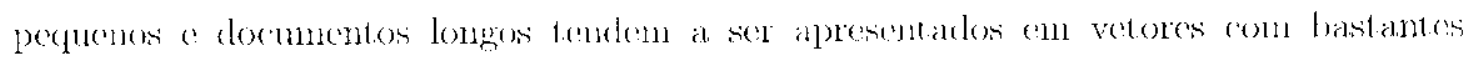

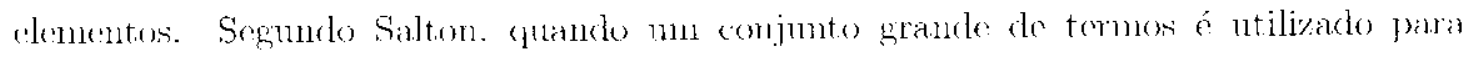

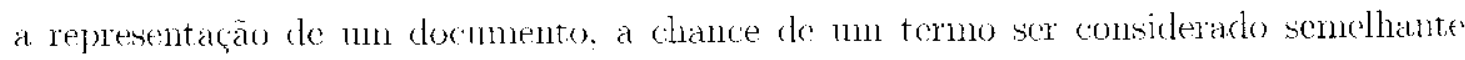

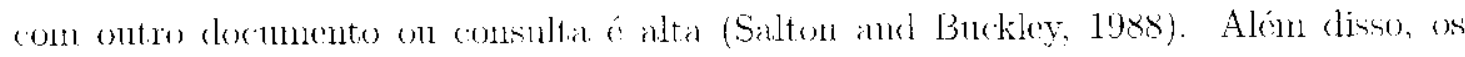

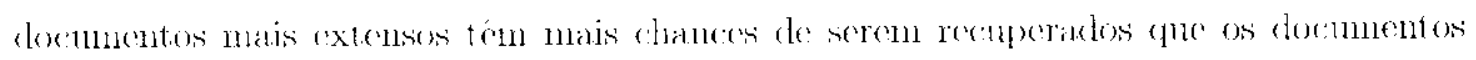


mais compactos. Portanto, deve-se cuidar para que o tamanho dos docuncntos nào

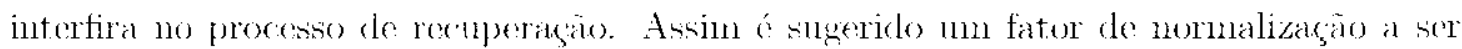
incorporato na fómula /f $\times$ idf. Assmmindo que we represente o peso do termo t calculado utilizando a fómmula original de tf $\times$ idf o peso tinal normalizado pode ser definido como $\frac{n !}{\sum_{i} u_{i}}$.

Alguns exemplos de esquemas de atribuiça de posos que utilizam combinaçós das

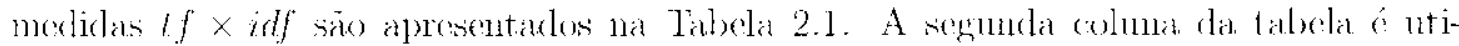

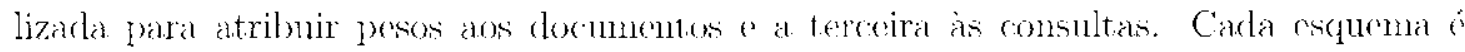
composto pela freqüència do temo $(t f)$, pela frecüincia inversa (idf) e pela variável do nomaliza(săo.

Tabola 2.1: Esquemas de atribuiçáo de pesos (adaptada do (Salton and Buckley. 1988))

\begin{tabular}{|c|c|c|}
\hline Nome do Esquema & $\begin{array}{l}\text { Esquemas de at } \\
\text { documentos }\end{array}$ & $\begin{array}{c}\text { buição de pesos para: } \\
\text { consultas }\end{array}$ \\
\hline \multirow{2}{*}{$\begin{array}{l}\text { Esquema totalmente normali- } \\
\text { zado }\end{array}$} & $f(i) \cdot\left(\log , \frac{\pi}{n_{2}}\right)$ & \multirow{2}{*}{$\left(0,5 \cdot 1\left(\frac{0,5+l f(j)}{\max t f(i j)}\right)\right) \cdot \log \left(\frac{N}{n_{i}}\right)$} \\
\hline & 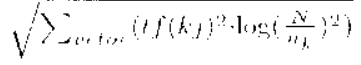 & \\
\hline Esquema probabilístico & $0,5+\left(\begin{array}{c}0.5 \cdot t(j) \\
\operatorname{miax}(f) j)\end{array}\right)$ & $\log \left(\frac{N-n_{7}}{n_{1}}\right)$ \\
\hline \multirow{2}{*}{$\begin{array}{l}\text { Esquema clássico } i d f \\
\text { Esquema de independência } \\
\text { de termo binário }\end{array}$} & $\log \left(\frac{1}{n_{1}}\right)$ & $\log \left(\frac{D}{n_{i}}\right)$ \\
\hline & 1 & $\log \left(\begin{array}{c}n-n \\
n_{1}\end{array}\right)$ \\
\hline Esquema de peso padrão /f & $\frac{d f(j)}{\sqrt{\sum_{\operatorname{tater}} / \int(h)}}$ & $t f(j j)$ \\
\hline
\end{tabular}

No modelo vetorial, índices sà considerados muthamente independentes e cosa asserça implica ell funçes lineares de atribuigan de posos. Entretanto o trabialho de

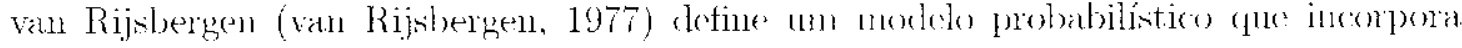

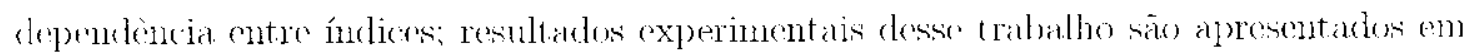
(Harper and van Rijpbergen, 1978). A dependencia dos temos é derivada da distribuiçäo

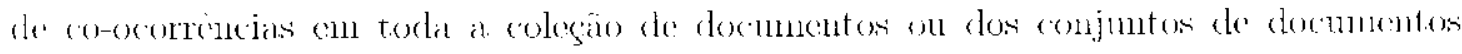

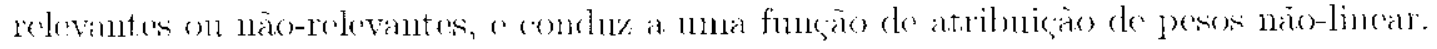

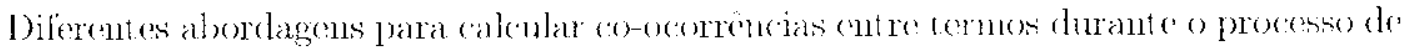

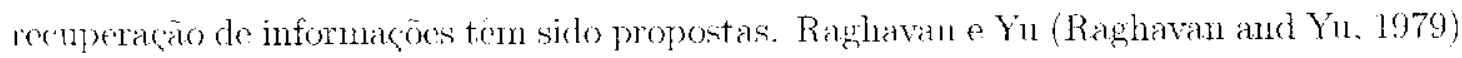
ntilizan análises estatisticas para relacionar $10 \mathrm{~m}$ conjunto de consultas com documentos

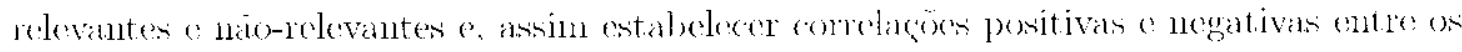

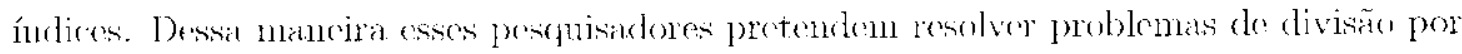
zero em cáleulos de similaridades. Possas et al. definem nm nove esquema de atribuiçăo

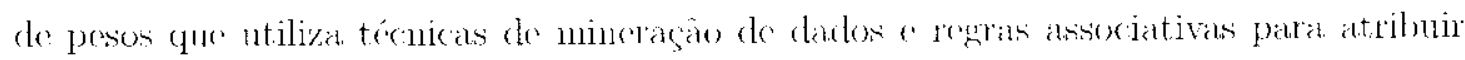


pesus a índices (Fossas et al., 20002).

Esquemas de atribuiçào de pesos podem também ser aplicados a modelos o comsultas bouleanas.

\subsection{Consultas}

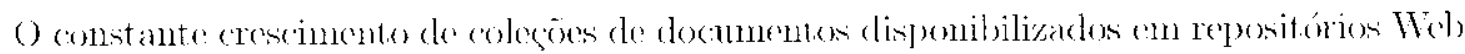
dr infomacoes tem sido abordado em diversas áreas e projeton de pesquisat. como é o (aso do projeto InCA-SERVE o do trabaho reportado nesta clissertação. Na área de

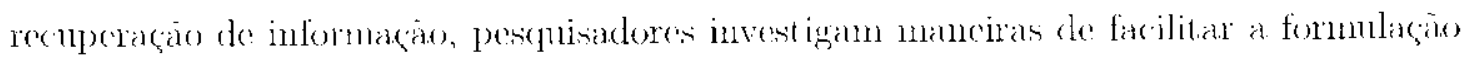

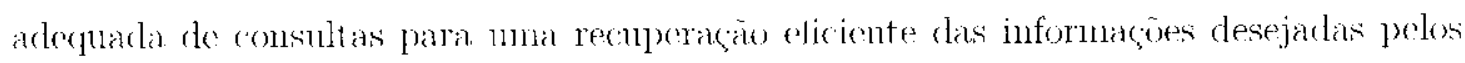
usuários, q1e nem sempre conseguem representar suas necessidades através da especifi-

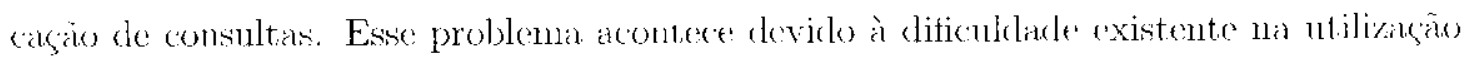

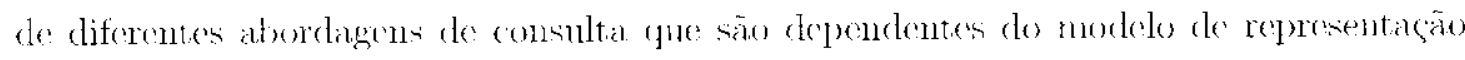
utilizarlo. Os diferentes tipos de consultas porlem ser agrupades, segundo Bacza-Yatos (Batezat-Yates and Ribeiro-Neto, 1999). cm:

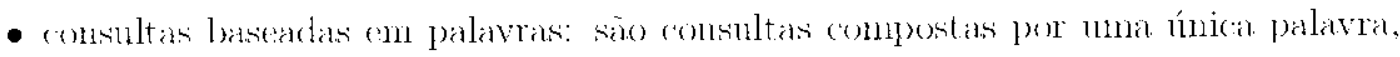
por frases on por combinaçóes complexas envolvendo várias palavras e diferentes operardores:

- consultas baseadas em comparacios de padrós: saro combultas que envolvem "

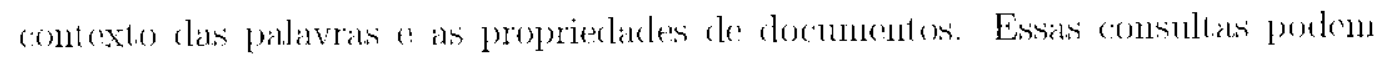

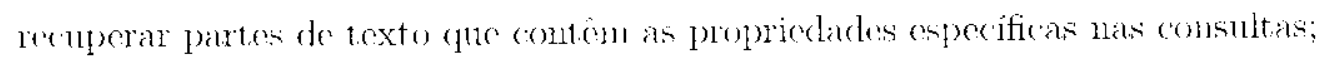

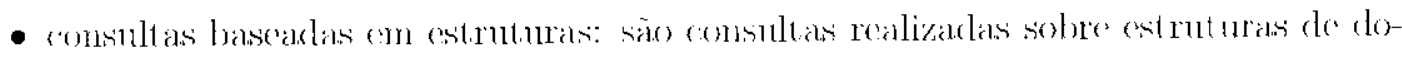
cumentos text uais cono. por exemplo. cotruturas de hiperdocumontos e estruturas hierórquicas.

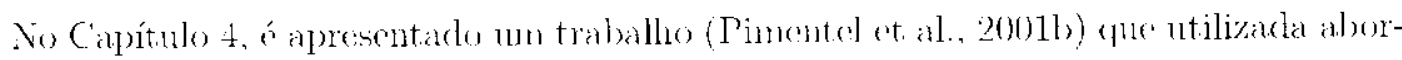
dagens do consultas baseadlas m palavas para a definiçào de ligaçues entre repositórios. 


\subsubsection{Consultas Baseadas em Palavras}

$A$ categoria de comsultas baseadas om palavras pode ser subdividida cm consultas esperificadas por uma única palavra, consultas bascadas em contcxtos c consultas boolcanas.

Consultas baseadas m uma única palarma são o tipo de consult a mais utilizado. Segmolo pesquisas, $25 \%$ dos usuários de seanch enghtes Web ut ilizam apenas ma palavra

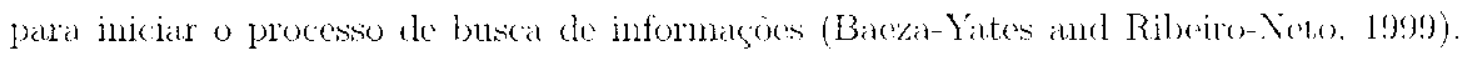
Acredita-se que cese fato seja decorrente da complexidade de se especificar combultas baseadas na combinagào de termos.

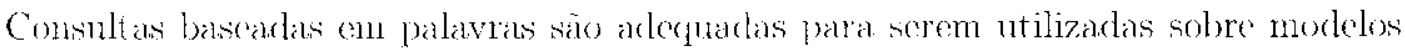

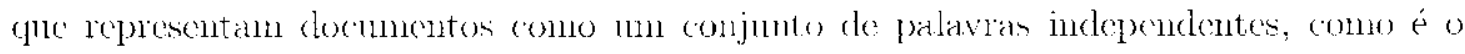

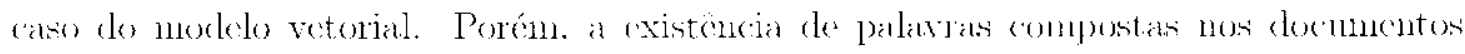

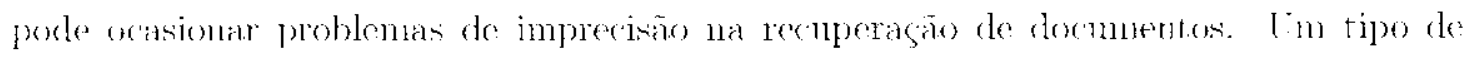
consulta que pode resolver problemas relacionados à compararga de palavaras compostas éconsulta bascatla com contexio.

Consullas bascudus em conledes proporcionam maneiras de buscar palavras que cole-

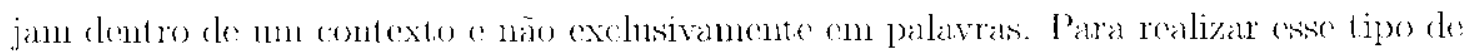

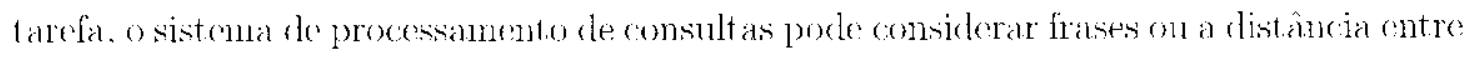
palavras. Ao considerar a distancia ent re as palavras, o sistema de consulta näo considera

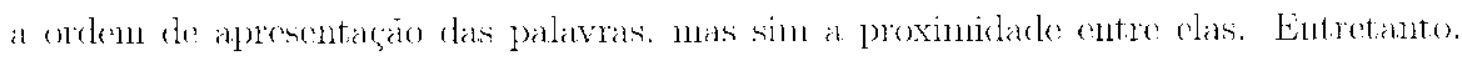

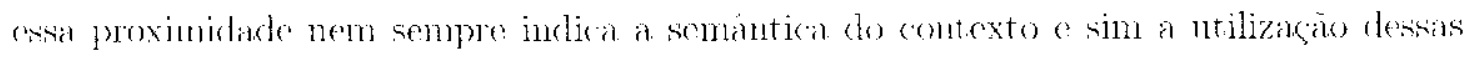
palavras dentro mon mesmo parágrafo.

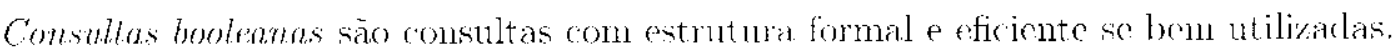
Esse tipo de consulta fo formado pela combinagio de palavaras on frases concatonados

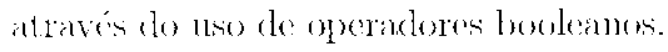

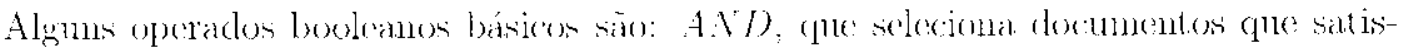

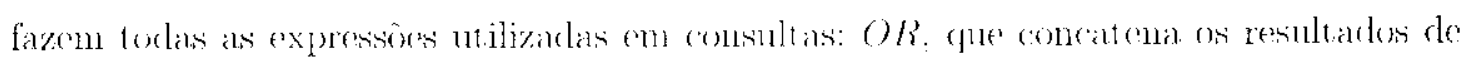
(ada expressio em particular; o BVT. que seleciond aqueles documentos que satisfazem

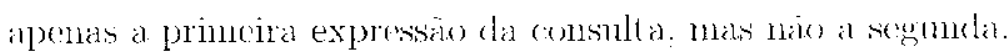

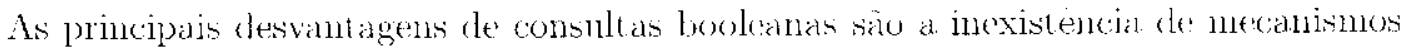

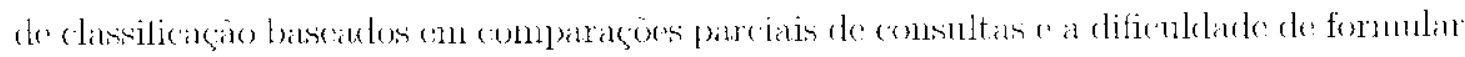
comsulten utilizando operadores booleanos. 
Consultas baseadas em linguagem natural combinam caracteristicas das consultas booleanas nelulosas (Juzzy) com características de consultas intuitivas. Esse tipo de consulta permite a recuperaçäo de todos os documentos que sảo parcialnente similares à ('onsulta. Porém, linguagem natural é un dus desatios de pesquisa dà área de inteligencia artificial devido à complexidade e irregularidade da linguagem humana. Assime combultas bascadas em linguagem natural säro complexas de serem procensiadals.

\subsubsection{Expansão de Consultas}

Técuicas para expansão de consultas surgiran a partir de observaçoes da dificuldade dos usuários com formular consultas e do fato de que os usuários sempre reformulavam a consulta original em una tentativa de aprimorar os resultados olutidos.

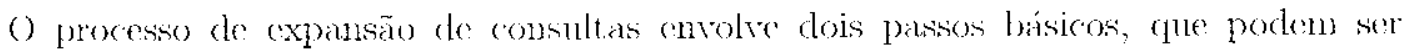
executados várias vezes eln sistemas de IR: (1) expansão da consulta com os novos temos

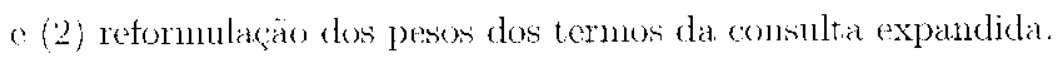

O primeiro passo do processo de expansäo de consulta consiste nu interaçäo com

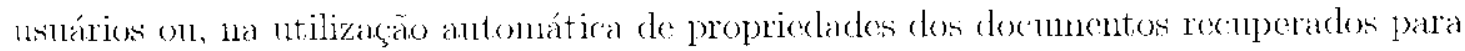
expandir a consulta para tentar torná-la mais efetiva. () segundo passo. reformulaçào dos pesos. é dependente do tipo de modelo utilizado na indexaçăo dos docunnentos dia coleçäo manipulada e do esculuna de atribuigào de pesos. Por exemplo, para modelos veteriais

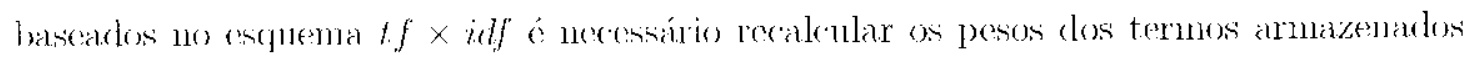
nos vetores que representam os documentos.

Säo apresentadas respectivamente, a seguir, abordagens de expansão de comsultas

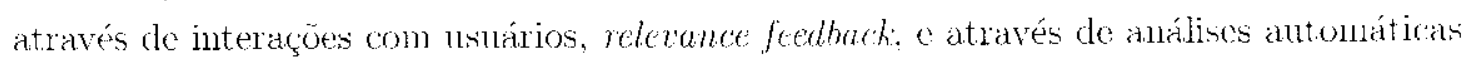

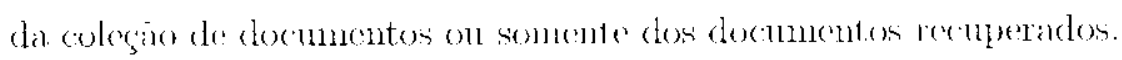

\section{Relevance Feedback e Expansão Automática de Consultas}

Relevance fexdbach ó um processos através do clal consultats podem ser selelivanente:

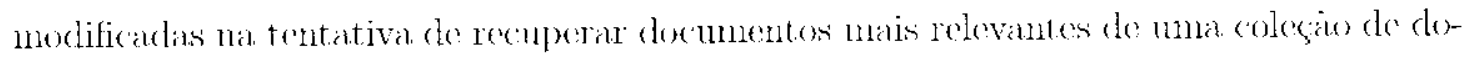
('umentes (Bacza-Yalce and Ribeiro-Neto). 1999). A (onsulta pode ser nodificada através de ajustes de pesos de termos da comsulta da inchisáo de novos termos ou da conibinagão

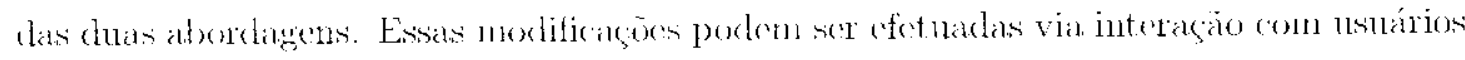


on através da utilização automática de propriedades dos doctunentos leecuperados.

O cálculo de relevance feedback proposto por Rocchio em (Rocchio, 1971), apresentado na Équaçäe 2.3, incorpora à consulta inicial, após málise de relevancia realiyada pon

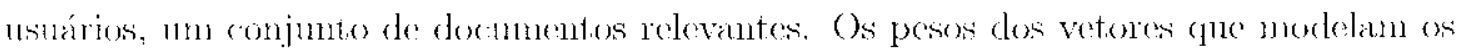
docimentos considerados relevantes são somados $\left(\vec{d}_{j}\right)$ e os vetores são nomalizados cun um novo vetor $\left(\mid D_{r}\right)$ dividindo-se o vetor-sona de documentos relevantes pelo múmero de: documentos relevantes. Em processo similar pode ser vealizardo para os docmementos considerados năo-relevantes. Os velores resultantes podem ser modificados através da

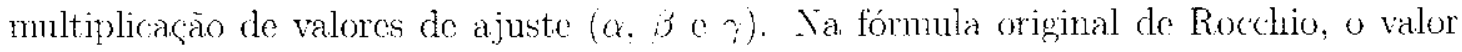
de or deve sere comsiderado "l". Finalmente, o vetor da consulta (ä) original deve ser modificando incluindo-se o novo vetor de documentos relevantes o sublraindo-se o nowo vetor de documentos náo-relevantes. Todo esse processo pode ser repetido através de

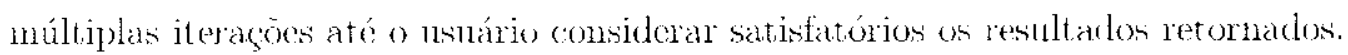

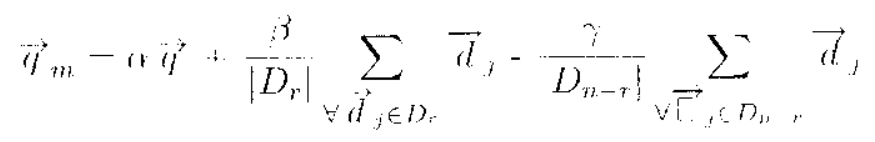

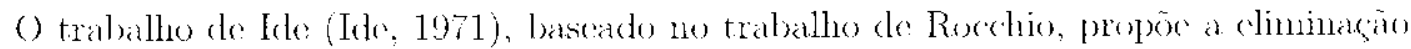
dos vetores nomalizados ( $\mid D_{v}:$ a $\left.D_{n-r} \mid\right)$ como apresentado na Equação 2.4 . Irle considera $a=\beta=\gamma \quad 1$ e também propoe a diminuiçào do valor de ajuste do $\%$ considerando

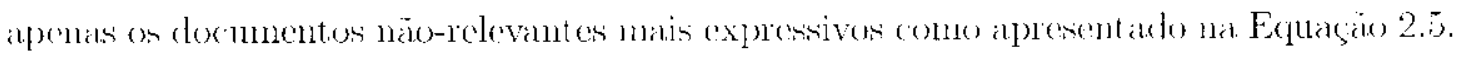
Algumas vezes, a pode ser considerado zero ocasionando con mua estratégia de feedhack totalmonte positiva, isto é. baseada apenas no conjunto de docunnentos relevantes.

$$
\begin{aligned}
& \vec{q}_{m}=\alpha \vec{q}+\vec{p} \sum_{\forall} \vec{d}_{j}-\sum_{\forall, D_{m}} \vec{d}_{j} \\
& \vec{q}_{m}=\alpha \vec{q}+\beta \sum_{\left.\forall \vec{J}_{j} \in D\right)_{r}} \vec{d}_{j}-\gamma_{j} \text { max }_{m o n-\operatorname{recomin}}\left(\vec{d}_{j}\right)
\end{aligned}
$$

Sogundo Bacza-Yates e Riluciro-Neto, as principais vadulagens das técnicas de relenunce

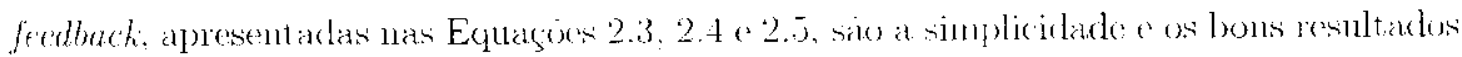

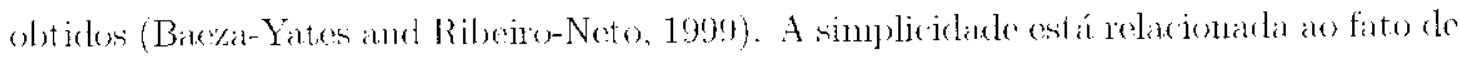
que os pesos dos termos modificados säo calculados diretannente a partir do conjunto de

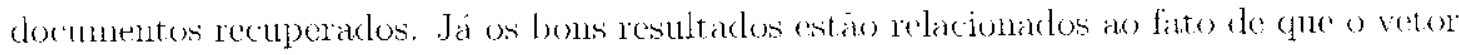


modificado de comsulta $\left(\vec{q}_{m}\right)$ procura refletir a consulta semantica pretendida. Poróm.

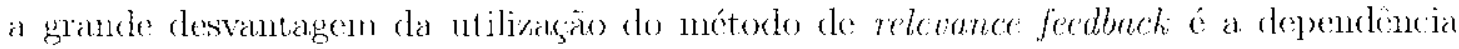
do julganento de revevancia por parte de usuários. Una soluça que tem sido adotada para esse problema é a utilização automática de propriedades de documentos como se elas

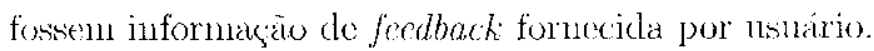

Harman realizon experimentos comparando o desempenho do mótodo de relevance fredback para informaçoes morteladas através do liso de vetorese (mortelo vetorial) e para informackes representadas de acordo com propriedades do conjunto de docmentos manipulado (modelo probabilistico) (Harman, 1992). Harman conchun que relevance feedback ‘ mais efetivo para informaços reprenentadas através do modelo vetorial, como ó o caso daténicar de LSA.

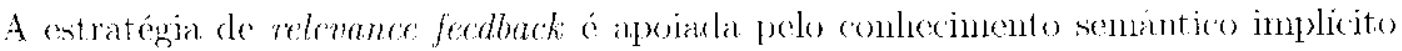
des nsilários durante a análise de rolevancia dos docunentos. Entretanto, essa análise pode ser anxiliada pelo próprio sistema de IR a incorporar temos para a expansão

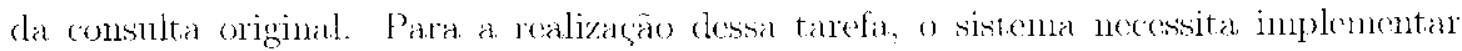

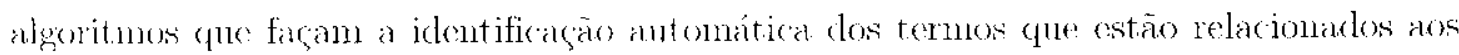
termos da consultid. É nesse tipo do abordagem que os procedimenos de expansáo antomática de consultas estano bascados. Existenn expansós antomáticas de consultas

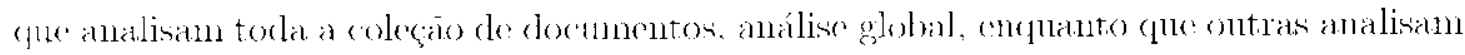
apetras os docmenentos recuperados, análise local.

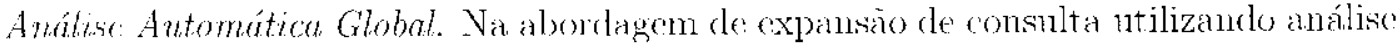
global dos docunentos, todos us documentus da coleção são utilizados para deterninar

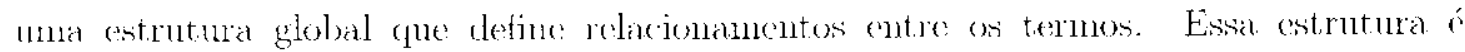

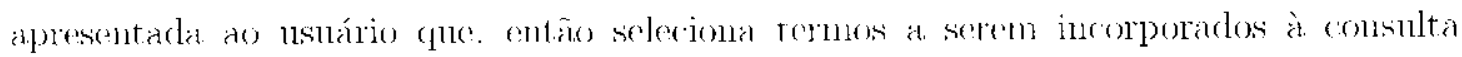
expandida.

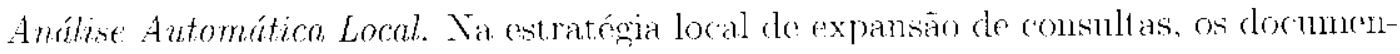
tos recuperados para una consult a q são exaninados on tempo de execuçăo da comsulta

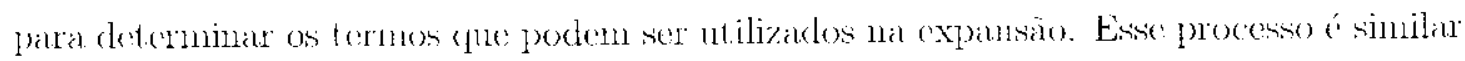

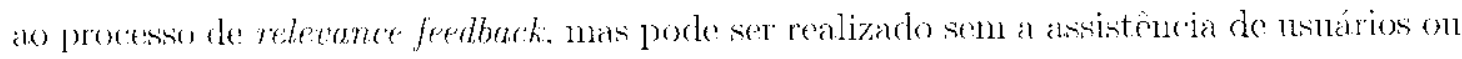
con a participaçăo parcial dos mesmos. As estratégias de análise local mais conheridas

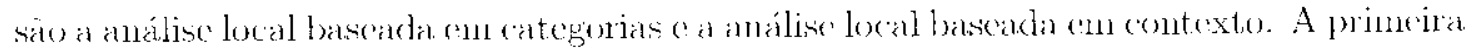

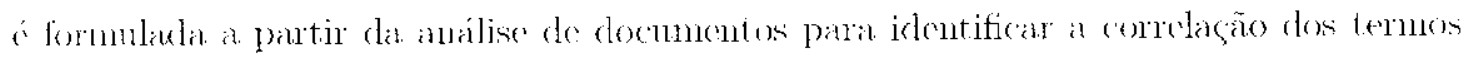
para a expansão da consulta, o a segunda explora as vantagens de combinar as técunicas de alláline global e local. 
No traballo apresentado nesta dissertagão, foram utilizadas abordagens de expansäo de consultas para o refinanento de ligaçoes autonnticas clefinidas entre repositórion.

\subsection{Medidas Clássicas de Avaliação}

As medidas tradicionais para avaliar a eficiencia de sistemas de IR säu o indien de revocaçäo e o índice de precisào. Entretanto. para pernitir a avaliaçăo de resultados desses sistemas, em termos de precinào e de revocação, us repesitórios de informaçócs

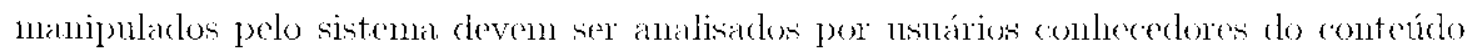
manipulado com o intuito de criar uma coleça de referéncia a ser comparada com os resultados obtidos.

O indice de renocaçào é definido romo a fraço de documentos relevantes cue forann recuperados pelo sistema de IR. Esse indice indica o gran de exanstäo de execunäo de

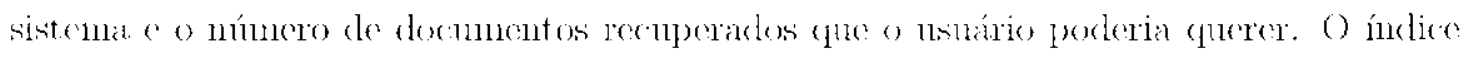
de revocação é definido por:

$$
\text { indice Delerocacao }=\frac{\operatorname{Re} l \cap \operatorname{Re} t}{R \cdot l}
$$

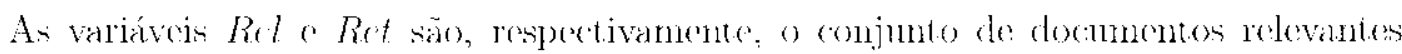
recuperados e o conjunto total de documentos recuperados. O melhor índice de revocacaio é 1.0 (ou $100 \%$ o o pior 0.0 .

O indice de precisão corresponde à fração de documentus recuperados que năo rele-

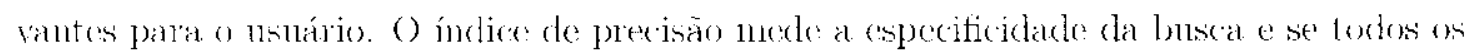

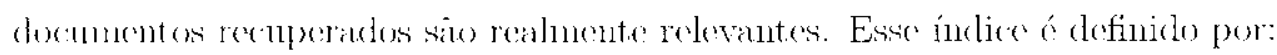

$$
\text { Indiec DePrecisto }-\frac{|\operatorname{Re} l \cap R t t|}{\mid \operatorname{Ret}}
$$

() melhor indice de precisäo é 1.0 e o pior 0.0. () objetivo dos sistenals de Ile é oluter.

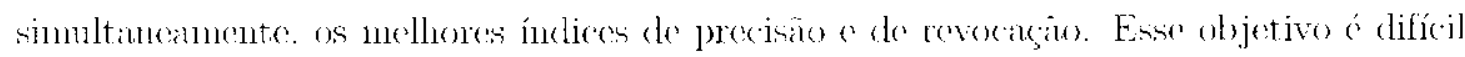
dreseralcançado pois gerahnente, sistemas de IR com baxixo indice de precisão possuen alto índice de revocação e vice-versa. 
Calcular a eficiència global de $n$ sistena de IR é una tarefa complicada. Normahnen-

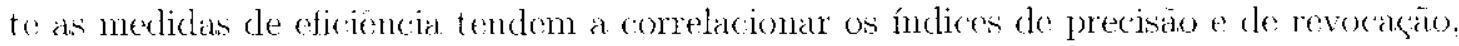

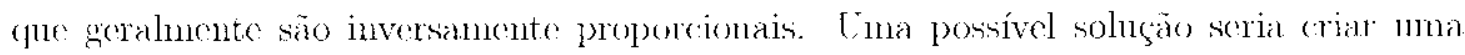
medida que realizasse una junção dos dois índices em vez de corrclacioná-los. Algums pescuisadures propoem novas medidas (Jin et al., 2001) a metodologias (Soboroff at al..

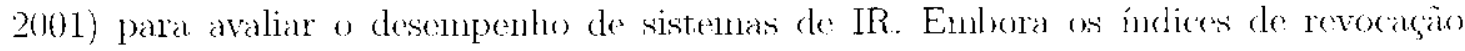
e de precisão tenham sido descenvolvidos para medir a eficiencia dos algoritmos do IR. outros pesquisadores propóm a utilização desses índices para qualificar o desempenhu rombinado de usuário e sistema de IR (Nielsen, 1990). Por exemplo, Swan a Allan utilizam os indices de precisão e de revocação para comparar a usabilidade de diferentes interfaces de visnalizaçào (Swan and Allan, 1998). Entretanto, deve-se considerar possíveis

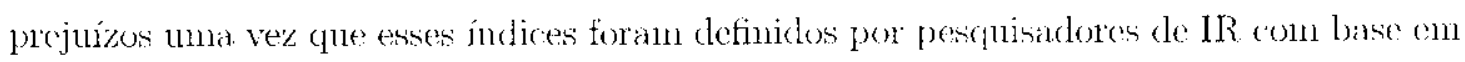
experimentos gnantitativos.

\subsection{Considerações Finais}

Para dar suporte ac crescimento do volume de informacoes disponíveis, industrias tem traballado no desenvolvimento de equipanent os com nador apacidade de processannento

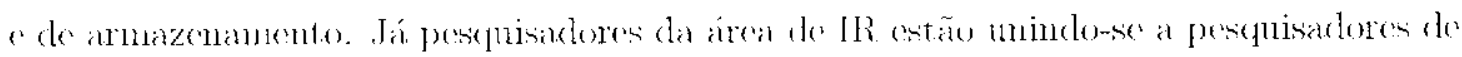
outras áreas, como hipermídia, computaço sáfica e inteligoincia artificial, na tentativa de desenvolver mecanisnos eficientes que promovann a manipulaçäe das informaçiese disponibilizadas.

Com o intuito de integrar informagoes contidas tem repositórios Web, o grupo de

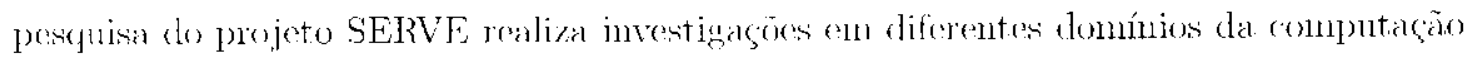
como. por exemplo recuperaça de informagão e hipornídia. O trabalho reportado nesta.

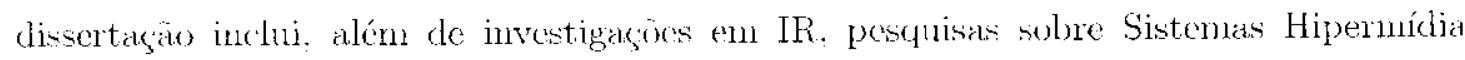
Abertes. No preximo capitulo, sär apresentades Sistemas Hipermidia Abertos em relaça

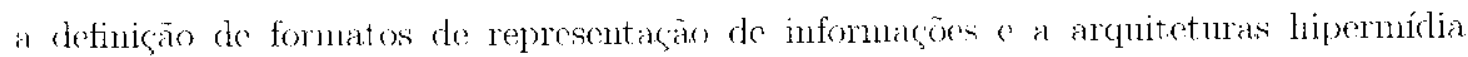
abertas an quais podem ser utilizadas em sistemas de IR. 


\section{Capítulo 3}

\section{Sistemas Hipermídia Abertos}

\subsection{Considerações Iniciais}

Nà década de 90. com o rescimento da Wéb. tornaram-se realidade anpectos da ma-

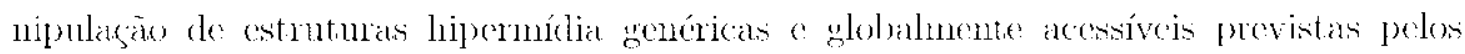

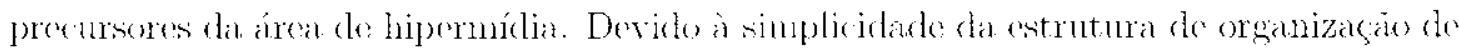

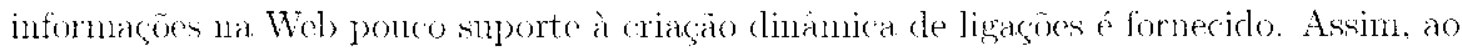

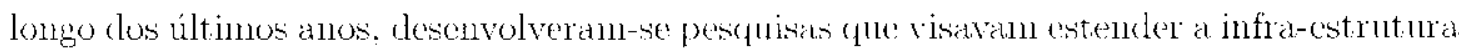

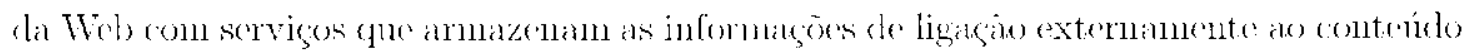
de docmuentos (Croubatek et al. 1997).

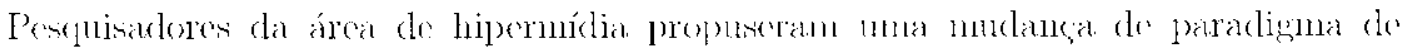
projeto de sistemas hipennídia tradiciomais para sistemas hipernídia ahertos. Cm Sistema

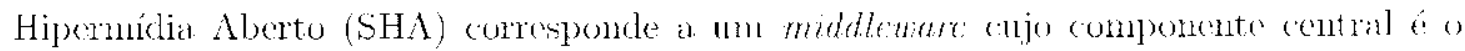

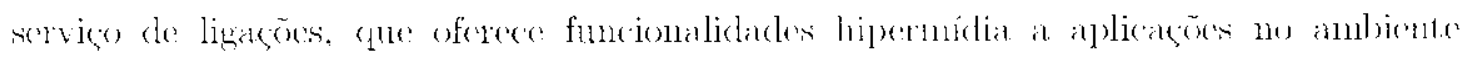

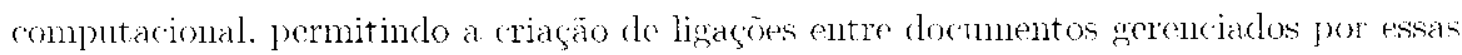
aplicacires. sẹn alterá-lus (Davis et al., 1996).

Ao incorporar os serviços de $u m$ sistema hipermidia abertos. aplicaços podem se

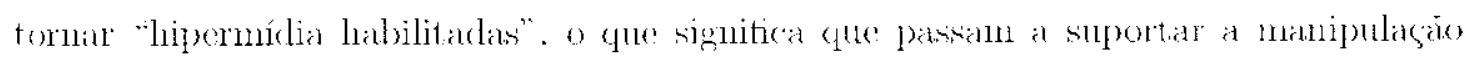

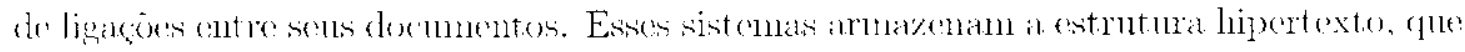
correponde as ligacoes estabeleridas entre informaços. separadimente do conteúdo das

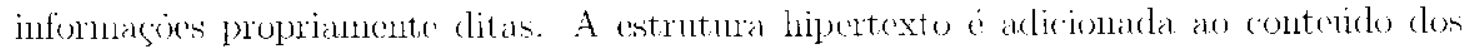

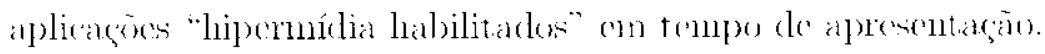


De acordo com Walcon e outros pesquisadores, as principais motivaçoes para o desenvolvinnento de SIIAs sào a redução do esforço de antoria do aplicacoes hipermídia em grande escala e a necessidade de tomá-las mais fádeis de serem manipuladas (Malcom et. al., 1991).

\subsection{Características de Sistemas Hipermídia Abertos}

Apesar do objetivo geral do projeto de SHAs cstar centrado no suporte a servicos li-

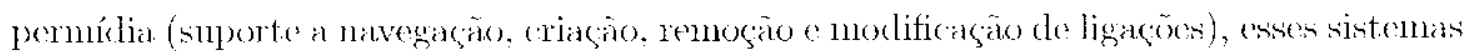
podem ser especificades de difurentes formas, o que faz com que existan variacies no tipo de suporte oferecido. Essas variaçoes estão baseadas na existéncia ou năo de algumas caracteristicas como (Niotico and fortes. 2000):

- suporte a diforentes protocolos de comunicação com aplicaços "hipermídia habilitaklas":

- suporte a cliferentes modelos de dados hipermindia que varian de acordo com o minnero de pontos linajo de muna ligaçäo (dois on mais):

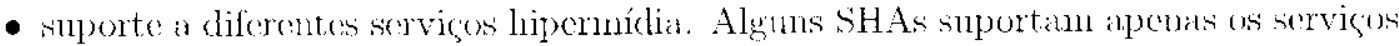
báwicos para pernitir que ancoras e ligacós sejam asseciadas a informaçoes existentes: ontros SHAs suportam características mais avançadds, como suporte à antoria

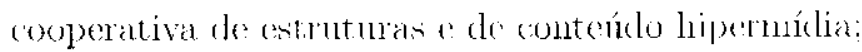

- suporte a diferentes arquiteturas de sistemas hipermúdian, desele arquitet uras clienteservider contralizada a arquitetoras multi-camadas com serviges de armazenamento múltiplos entn diferentes domínios da. Internet:

- suporte a cliferentes tipos de estruturas além de ligaçós comw. por exemplo, conr-

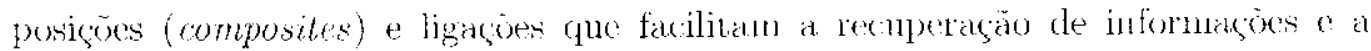

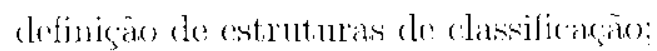

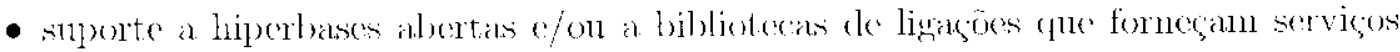
bésicos de ligacós hipermídia a um comjunto aluerto de aplicacoes. Entretanto, liperbases abertas tanbén fornecom serviços de armazenanento hipermídia que

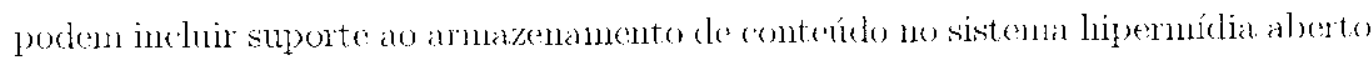

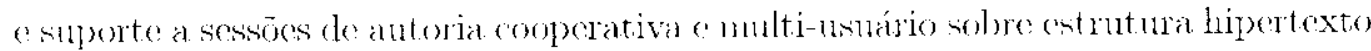
s conténdo. 


\subsection{Requisitos de Sistemas Hipermídia Abertos}

Como requisitos de SHAs formu identificados os seguintes itcols (Davis et al., 1996):

- SHAs deven suportar ligaçóes a elementos de conteńdo de ducumentos. Fisses elennentos podem ser sentenças em arquivos de texto, regiós cun inagens, on ol jetos em novimento em streams do vídeo;

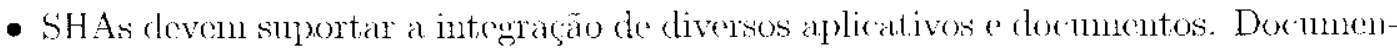

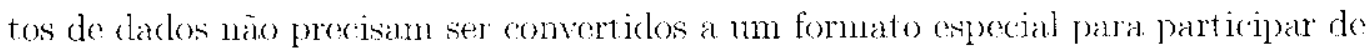
um anmbiente hipermídia. Docmentos de diferentes origons porlem farer parte da messma rede hipermidia;

- SHAs deven pemitir ligagoos en termos de semántica da informaţäo, on seja,

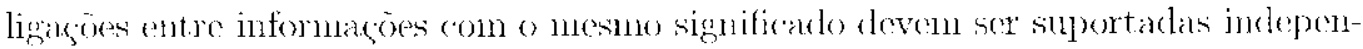
demente da identidade dos documentos que encapsulam essas informacooces. Tais ligaçues são chandadas de ligarges bascadas em contexto porcute conectann signifi-

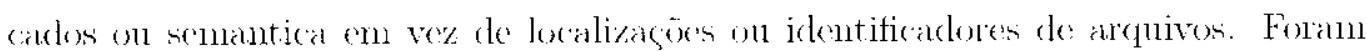
definidos serviços de criaçăo automática de ligasoes semaint icas. descuvolvidos pelo antor eme colaboragäo com o grupo de pesquisa do projoto InCA-SERVt, bascados

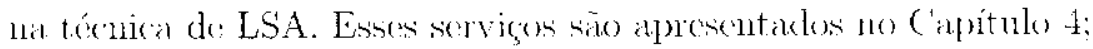

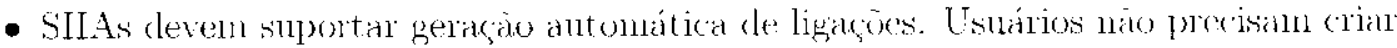

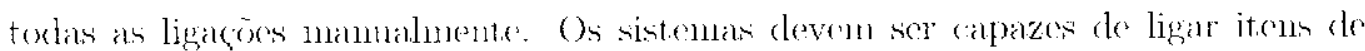
informaçoes relacionadias antomaticamente quando esses forem dofinidos no sistema

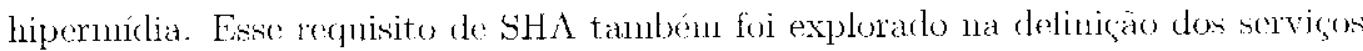
apresentiados no (apjétulo d:

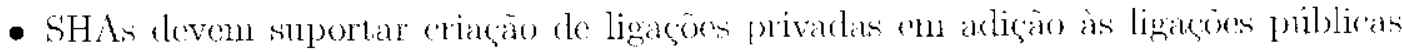
Uefinidas pelo antor dia aplieaçán:

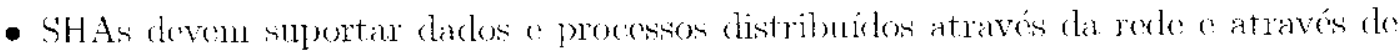
diferentes plataformas;

- SHAs devem pemitir a adiço de funcionalidades a sua infra-estrutura. on seja. novos mórbules de programa devem ser inscridos farilnemte.

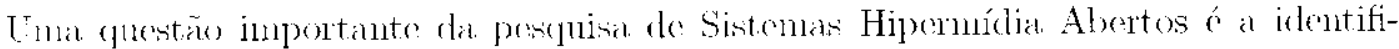
caça de arquiteturas on modelos hipemidia de referencia para esse tipo de aplicacä́. 
Várias arquiteturas de referencia utilizam princípios do modelo Dexter para projetos de hipermidia aberta (Halasz and Scluwartz: 1994). Alón do Dexter, existem outros modelos e arquitcturas para SHAs como, por exemplo, a arquitetura cm camadas do Devise Hypermedia Model (DHN), que servin como referencia para o projeto de um SHA integrado a Web, denoninado Webrise (Gronbek et al., 1994). Nesse contexto. foi propesto o Protocolo Hipermúdia $\Lambda$ berto. discuticlo a scyuir.

\subsection{Protocolo Hipermídia Aberto e o Padrão XML}

Em arquiteluras baseadas uo Modelo Dexter (Halas and Schwartz, 1994), o Protocolo Hipernídia Aberto (Open Hypermedia Protocol - (OHP) está localizado na canndad de

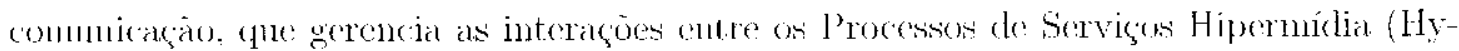

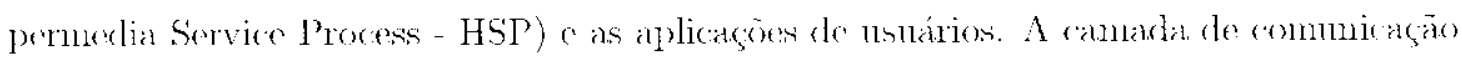
esperifica uma interface o um protocolo genérico, denominado Protocolo Hipermídia

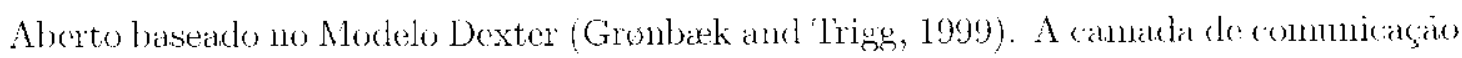

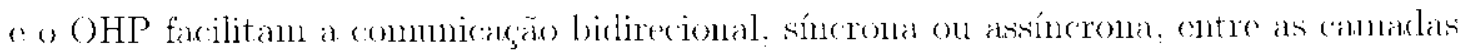
do apresentaçàn e de aplicaçōo.

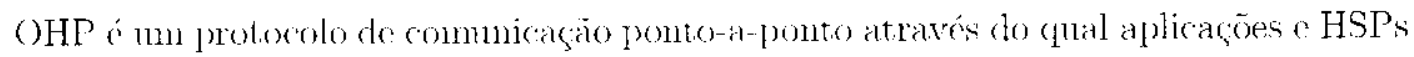
polen recober e enviar nentiagens. Implementaçoes simples do OHP utilizam mensagen

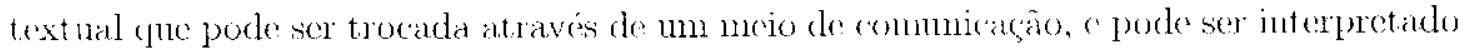

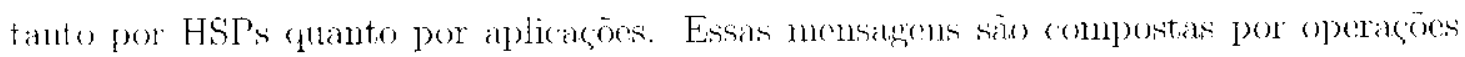
- listas de parametros. Os tipos de parametros codificados nas mensagens do OHP säo descritos na labela 3.1. Por cxemplo, a utilizaçán do paranetro applicationtD em

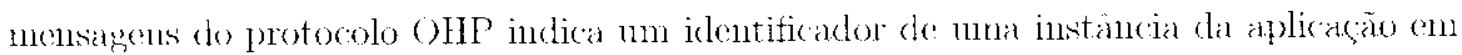

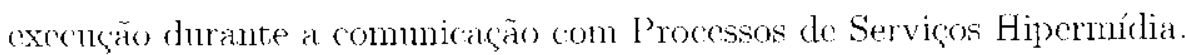

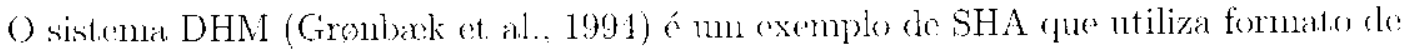

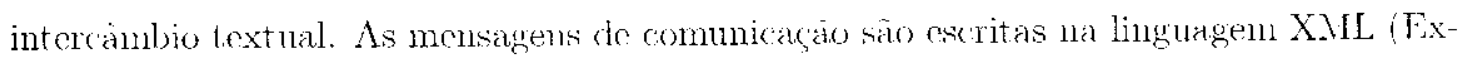

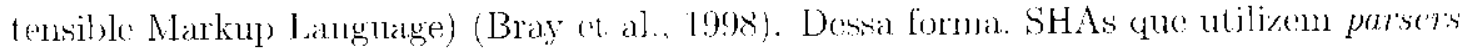

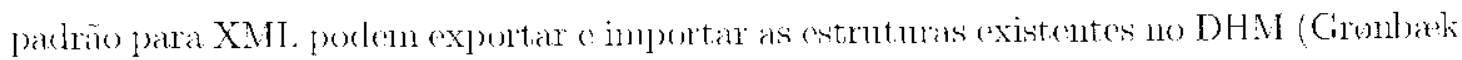
(4) al. 2000).

Basicamente, existem quatro tipos de mensagens on sub-protocolos do OHP: (a) sub-protocolo para conexáu, (b) sub-proucolo de ligaçäo, (c) sub-protocolo para nave-

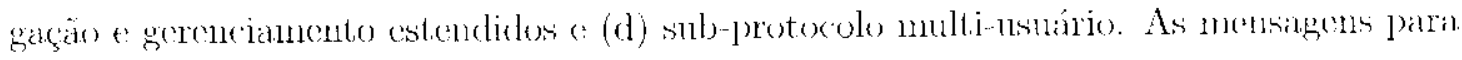


Tabela 3.1: Parámetros das monsagens do OHP (Gronbark ct al., 1999)

\begin{tabular}{|c|c|}
\hline Parâmetro & Descrição \\
\hline userName & Nome de login de usuário \\
\hline applicationID & Îdentificador para uma instância de uma aplicação em execução \\
\hline hyperSpacelD & Identificador para um objeto hyperSpace \\
\hline CompID & Identificador para um objeto componente \\
\hline opCode & Código do comando corrente \\
\hline accessCode & $\begin{array}{l}\text { Determina os direitos de disponibilidade e de acesso para um } \\
\text { dado objeto }\end{array}$ \\
\hline N & $\begin{array}{l}\text { Indica às aplicações e aos HSPs que uma lista de parâmetros de } \\
\text { um certo comprimento está no final da mensagem }\end{array}$ \\
\hline nodeSpec & Identificador de conteúdo para um componente \\
\hline docType & Tipo MIME para um documento \\
\hline locSpec & Especificação de uma localização dentro de um documento \\
\hline PSpec & $\begin{array}{l}\text { Codificação da informação relevante à apresentação de um dado } \\
\text { documento ou uma âncora dentro de um documento }\end{array}$ \\
\hline direction & $\begin{array}{l}\text { Determina a direção de uma extremidade de uma ligação (fonte, } \\
\text { destino, ambos, ou nenhum) }\end{array}$ \\
\hline linkType & Codifica o tipo de ligação em questão \\
\hline lockValue & Determina o tipo de bloqueio sobre um dado componente \\
\hline responseCode & Indica o resultado de uma operação \\
\hline
\end{tabular}

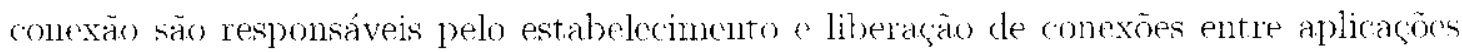

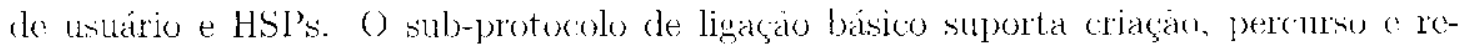

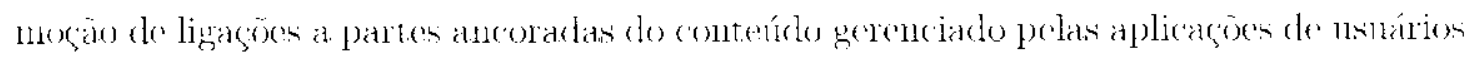
(pue adquirirano funcionalidade lipermídia. () sub-protocolo de navegaço e de geerenciamento estendidos é opeional o permite que browsers e comandos manipulem cstruturas

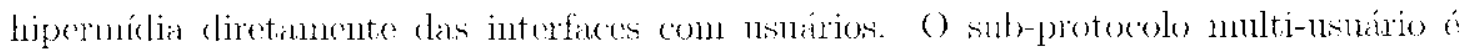

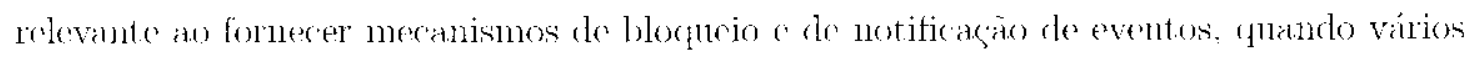
nsuários estào compartilhando simultaneamente um hipcrespaço (Gronbek and Trigg, 1999),

As mensagens do OIIP podem ainda ser thivdidas em duas categorias: as que saio

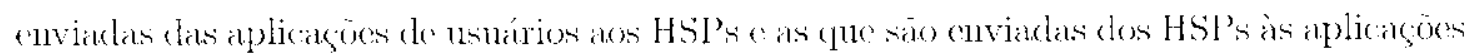
de masuários. 


\subsection{Estudo de Caso de SHA: Web Linkbase Service}

() Web Linkbase Service (WLS), desenvolvido por pesquiwadores do projeto InCA-SERVE. é mu serviço aberto de ligaçôes hipernídia para Web baseado en XML, cuja infra-estrutura foi proposta para atender aos scguintes requisitos (Bulcão Neto et al., 2002): (a) dis-

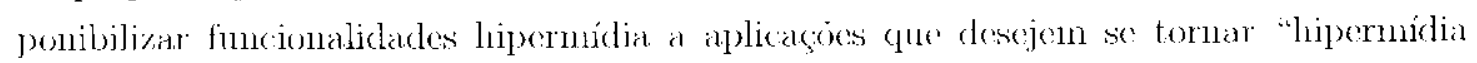
habilitadas"; (b) integrar um eonjunto em aberto de aplicacoss "hipermídia habilitadas"; e (c) disponibilizar o serviço em ambiente Web através da utilizaça de tecnologias hipermindial at llais.

() WLS foi defindo como una API (Application Programming Interface) para ane

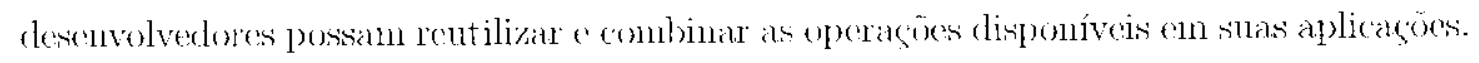
Assim. o WLS pode ser reutilizado en diferentes contexios, reduzinde a sobrecargal. cognitiva imposta a projetistas de aplicacôes hipermídia. () WLS é explorado também para armazenar reliaxionamentos semanticos extraidos de repositórios Web.

\subsubsection{Requisitos do WLS}

() antores do serviç do ligaçoes WLS selecionaram alguns requisitos e característicias de SHAs para a poiar o desemvolvinento desse serviço:

- separacio explícita contro conteńdo e cetrutura de informaçes (Davis el al., 1996) (Gronbeek and lrigg: 1999):

- inter-relacionamento de informaçoes com o mesmo significado. () inter-relacionamento deve ser suportado independentemente do docmunento (11e conlém a informaşàn) ('Tari. $1996)$;

- ligaçoes poden referenciar docunentes ene diferentes formatos (Tai. 1996);

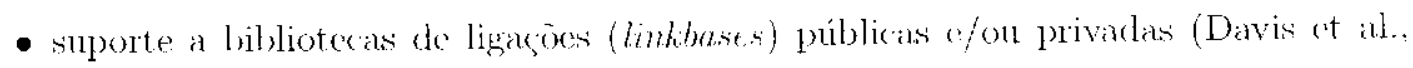
1996) (Gronb)akk and Trigg. 1999);

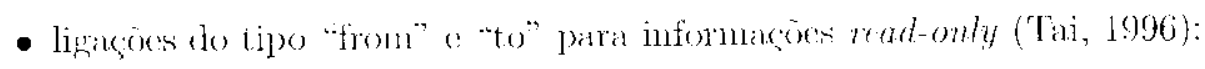

- suporte a diferentes tipos do relaciomsamentos contre documentos como, por exemplo. ligacoes específicas, bi-directionais, locais c globais (Davis et al. 1996) (Cronbetk and Trigg, 1999). 
Esse subconjunto de cararterísticas e requisitus orientun a modelagem do WLS.

\subsubsection{Modelagem do WLS}

A arquitetura de reforencia bascada no Modelo Dexter o suds extensoes foram utilizaddas cono fundamentação téórica para o projeto e a implementação do WLS. Nesse contexto, o gerencianento da rede de estruturas é de inc umbencia do WLS, enquanto que o arma-

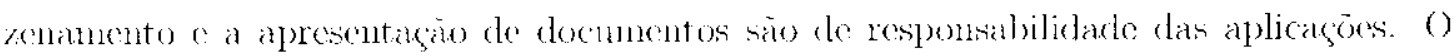
modelo de dados conceitual do WLS. definido segundo o modelo navegacional do OHP, o us relacionament os entre os objetos das classes especializadas podem ser visualizarles na

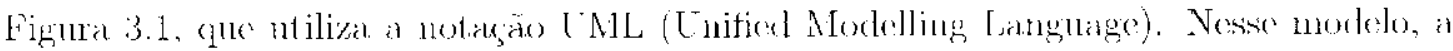
dasise Contexto represcuta una coleção de nós, ligacoes e contextos aninhados (conjunto

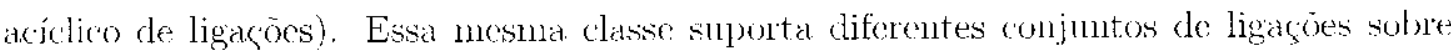

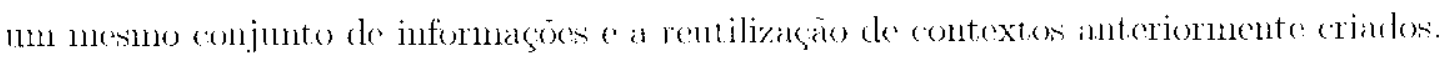

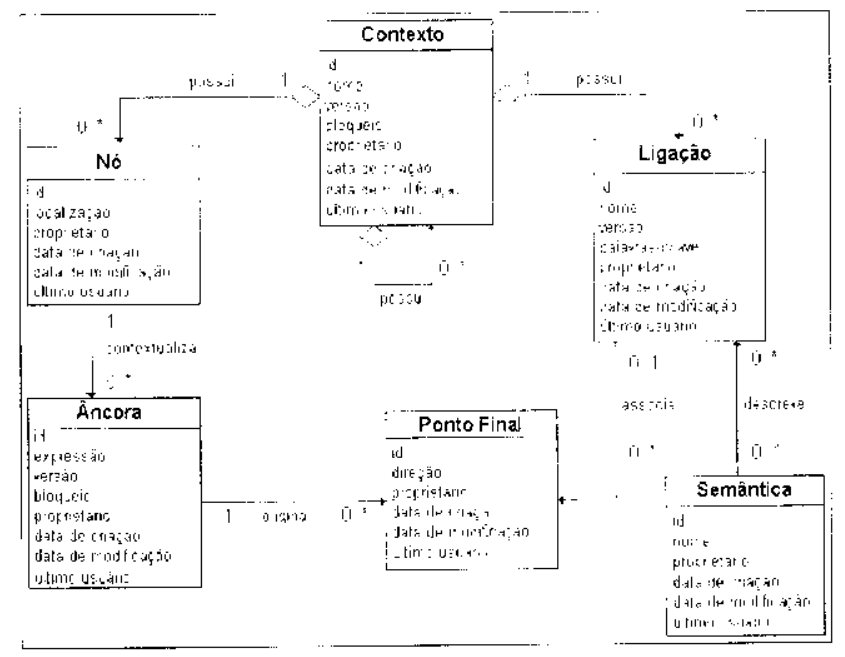

Figura 3.1: Moxtelo conceit ual do WLS (Bulcaio Neto. 2001)

() foro principal do modelo conceinal do WLS é apresentado alravés do relaciollamento entre as classes Âncora, Ponto Final o Ligação. Segundo os relaciomannentos

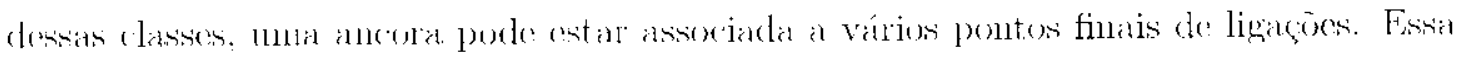
abordagem de projeto é relevante mua vez que esces tipon de ligagoes sáo suportados pelos princjpais serviços de ligacoes.

A classe Âncora define uma bocalizad(à) interna no contelido de um nó hipermídia

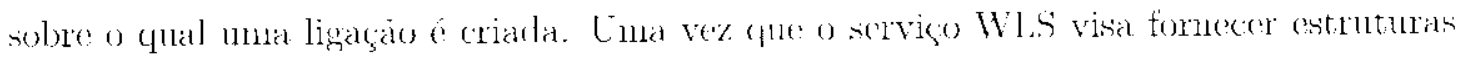


hipermídia a aplicaçöes XML, seu modelo de ancoragem utiliza a especificaçăo XPointer (DeRose et al., 2001). A proprielade expressão armazena a localizaçäe de ancoras na. sintaxe XPointer.

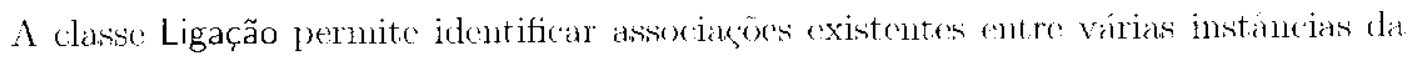
classe Ponto Final, cadda una correspondente a uma extremidade de uma ligação con sula respectiva direção (fonte, destino ou bidirecional).

Outra característica interessante do modelo conceitual do WLS ć a presença da classe Semântica. Essid classes pretende prover explicitanente relacimamentos scmanticos entre

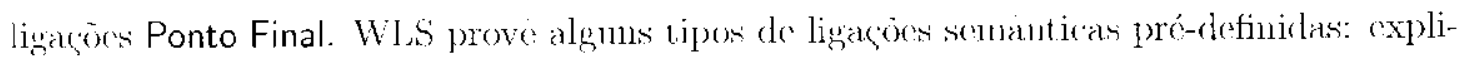
(ação. exemplo, conse tho e etc. Algmus desses tipos também fazen parte dos tipos de anntaçoes do servidor Annoted (Kahan ct al., 2001).

\subsubsection{A Arquitetura do WLS}

A API do WLS implementa mu conjunto de operacose para carla chase do modolo conceitual do WLS. Utilizando essats operaçoes. aplicaçoes poden se tornar "hipernuidia. habbilitadas".

A arquitetura do WLS é apreschtadla na figura 3.2. Os passos de 1 a 11 , descritos

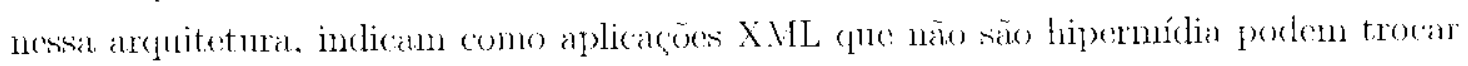

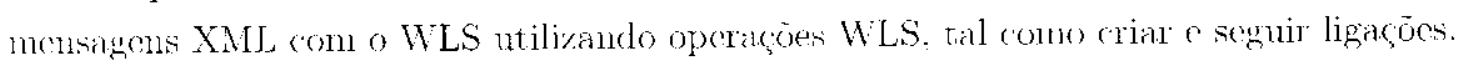
Cono integraçáo é o ponto principal da abordagen de SHAs adotada pelo WLS, aplicaçós interessartas en utilizar o WLS devent:

- prover a localização de seus docmentos;

- idcutiticar e codilicar ancoras na sintaxe de XPointer:

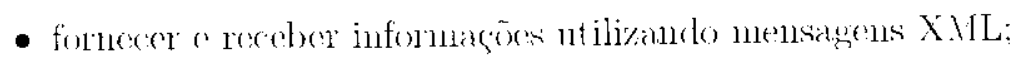

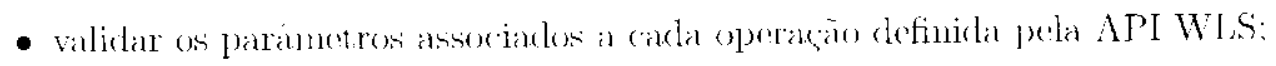

- prover funciomalidade hipermília atravó de sulas interfuces. 


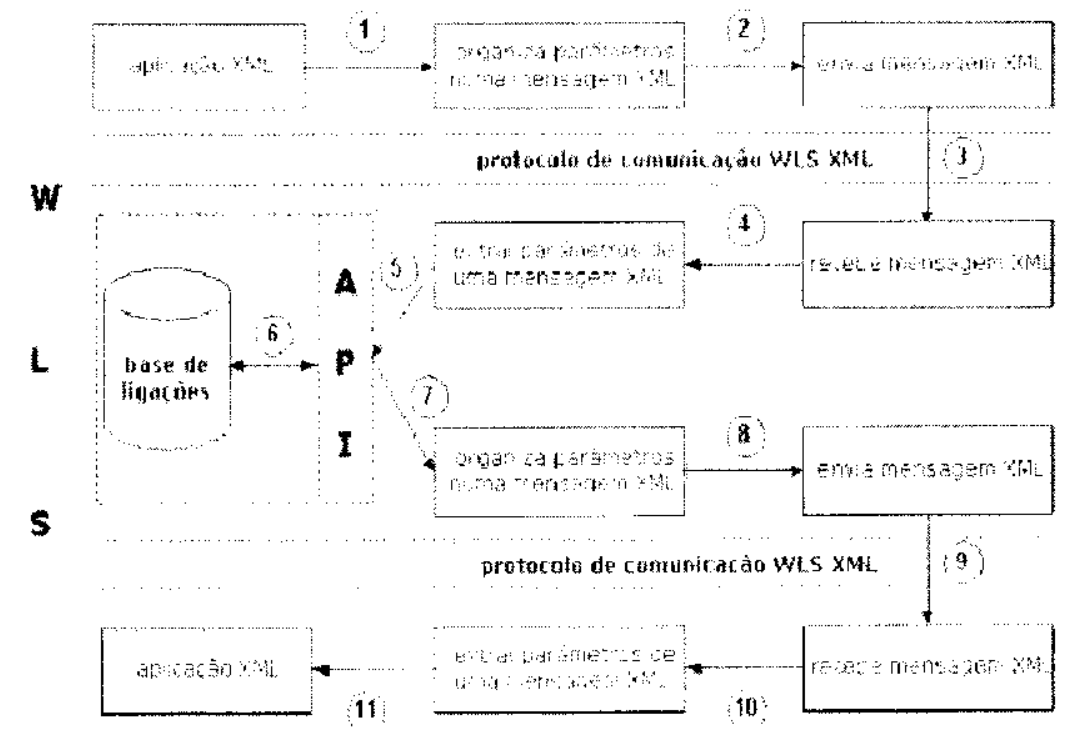

Figura 3.2: Arquitelura do WLS (Bulcano Neto, 2001)

\subsection{Considerações Finais}

O Wob) I.inkbate Service (WLS) foi 11 ilizado em algumas etapas do trabalho apresentado nesta dissertaçäo clevido principalmente aus segunintes requisitos presentes nesse serviço:

- SHAs devem permitir ligacies em termos de semantica da infomatga, on seja, ligacies a informacóns com o mesmo significado devem ser suportadas independe-

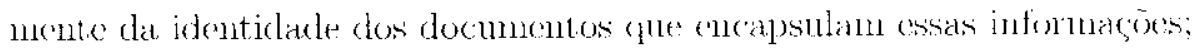

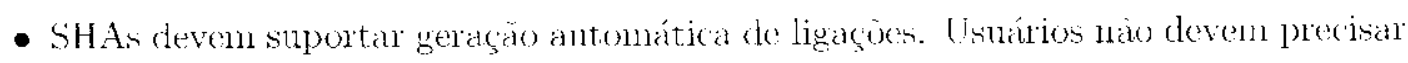
(riar todas as ligagoes manulalnente.

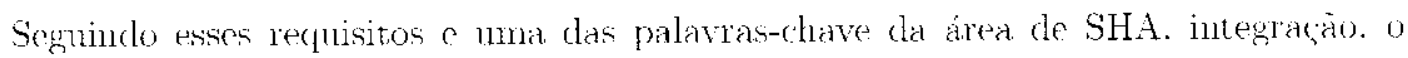
trabalho apresentado nest a dissertaço explenou anpectos de Sistemis Hipermidial Alsertos

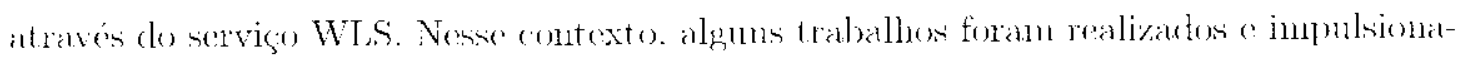

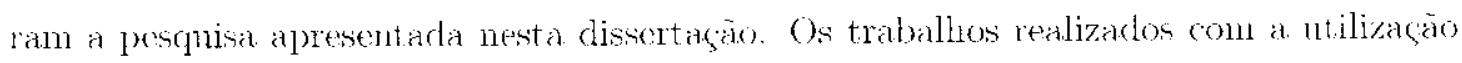
do WLS sáa apresentados no próxino capítulo. 


\section{Capítulo 4}

\section{Criação Automática de Ligações}

\subsection{Considerações Iniciais}

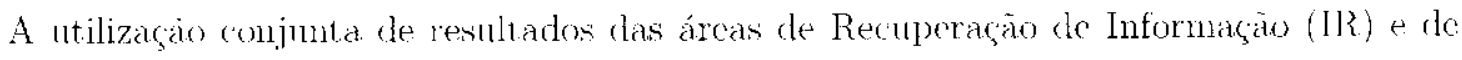

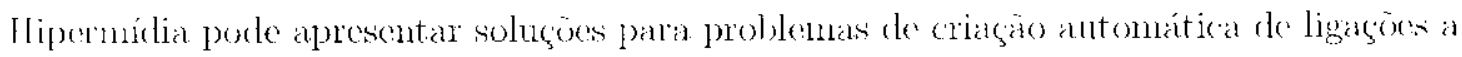
fim de integran diferemes repositories Wols.

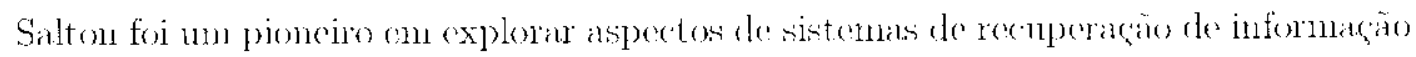

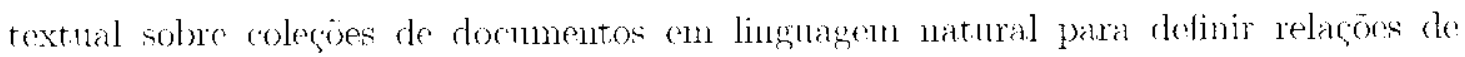

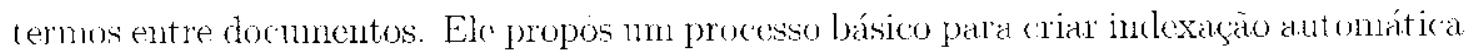

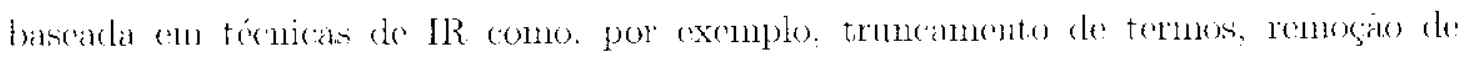

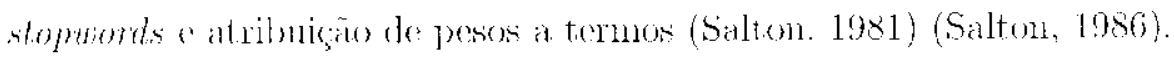

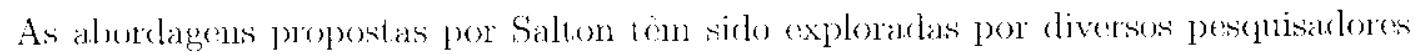

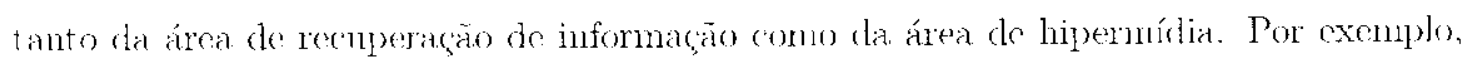
a geragan antumática de ligacoes hipertexto tem side cxplorada por Salton e Alian em

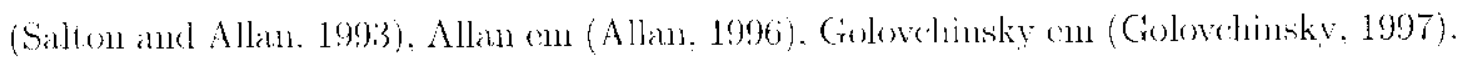

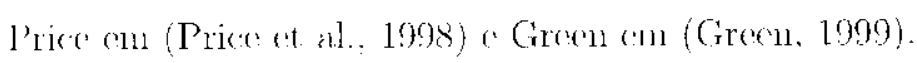

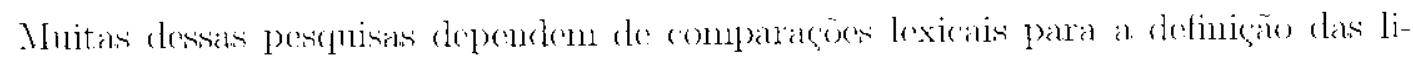
gacoes hipertexto. Entretanto. simples comparaģos lexicais podem onit ir relacionanuentos entro temos devide a variabilidade de palavras para descrever um mesmo oljoto

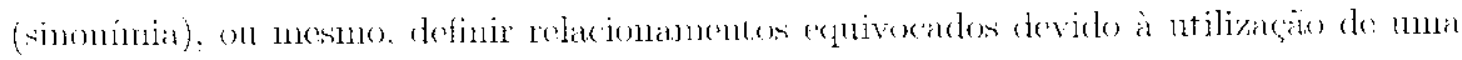

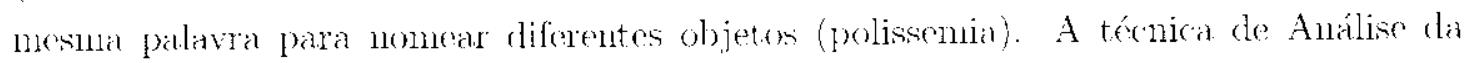

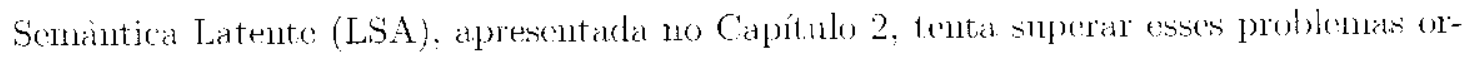


ganizando objetos textmais em estruturas semanticas mais apropriadas para comparaçoes

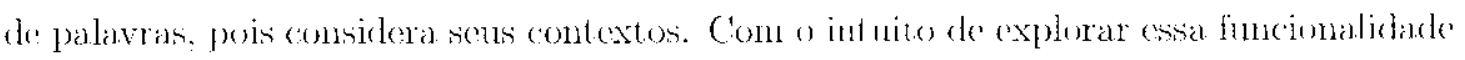

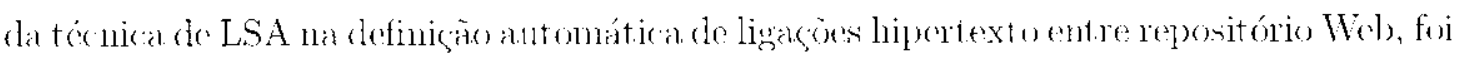
definida uma infra-cstrutura c num serviço para a criaçäo antomática de ligaçoes semänticas (Naredo et al., 2001).

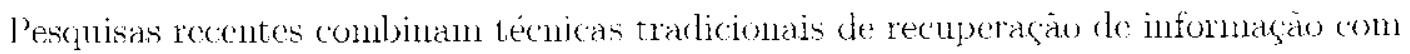

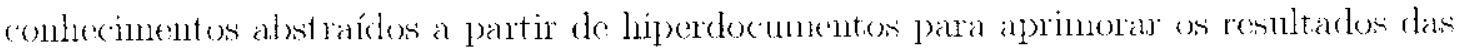
buscas realizadas através do search enghes disponíveis na Wob (Henzinger et al., 1999) (Silva et ał.. 2000) (Ng et al., 2001) (Henzinger, 2001).

Enu sistemits hipermídia abertos, apresentados no Capitulo 3, ligacies hipertexto sino

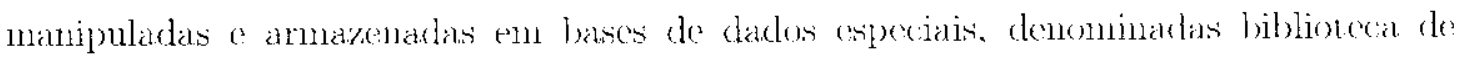

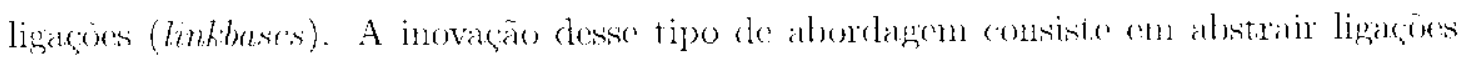
de docmmentos e ammarenálas separadamentes. Funcionalidades hipermídia podenn ser incorporadas a cualquer docunento sem modificar of formate do documento original.

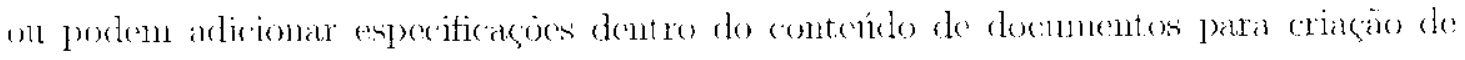
ligancios.

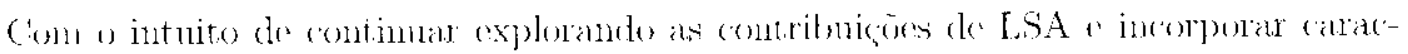
torísticas de sistemas hipemódia abertos solme repositórios Web, foi definida una segunda.

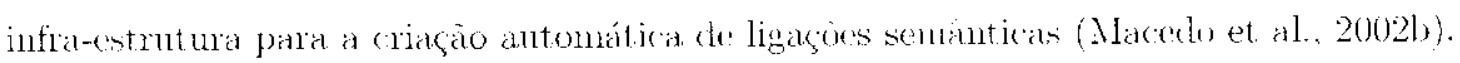

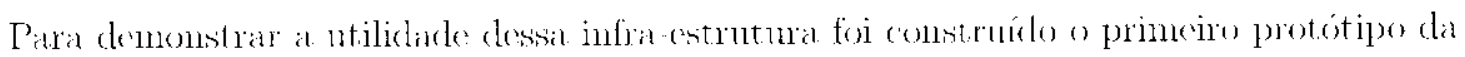
ferranenta LinkDigger que é apresentada neste capítulo.

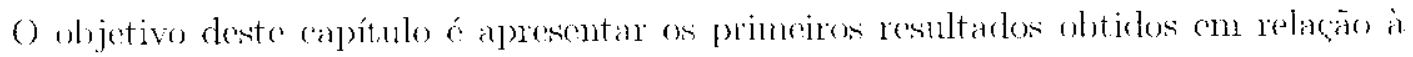
criagno automática de ligaços lippertexto. É importante mencionar que os traballhos appessentados foram realizados on conjunto com a dontoranda Alessandra Alaniz Marende

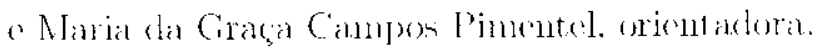




\subsection{Serviço de Criação Automática de Ligações Semânticas}

\subsubsection{Contexto}

O) eClass é mu ambiente instrunentado --- com lonesa cletronical, projetores, càneras do video, c microfones - que automaticamente captura experiencias ao vivo de saldas de anla

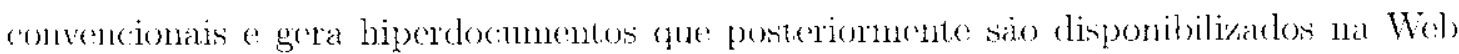
(Alowd, 1999) (Pimentel et al.. 2001a). Esse anthiente tenu sido utilizaklo por diversas tumnas de estudantes do GATECH (Goorgia Tech Institute) e de outras universidades ancricanas com exilo (Abowd, 1999), e vem sendo innplantado no ICXC-UST' sol) a

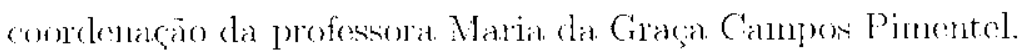

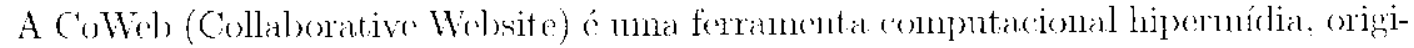
nahnente desenvolvida no GATECII, que permite a antoria colaborativa de páginas Web sem que o usuário necessite de conhecintento prévio de quaisquer te nologias relacionadas,

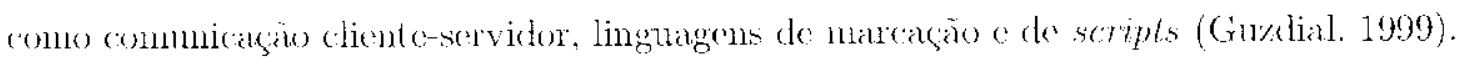

A fin de prover a professores a a ahmos um espaco para troca de informaçoes (pue:

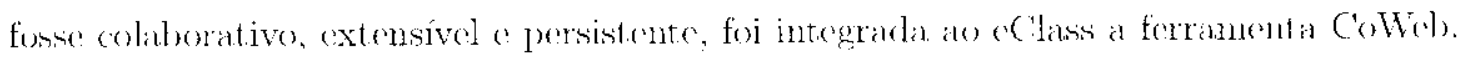
Essa integraçäo foi bascada cm um serviço de criaçäo mamal do ligaçăo bidirecional entre informages capturadas pelo eClass e páginas crialas na CoWob (Ahowd et al. 1999).

Outra alternativa de integração dos ambientes CoWob e eClass investigada foi a criaģão

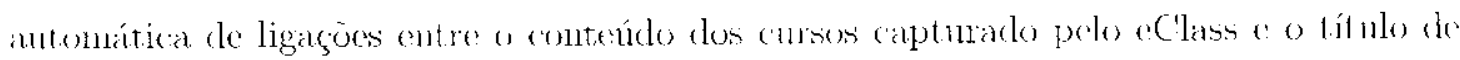
páginas (oweb) (Pinnentel et al., 20011)). Essa abordagem explora a homogeneidade do contenido dos repositórios utilizando apenas comparaçues lexicais de palavras em voz de técuicas elaboradas de recenperagion de informaşăo.

\subsubsection{Motivação}

O antor desta dishertação colaborou na construçäo de um Serviço de Criação Automática

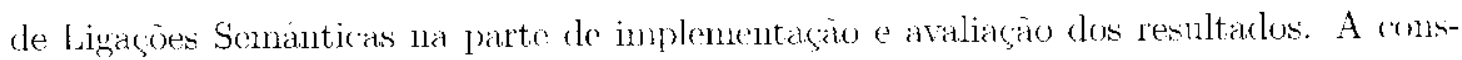

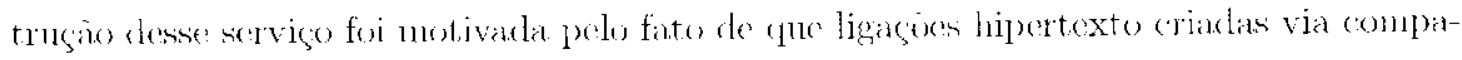

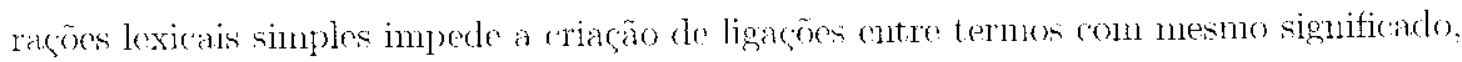
mas com ortografias diferentes. Além disso, comparacoes lexicatis porlen levar à definiçăo 
de ligaçōes para termos com a mesma ortografia, mas com signilicados distintos (Macedo et. al., $20(0) 1)$.

O serviço criado baseia-se na extraçàu de estruturas semanticas de repositórios Web

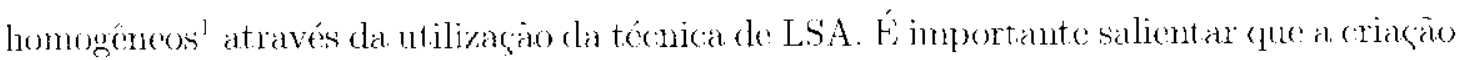
de ligacons, via esse serviço, nảo neressarianente define todas as ligaçós identificadas via comparaçào lexical. Portanto, o scrviço de criação le ligaçues semânticas não substituiria o serviço de criaça de ligaçoes lexicais definido anteriomente en (Pinestel et al.. 200 la).

O Serviço de Criagăo Antomática de Ligaçoes Somanticas foi construílo e cxuperimenttade sobre os repositórios eClass e CoWcb, como cletalhado nas próximas secoess.

\subsubsection{Infra-estrutura}

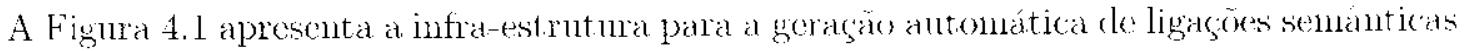

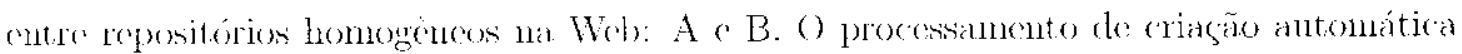

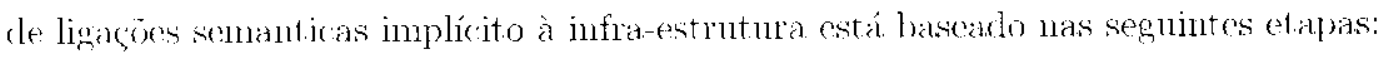

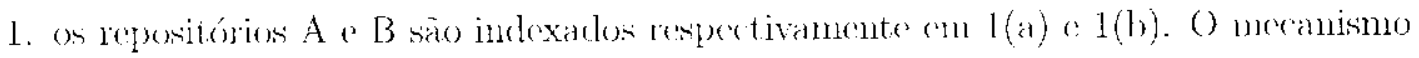
de inclexaño considera a natureza e o tannanho dos repositórios:

2. os índiers resultantes do processo 1 (a) säo nommalmente assoc lados aos repositórios (on maior múmero de palavras. Essce indicen säo ntilizados para gerar a matriz $X$ de trmos por dexamentes;

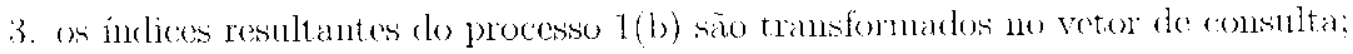

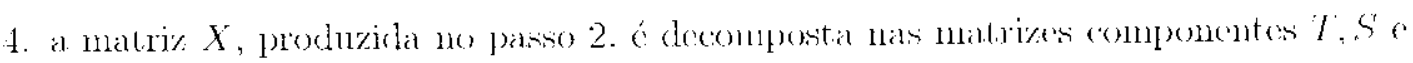

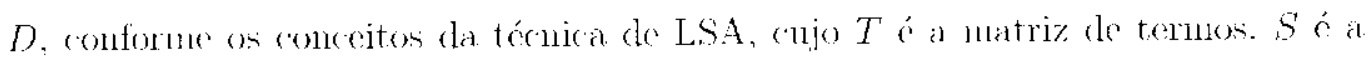
matriz de valores singulares e $D$ é a matriz de docmentos:

5. as matrizes T.S e J) săo reduzidas considerando $k=2$ de acordo com (Furmas et al.,

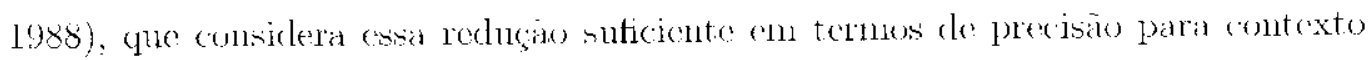
de compatagnes textolais:

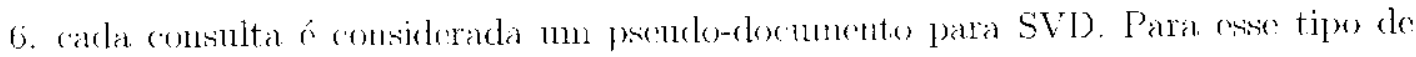
documento, os termos similares sân definidos através da multiplicagào do vetor de consulta pela matriz T rexhzida e pela transposta cla matriz $T$ reduzida:

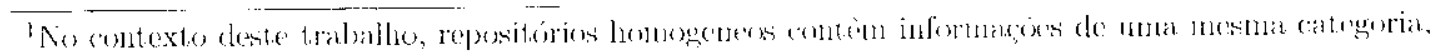
por exemplo, jornais ontine nas seçoss de nol icias esportivat. 
7. a matriz $X$ reduzida é gerada através da multiplicaça das matrizes $T$, S e $D^{t}$ também reduzidas:

8. a nuatriz somantica é finalmente gerada através do cálculo de co-seno contre as colmass da matriz $X$ co vetor de consulta:

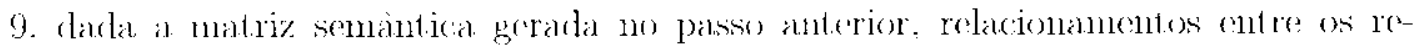
positórios são identificades considerando as cóhnlas dit matriz que tem os mais altos valores de similaridade. Relacionanentos semânticos dentro de un mesmo

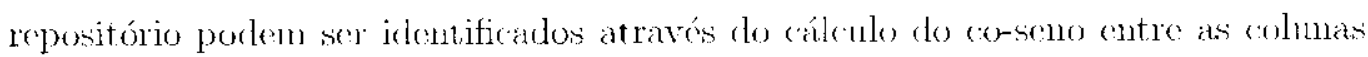
da matriz sembuntic a para o caso do Repositório A, e entre as linhas da mesma matriz para o Repositório 13 .

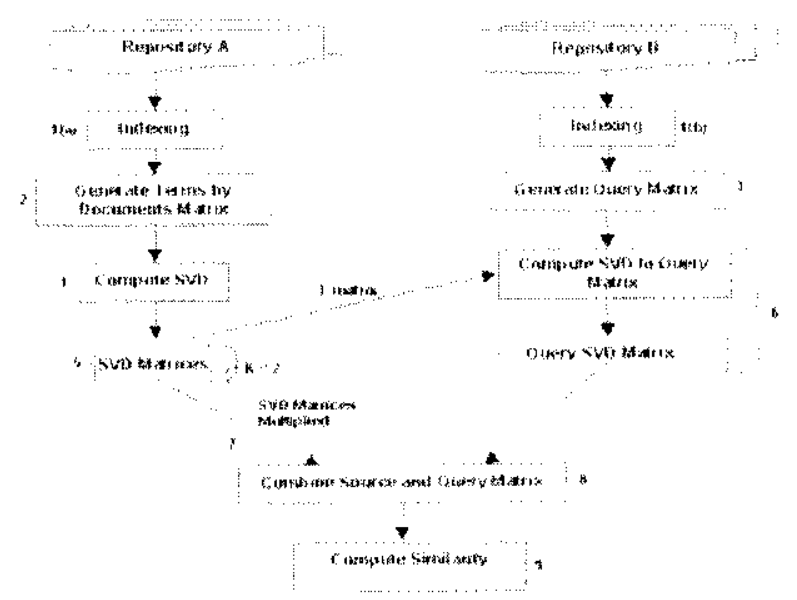

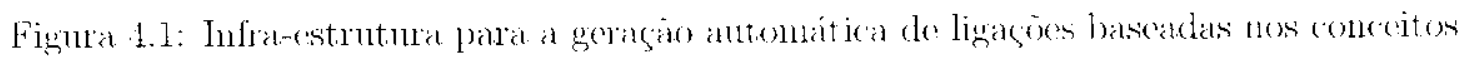
de Análiso da Semantica Latente (Macedo et al., 2001)

\subsubsection{Implementação}

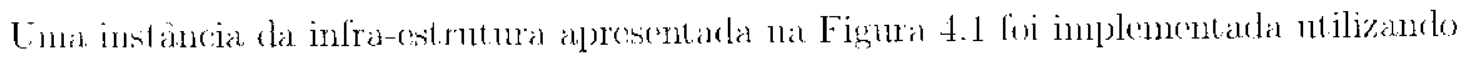

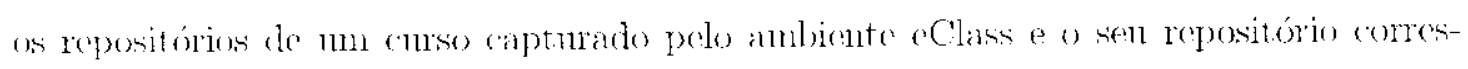
pondente na CoWeb, curso esse capturado em 1999 no GATECH. As aulas do curso

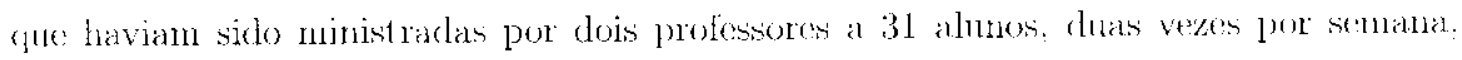

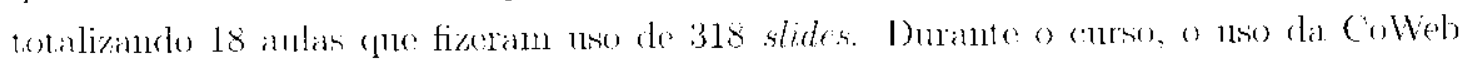
foi resulcrido para a criaço de páginas de resumos de leituras e páginas de identificaçà pessoal. resiltando en 303 páginas criadas (Alowd et al.. 1999). 
Em relaçăo ao serviço que explora LSA, a indexaçăo do eClass foi realizada utilizando

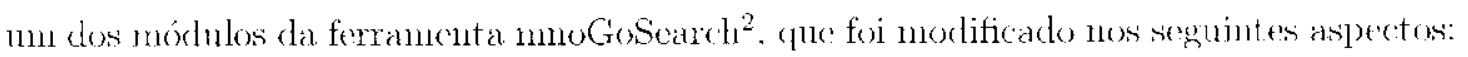
o diciomário do stopwords da ferramenta foi adaptado com palavras utilizadas no contexto do repositório eclass, o o córligo do módulo de indexaçäo foi alterado a fim de permitir extraçăe de palavras a partir de páginas Webs ativadas viat Javaber rijot.

O processo de indexaçăo geron 1904 temos (índices) en 616 docunentos correspon-

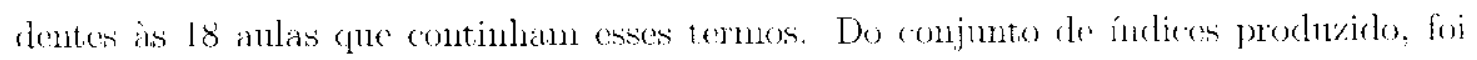
gerata a matriz $X$ da ténich de LSA com dineensós de 1904 linhas por 616 colmas. Em seguida, foi aplicado o modelo SVD para decompor a matriz $X$ em suas matrizes

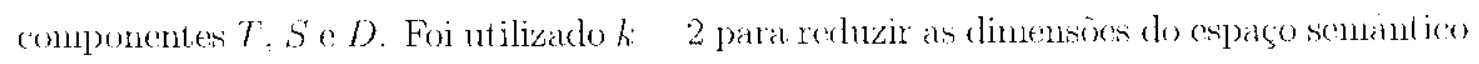
manipulards.

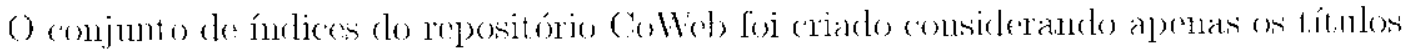
das príginas Web criadas para apoiar o curso (applurado pelo class. Títulos são considerados relevantes sendo, nomalmente, palavras-chave que inclicam o conteúdo da página.

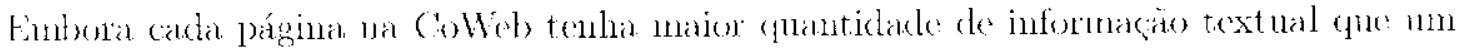

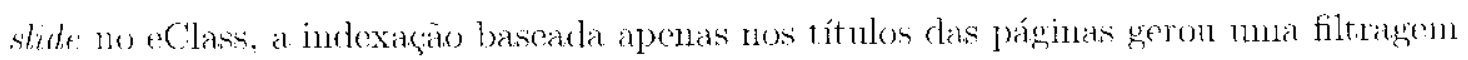
na informação a ser manipulada. Essa abordagem já havia sido adotada con sucesso

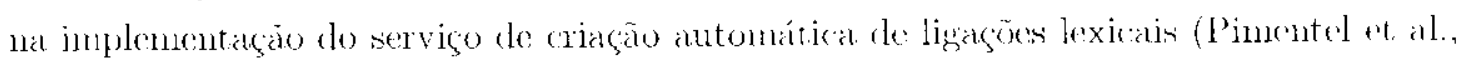

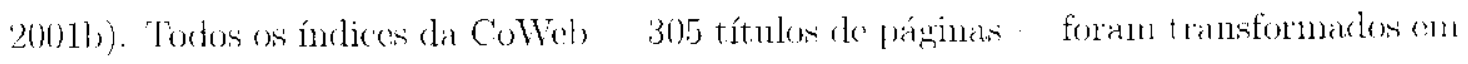
vetores do comsultid.

Finalmente, $11 m$ procedimento combinou as matrizes componentes reduzidas de $X$ e os vetores de consulta calculando o co-seno entre cada linha e colnua da matrís semantitica

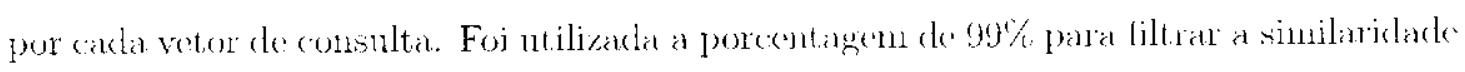
(r gerar a matriz somântica.

\subsubsection{Experimentos}

\section{Ligaçōes semânticas automáticas inter-repositórios}

O processo de criaçăo antomática de ligacóos semanticas baseddas em LSA entre os

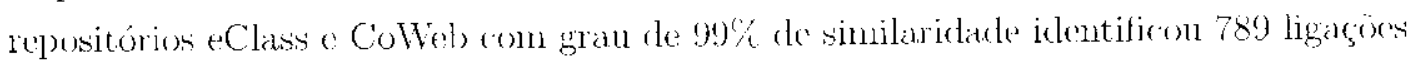

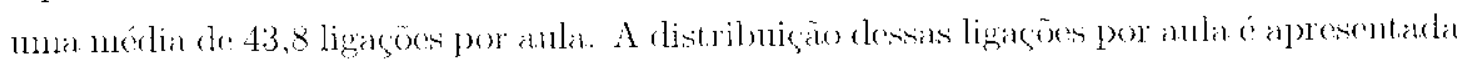
nal Figura 4.2.

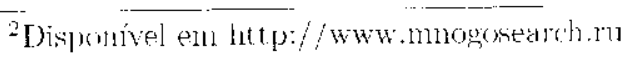




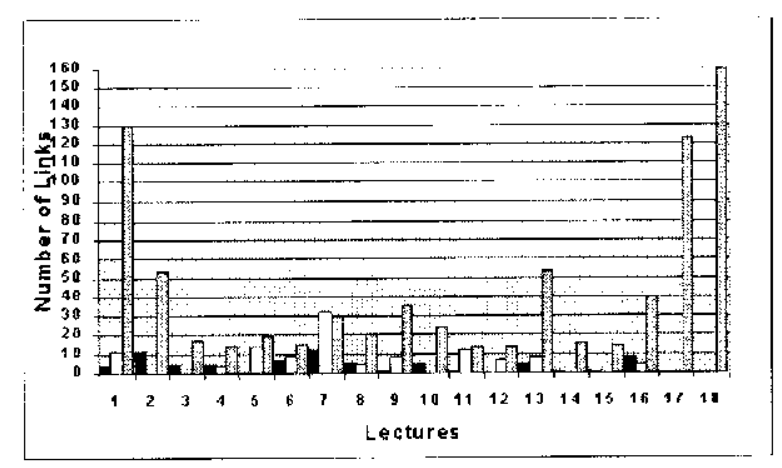

Figura 4.2: Ligaçöes mannuais (preto), ligaçöes lexicais automáticas (branco) e ligaçoes semanticas mutomáticas (cinza). separadas nas 18 anlas de 1 m curso de seminário capturako pelo eClass e documentado na CoWeb (Macedo et al.. 2001)

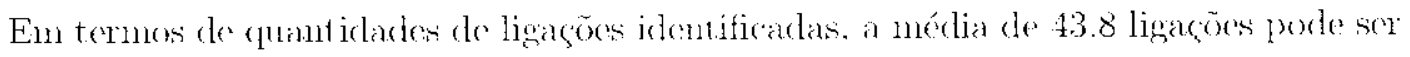
considerada um resultado positivo quando (omparado ao antigo processo de (riaça de ligaçues baseado en comparaçoes lexie ais de palavas média de 6.2 ligaçós por anla.

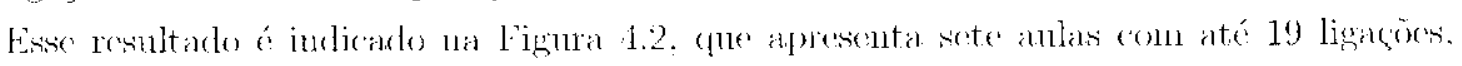
oito anlas entre 20 e 53 ligagons e tres aulas com mais de 120 ligacóen identificadias. () serviço criado identiticou um grande núnero de ligaçoes para as aulas 17 e 18 . Esso fato

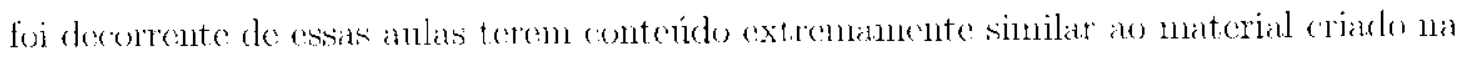

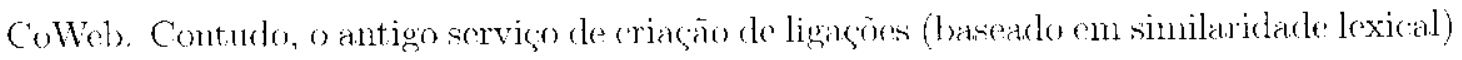
não timha identificado essa similaridade de comteńdo. Assinn. algumas das linitagons de

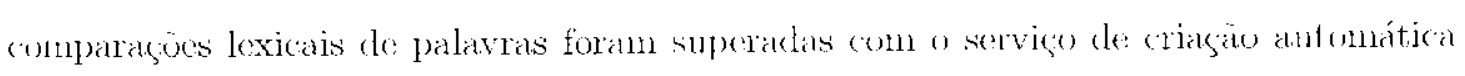
de ligaricen semantiticas.

\section{Ligações semânticas automáticas intra-repositórios}

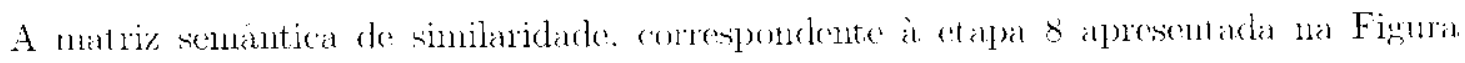

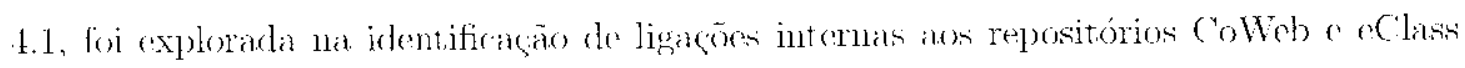
indexatlos. Essas ligaçoes foram criadas a partir do cále ulo de co-seno entre as colunas da

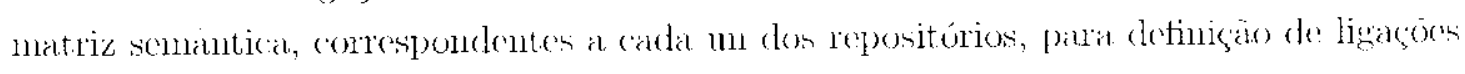

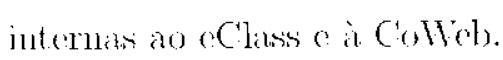

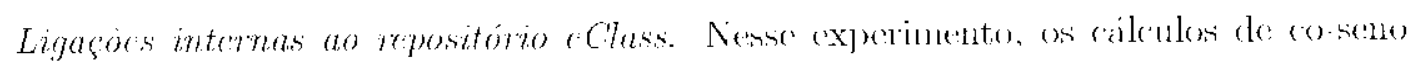

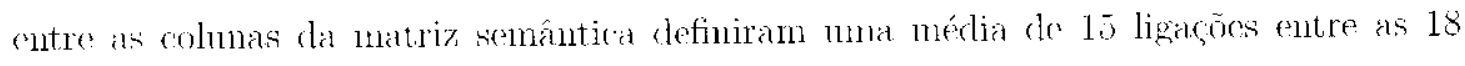
anlas. Esses valores eran esperados, pois as anlas comespondem a unn único curso. Lina média baixa iria contra a hipót cre inicial do experinento que comsiderava os repesitórios 
eclass e CoWeb homogeneos.

Ligacoes intemas ao repositório CoWeb. Ao calcular o co-seno entre as colmas da

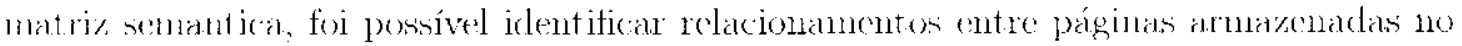

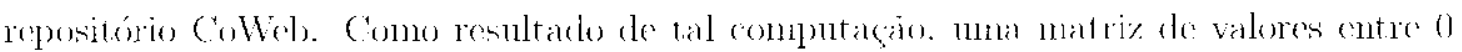

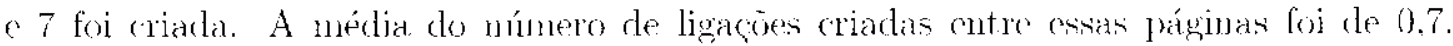

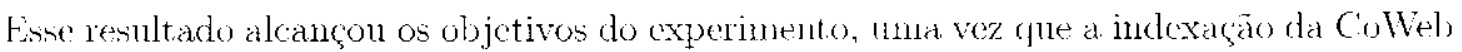

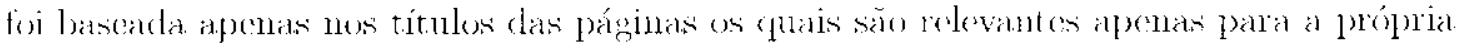
página.

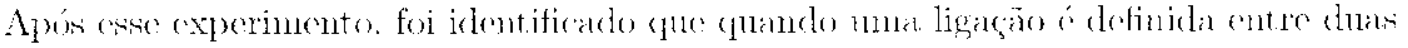
páginas CoWeb. as anlas capturadas pelo elass relacionadas com essats páginas também podenn ser interligadas. Isto annentaria o numero de relacionament os entre docmentos

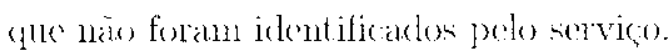

\subsection{Serviço Aberto de Criação Automática de Ligaçōes Semânticas}

\subsubsection{Motivação}

Conm una aloordagem geral para criar ligaçes subre cinalquer repositório Web reçner

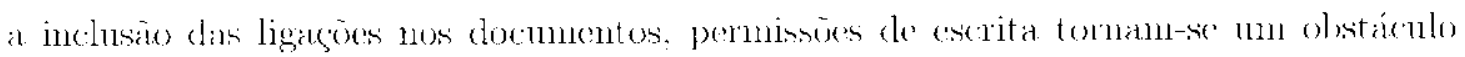

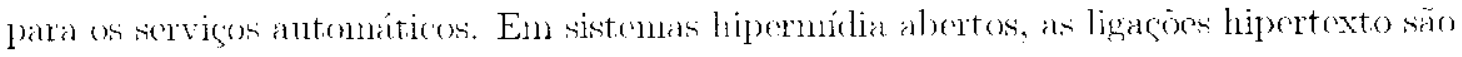
manipmladas via interface Wob independente e armazenaklas em bases de dados especiais. denominadias linktuats.s.

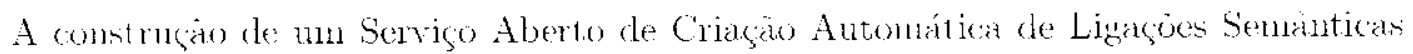

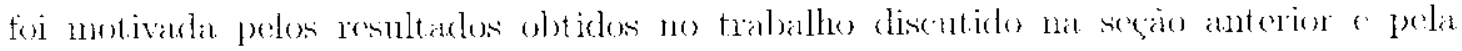
neressidade de:

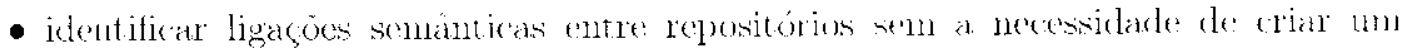

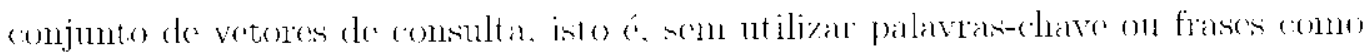

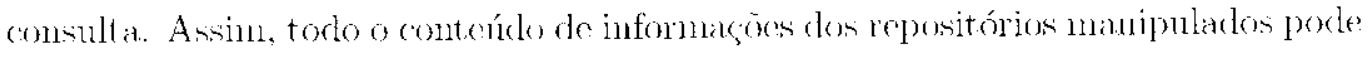
ser indexado e relacionade semant imnente:

- armazenar os relacionamentos das ligacous identificalas en una biblioteca de li- 
gaçôes que possa ser utilizadla por ontras aplicaçós, hipermúdia on nào. Esse requisito também faz parte da idéla de querer estender o servigo a qualequer tipo de repositório Wels. Para armazenar as ligascouesu identificadas separadamente do conteúdos dos documontos, o WJS (Web Linkbase Service), iapresentado no Capítulo 3. foi utilizudo.

\subsubsection{Infra-estrutura}

A infra-estrutura apresentada na Figura 4.1 foi modificadd e estendida para inconporar us nowos requisitos definides para o servigo abeeto de criação automática de ligaçoes

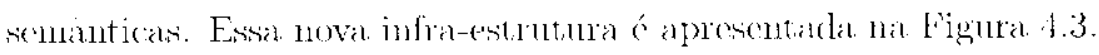

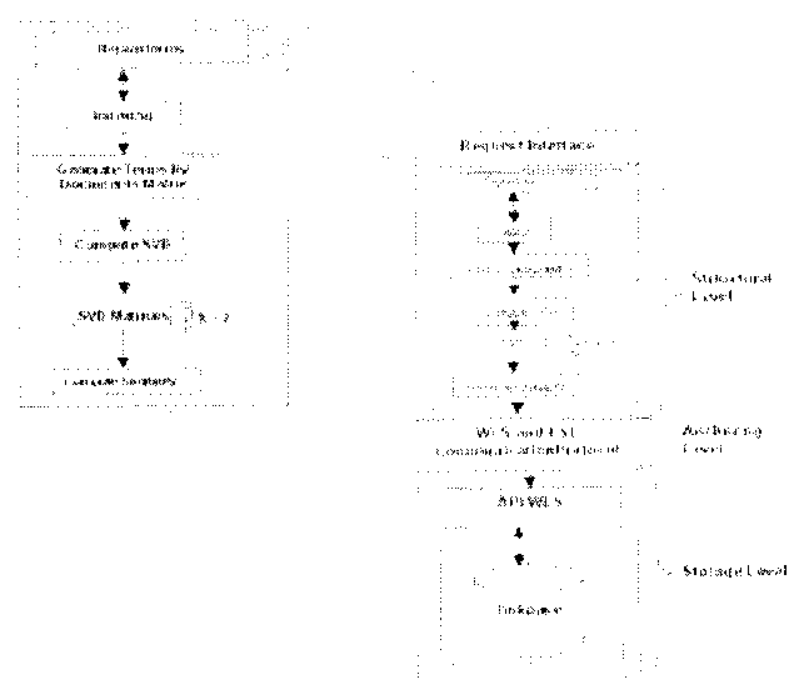

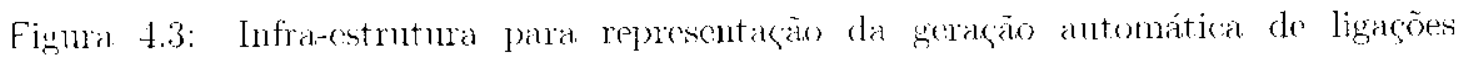
scminticas alyertas Wol) (Macedo el al., 2002b)

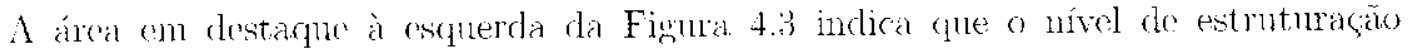
(structural betel) da infra-estrutura definida e connesto por parte da infra-estrutum

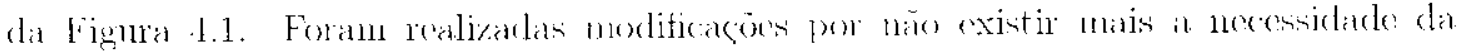

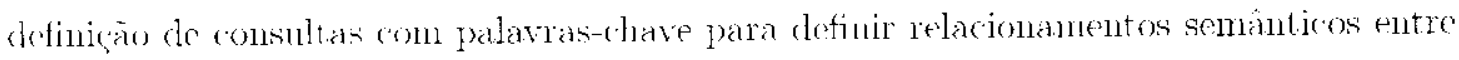
reponitórios Web. Toxkon us repositórios a screm indexadus sio manipulados pela mesmat.

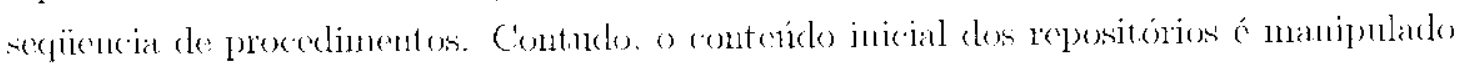

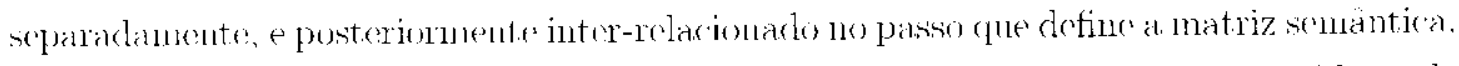
No nível de estrutuaçán a infra-estrutura manipula componentes de conteúdo o de

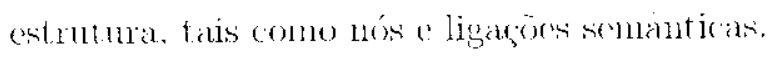


O nível de armazenamento (storage level) é composto pela biblioteca de armazenamente de ligaçons do WLS. A comminicasăe cutre o nível de amazenannento e o nível de estruturaça ó realizada at ravés de procedinnentess existenten no nivel cle ancoragem (anchoring level).

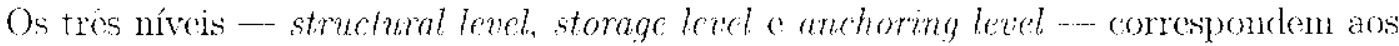
níveis homonimos da arfuitetura de Referencia Dexter de Sistemas Hipernídia Abertos (Hialatsz and Schwartz, 1994).

O nível de apresentaçäo (reques interface) é composto por interfaces como as apre-

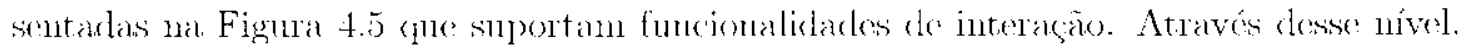
usuários podem fazer requisiçôes de serviços e visualizar as ligaçoes criadas no nível de estruturaça e armazenadas no nível de armazenamento.

\subsubsection{Implementação}

Foi alsstrádo $11 \mathrm{~m}$ algoritno, apresentado na Figura 4.4. para implementaça da infra-estrutura do Serviço Aberto de Criação Autunática de Ligaçues Semánticas. Nesse alguritmo

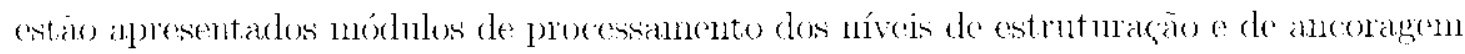

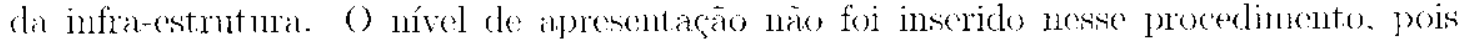
slla implementaçăo depende do contexio no gral o serviço é ntilizado. Já o nível de armazenamente é tratado pelo serviço do ligagues's WLS.

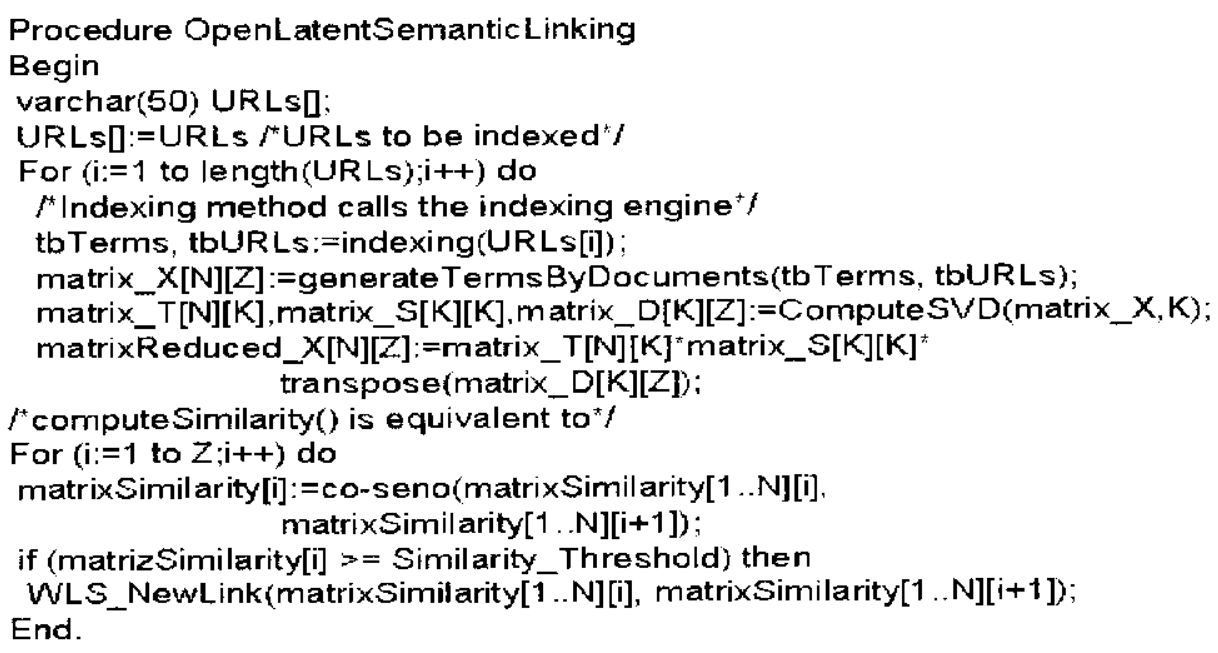

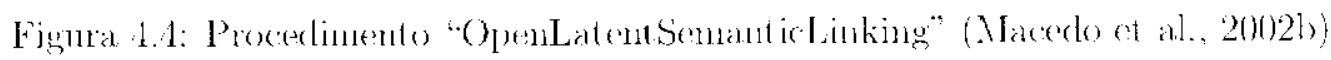


(os procedimentos e as funçeses do procedimento OpenLatentSemanticLinking foram

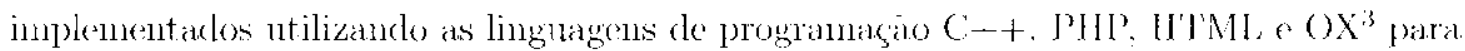

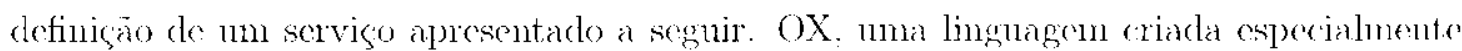
para a manipulação de matrizes. inclui o procedinnento ComputeSVD como parte de sua biblioteca de funçós.

\subsubsection{LinkDigger}

Para demonstrar a utilidade da infra-estrutura da Figura 4.3 definida foi construido o primeiro protótipo do serviço aberto de criação alutomática de ligaçoes --- LinkDigger suie? permite:

- a indexação de até (inco repositórios Wéb:

- a idcutificação de relacionanentos semant ieos entre os repositórios indexades. Caso

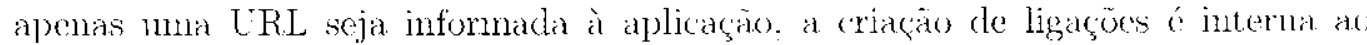
repositório;

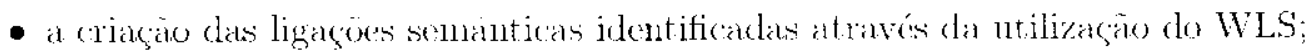

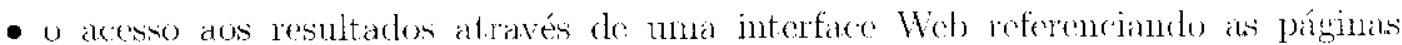
relatcionadas pelo LinkDigger com os repositorios inclexados.

A interface de entradia de informacoes do LinkDigyer, apresentada na Figura 1.5(a). é

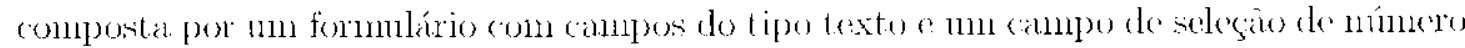

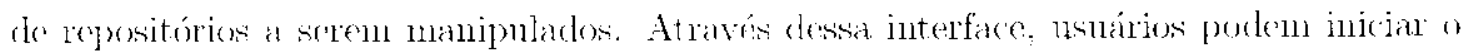
processo de relacionamento semántico entre repositórion Web segundo os seguintes passon: (1) selecionar o número de repositónios a serem relakionades; (2) disponibilizar un a-muil

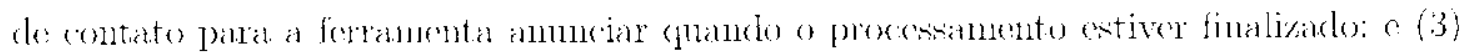
ativar a execucaro de processmento. É necessinio formerineento de une e-mail de contato.

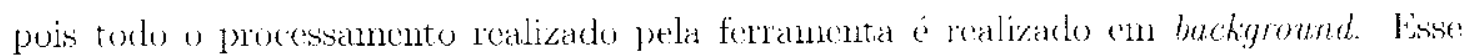

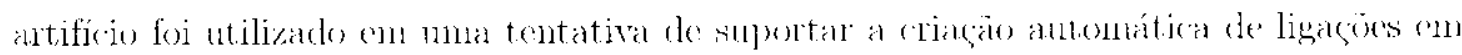
repositórios com gratnde quantidade de informatăon.

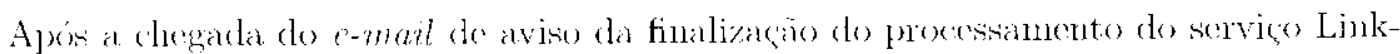
Digger, usuários podern acessar os resultados at ravés do uma interface Web que apresent a

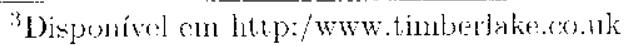


os relacionamentos criados cono ligaçes distribuídas hierarcuicamente. Lm exomplo de

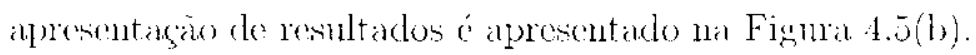

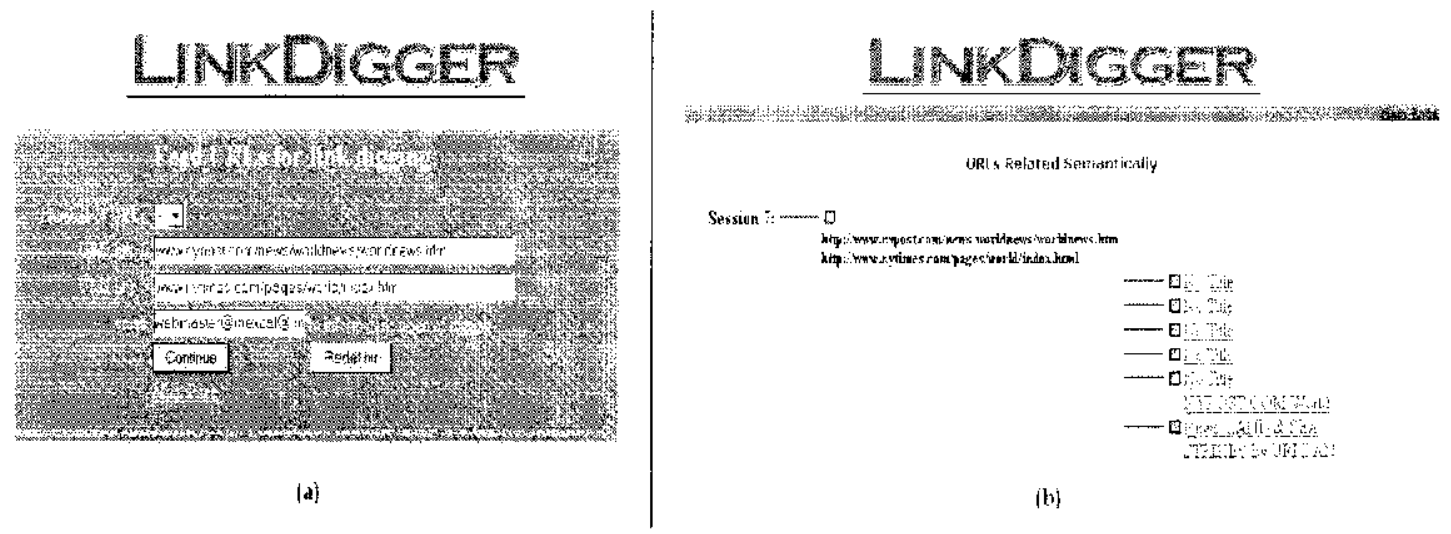

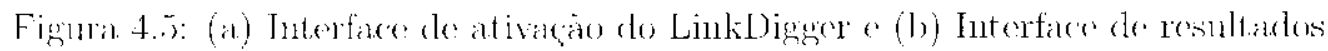

\subsubsection{Experimento}

Fin un experimente ink ial, o LinkDigger relacionou páginas con noticias mbime de dois jornais norte-andricanos o'The Vew York Times (NYT) eo New York l'ust (NYP). Esto

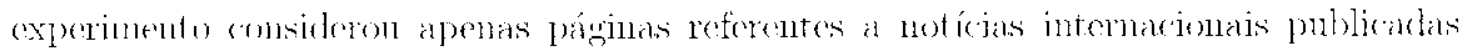
pelos dois jormais en 13 de janeiro de 2002: 16 notícias do jomal NYl e 9 notícias do jortial $N Y \mathrm{P}^{3}$.

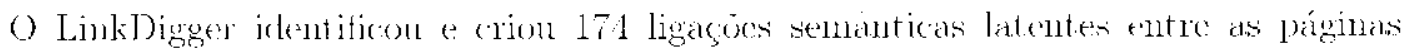

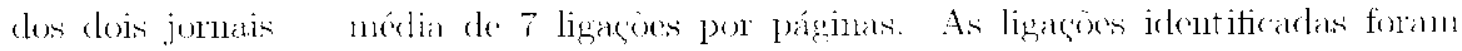
mmazenadas na biblioterat de ligagoes do WLS.

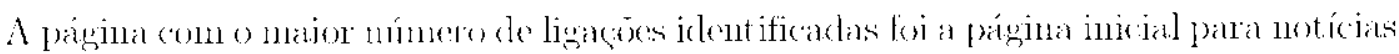
internacionais do NYT … 14 ligacoses. Esse fato cra espexado, pois esse tipo de página tem contexto rolacionado a todas as páginas indrexadats. Entretanto. 6 das 14 ligaçoes

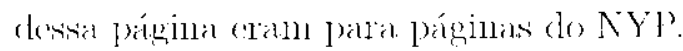

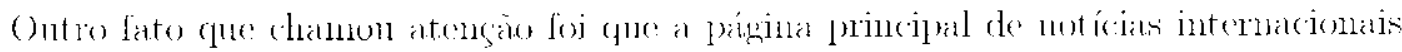

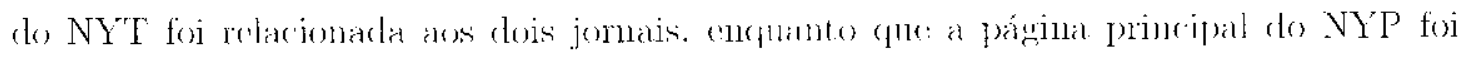
relacionada exclusivamente ao próprio jornal. Essa constataço pode ser explicada pelo

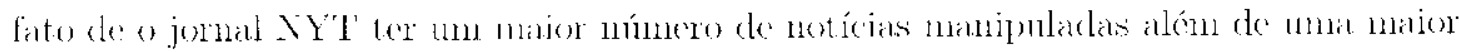
varieclate de informaçar. 


\subsection{Considerações Finais}

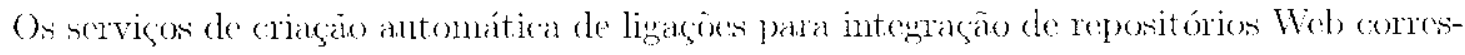
pondem à etapa inicial do trabalho apresentado nesta dissortaçäo.

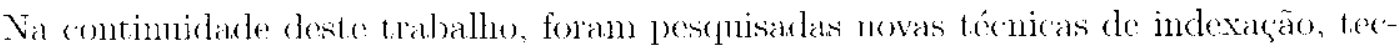
nologias e estratégias de recuperaçäo de informação para obter melhores resultados dos

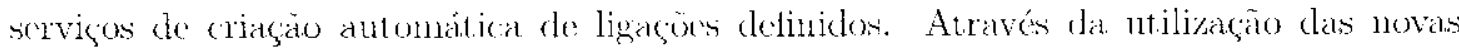

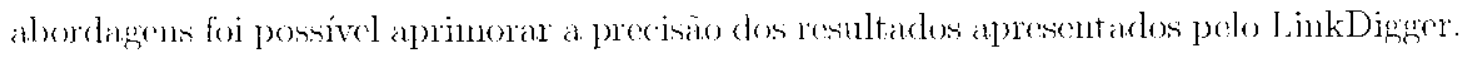
Esse trabladho de investigagào é reportado no próxino capítnlo. 


\section{Capítulo 5}

\section{Investigando abordagens de IR para a criação automática de ligações entre repositórios}

\subsection{Considerações Iniciais}

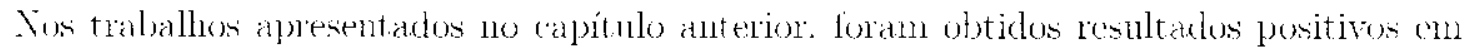

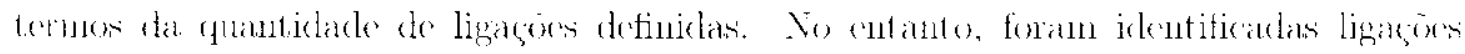

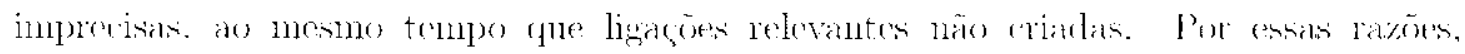

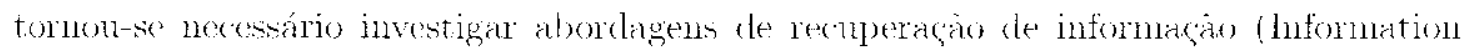

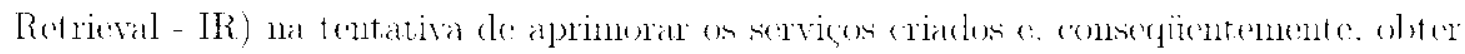

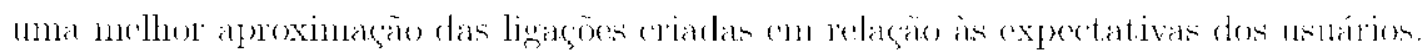

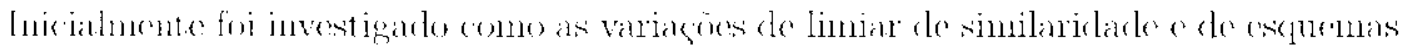

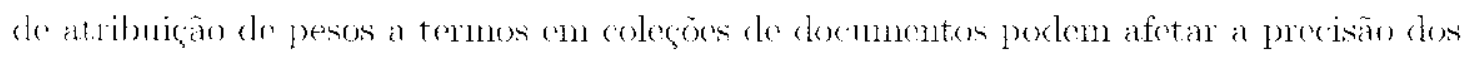

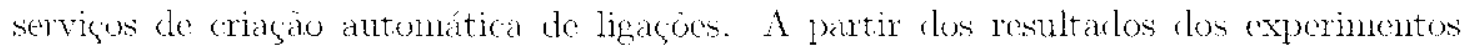

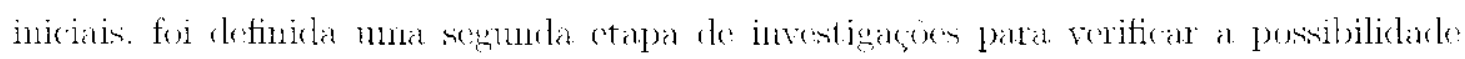

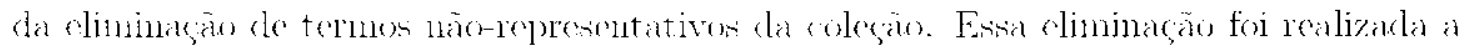

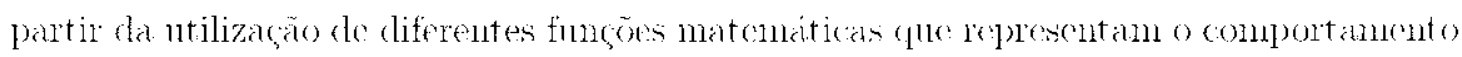

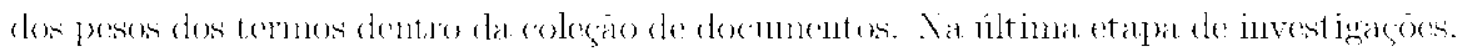

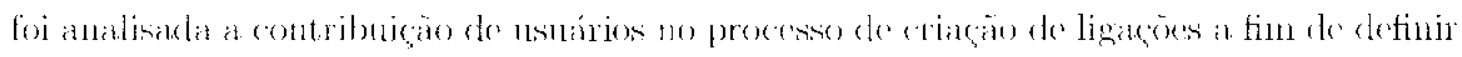

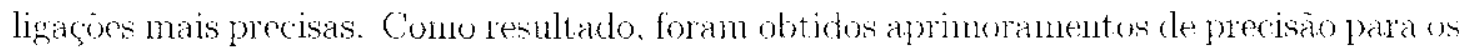

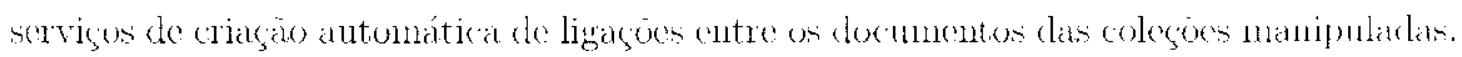


P'ara a realizaça das investigaçoes citadas a pard comparason de resultados. form

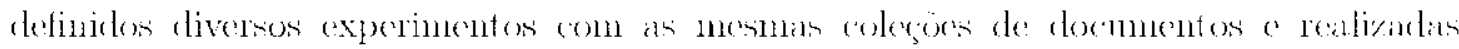

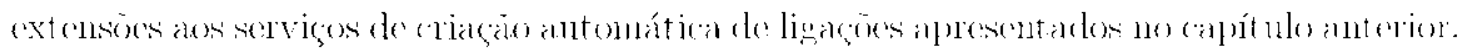
Esse conjunto de extensós possibiliton a definiçio de un scrvico configurádel parat a

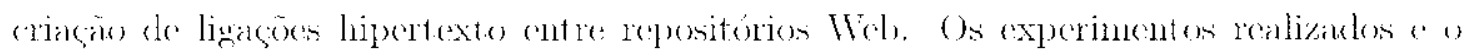

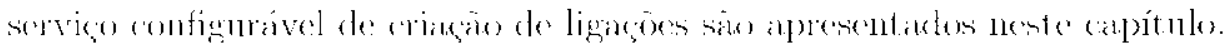

\subsection{Definição dos Experimentos}

\subsubsection{Ambiente operacional}

On experimentes forann realizados ene un compunator con procossator Intel Pentiun III

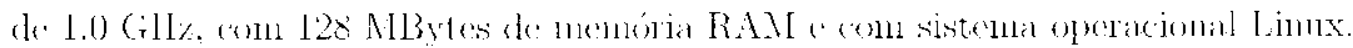

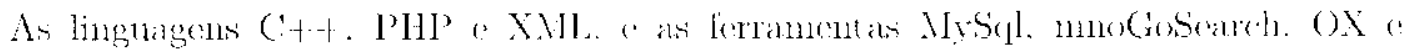

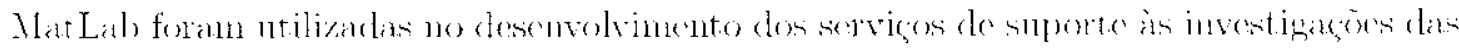
abordagens do IR.

\subsubsection{Descrição das informaçōes manipuladas}

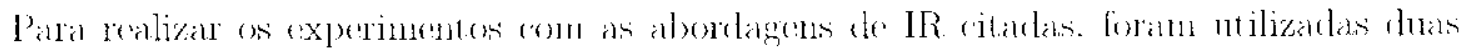
colecios do doc:untertes.

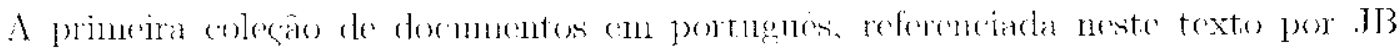

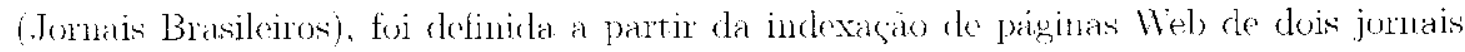

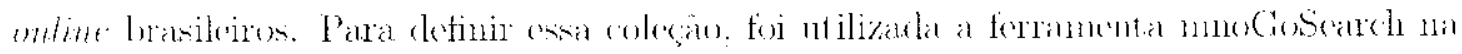

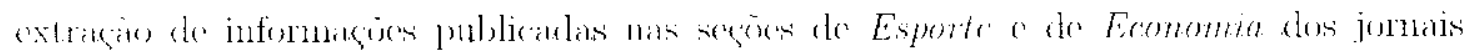

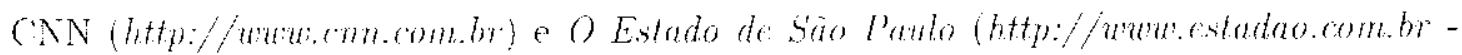

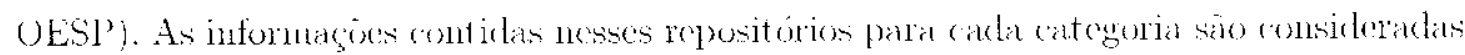

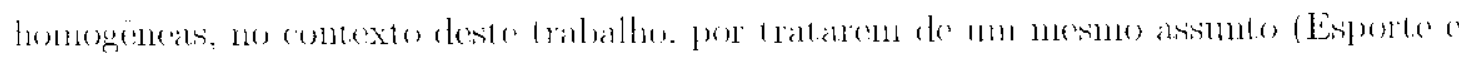

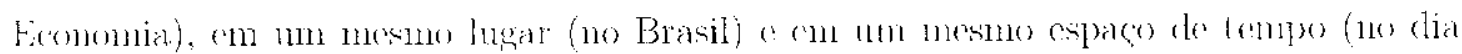

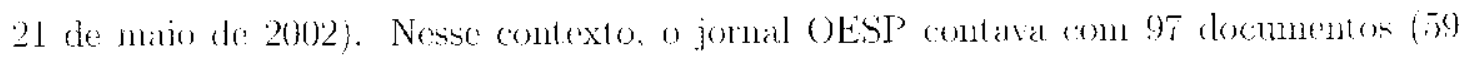

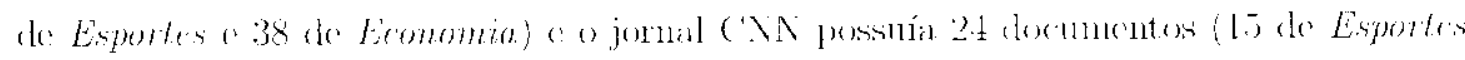

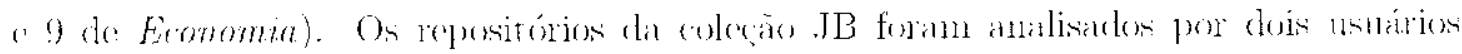

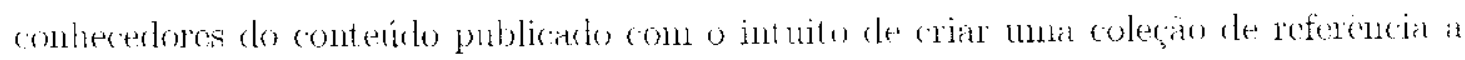


ser utilizada para a avaliaşo dos resultados des experinentos.

A segunda colegäo de documentos. Cystic Fibrosis (C'F), é formada por 12:39 docmenttos em ingles olutidos da base de dados MEDLINL da National Jilurary of Medicine e prom

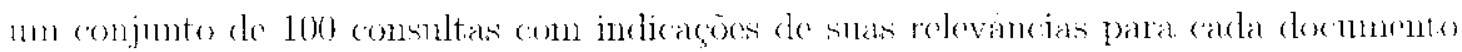

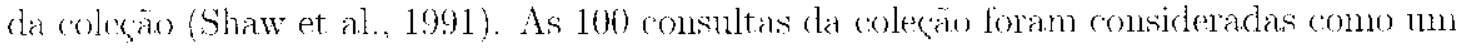
segundo conjunto de documentos que väa possíveis ancoras de ligaçoes deteminadas para

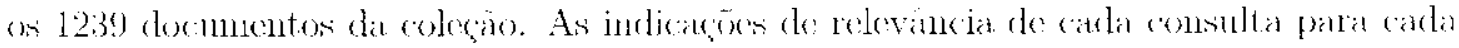

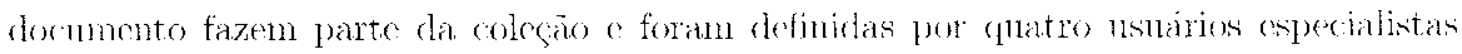
na áred de cystio fibrosis. Fssas informagoes possibilitaram a definiça da coleçio de referencia a ser utilizada para a avaliagno des resultades.

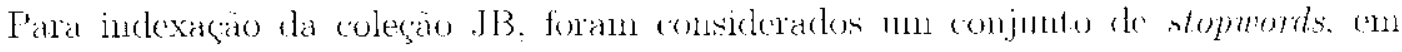

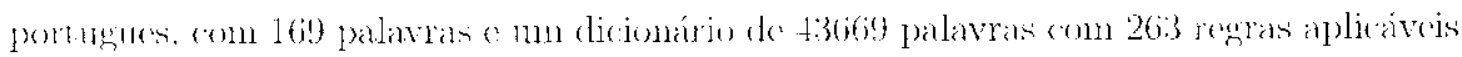

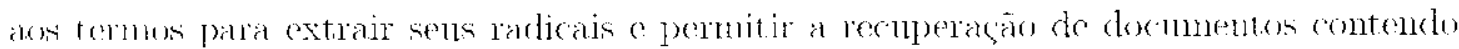

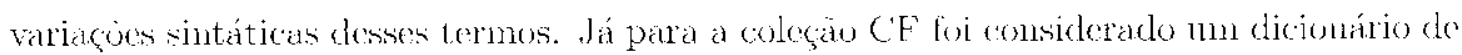

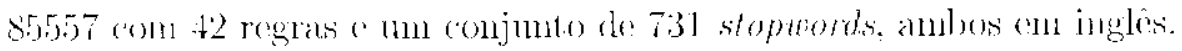

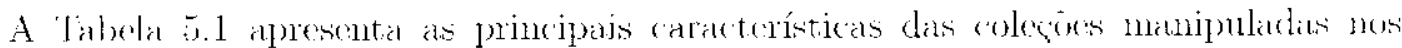
(xperinerentos denerites llas próximas segoes.

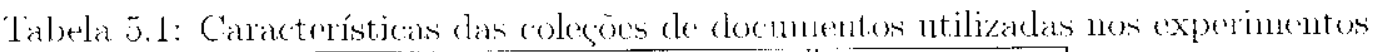

\begin{tabular}{|l||c|c|}
\hline Características & \multicolumn{2}{c|}{ Coleções } \\
\hline & $\mathrm{JB}$ & $\mathrm{CF}$ \\
\hline \hline $\begin{array}{l}\text { Número de documentos e } \\
\text { consultas }\end{array}$ & 121 & 1339 \\
\hline Número de termos distintos & 4.789 & 7.410 \\
\hline $\begin{array}{l}\text { Número de documentos rele- } \\
\text { vantes gerados pelo usuário }\end{array}$ & 42 & $4.8 \overline{19}$ \\
\hline Tamanho da coleção (MB) & 2.2 & 7.9 \\
\hline
\end{tabular}

\subsubsection{Medidas de avaliação}

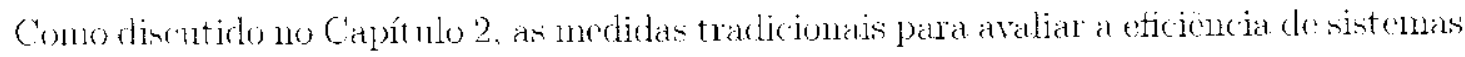

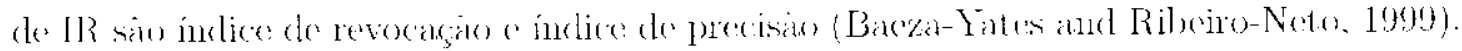

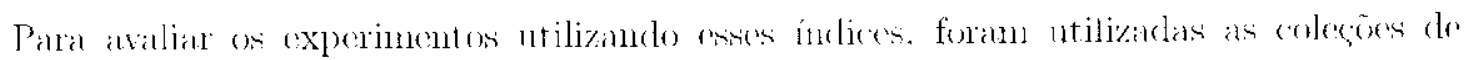
reforencia correspondentes a cada coleçăo manipularla, JB C CF. 


\subsection{Variação de Esquemas de Atribuição de Pesos e de Limiares de Similaridade}

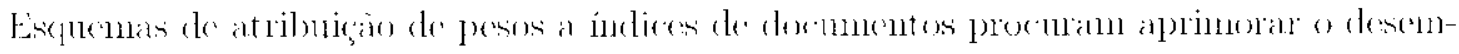

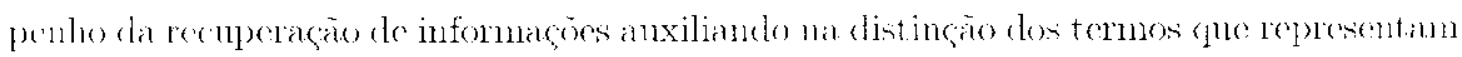

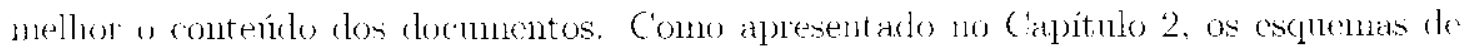

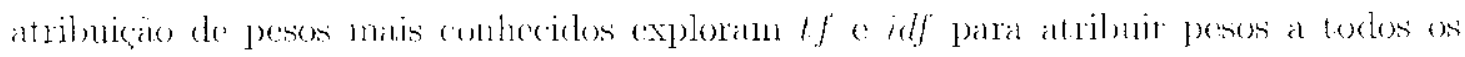

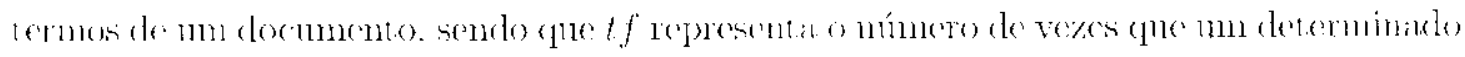
tormo ocorre cm $u$ dade documento e idf o munero de documentos no qual aquele

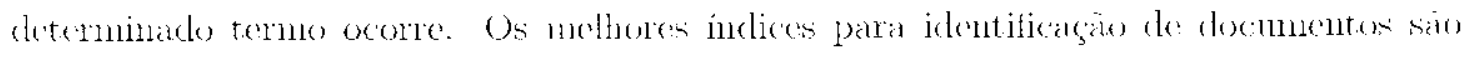

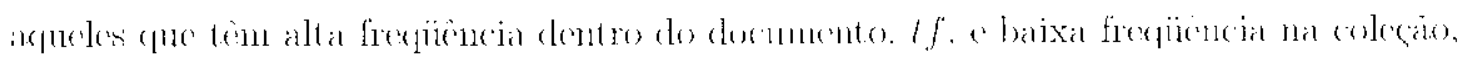
ilf.

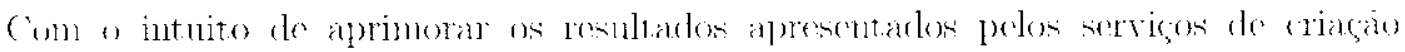

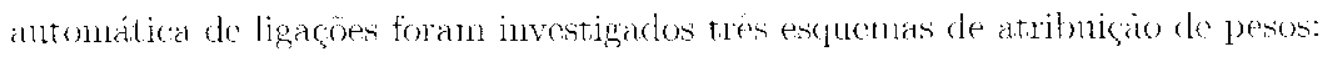

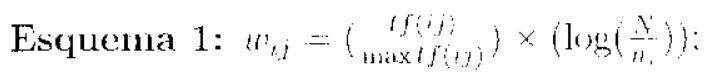

Esquema $\left.2: w_{i}-(1+\log (1)(j, j)) \times \log \left(\frac{y}{m i}\right)\right)$;

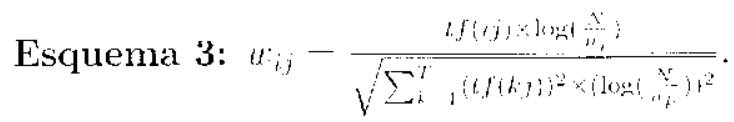

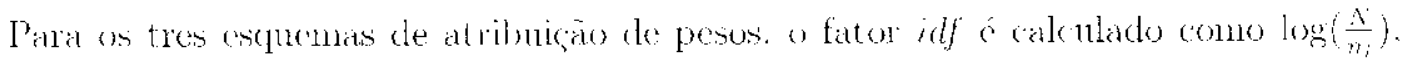

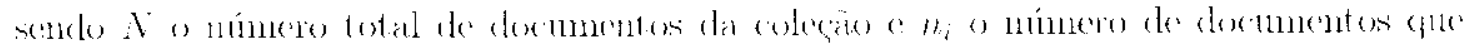

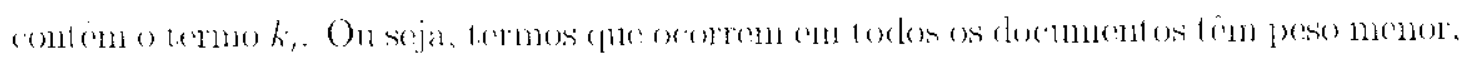

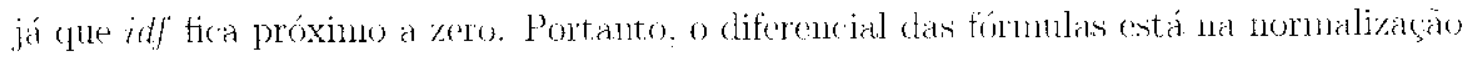

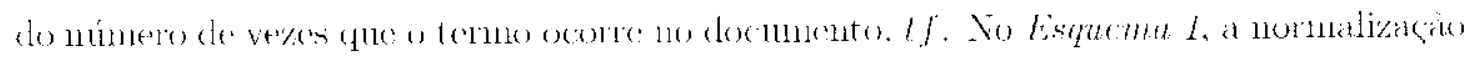

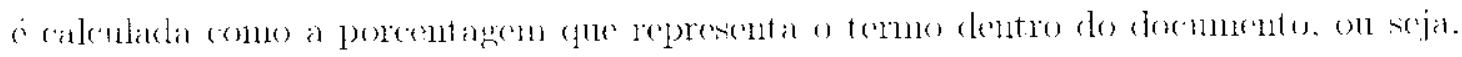

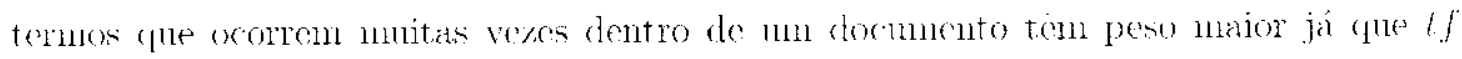

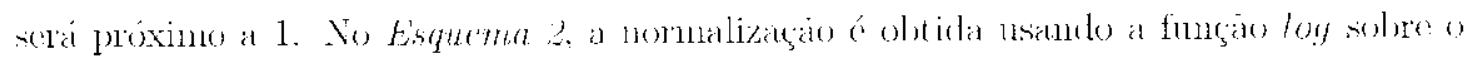

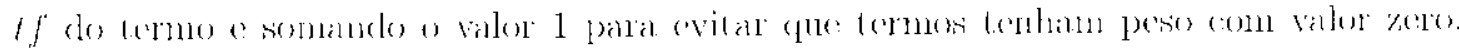

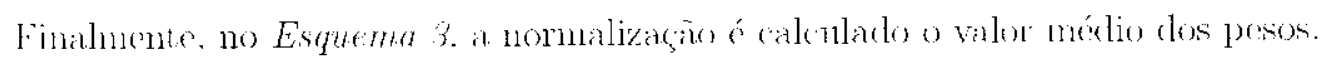

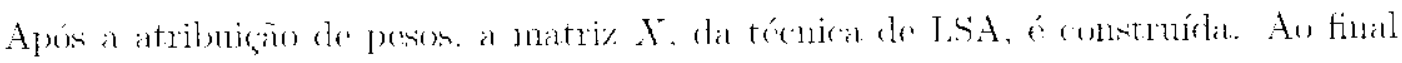

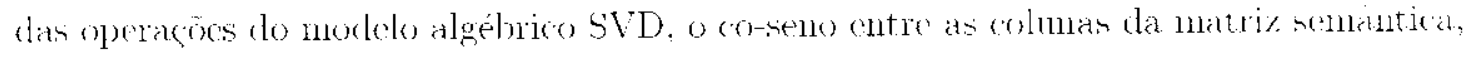

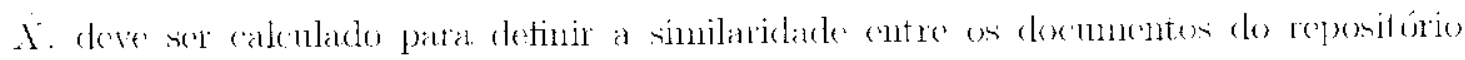




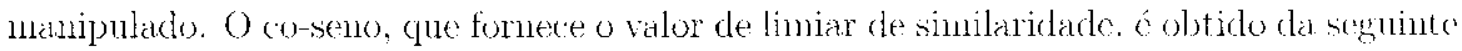
Hinntira:

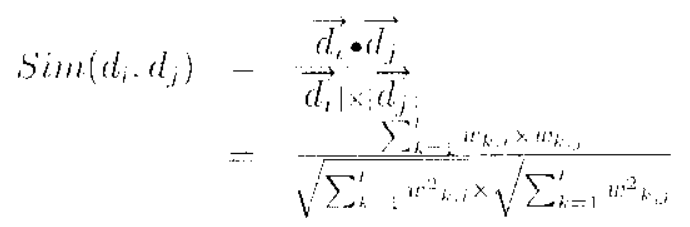

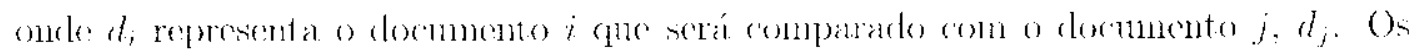

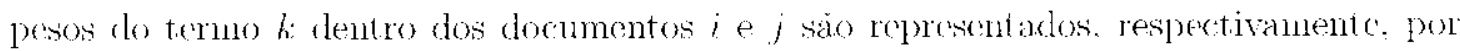

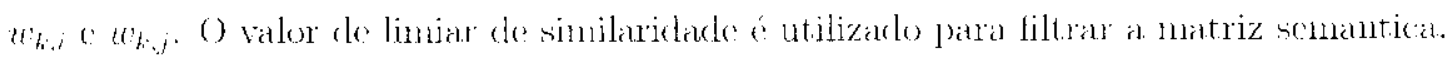

\subsubsection{Procedimento}

Parat realizar experimentos com os escuemas de atribuciano de pesos investigados, o al-

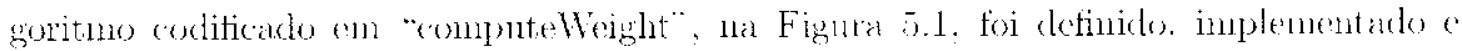
tentarlos.

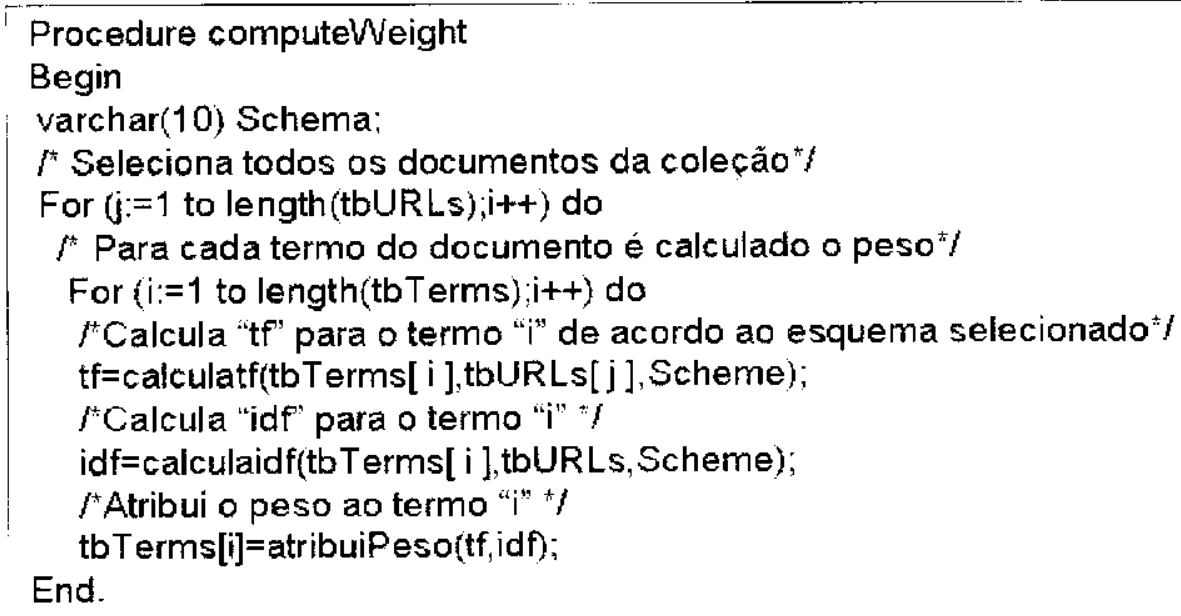

Figuma 5.1: Prexedinemes "compute:Weighte"

() procedinento "computeWeight" executa os seynintes módulos:

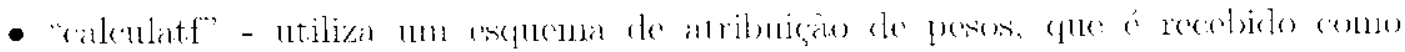

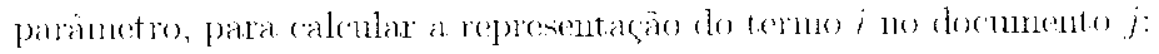


- "calculaidf" - calcula a co-relaçio gune cxiste cutre o termo i e toda a coleça de

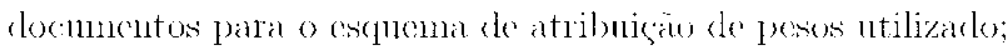

- "atribuil'eso" - annazena o valor do peso no termo i do vetor que representa a documento j. Esser valor á calculado cono $t f \times$ idf

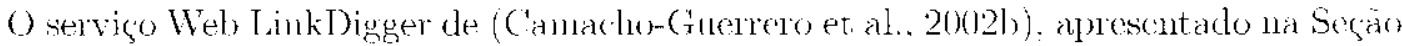

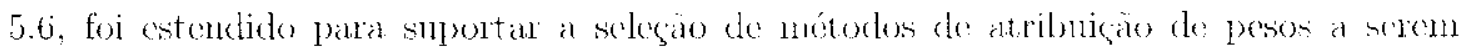

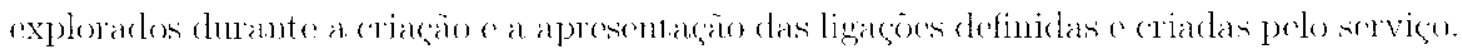

\subsubsection{Resultados}

As Figuras 5.2 e 5.3 alpresentan os diferentes esquenas de atribuigano de pesos investigades

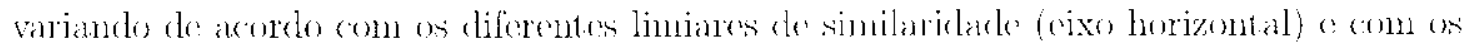

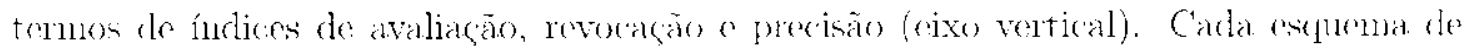

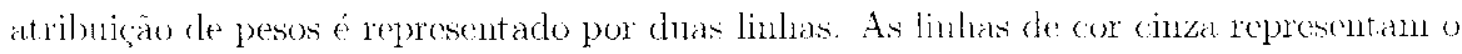

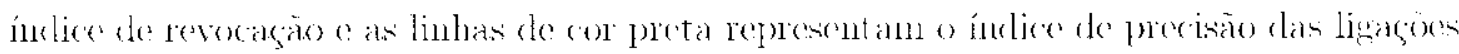
gerarkiats.

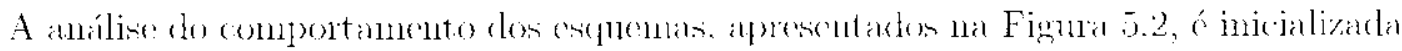
com o limiar de similaridade de $50 \%$. Entre 50 a $70 \%$, relacismanent os semant iros

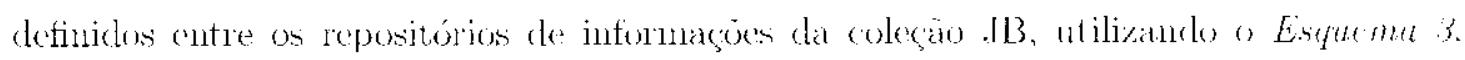

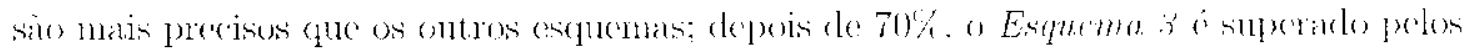

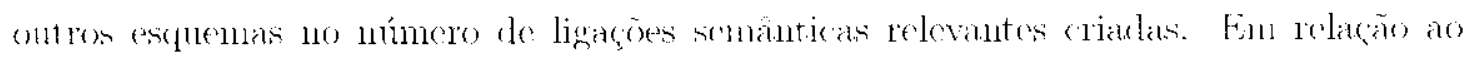

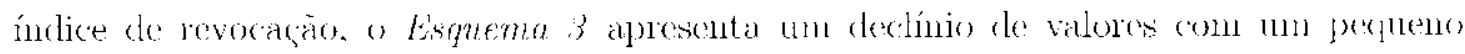
anneme cut re os lindiares de 60 a $70 \%$.

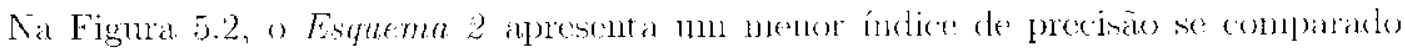

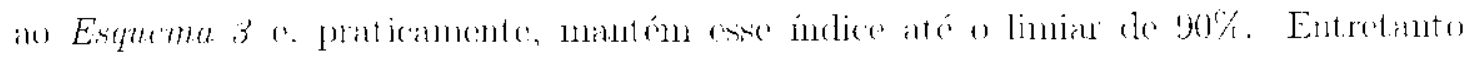

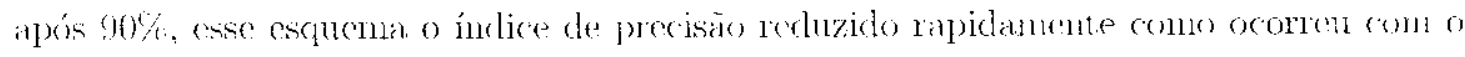

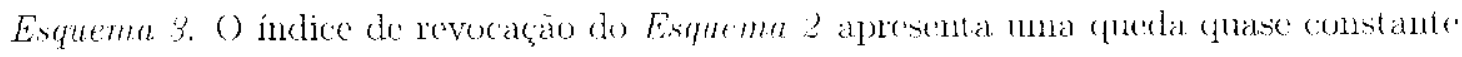

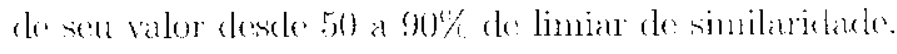

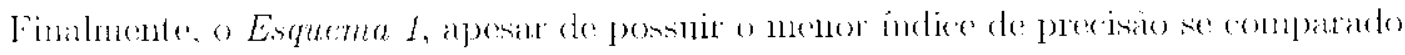

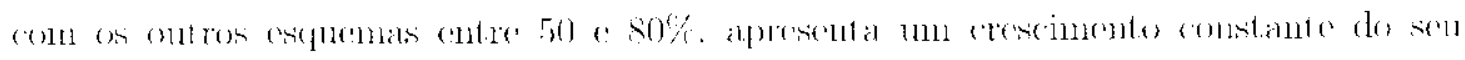

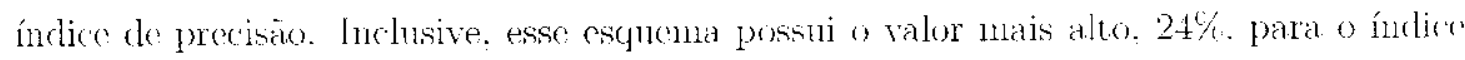

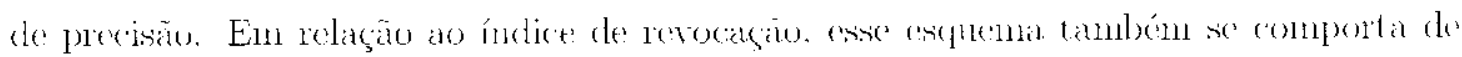


mancira satisfatória, una voz que a dimimuçäo desse indice é pequena so comparada

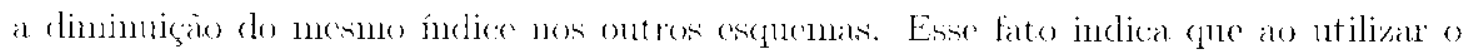

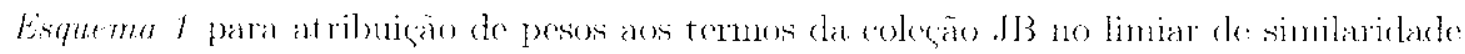

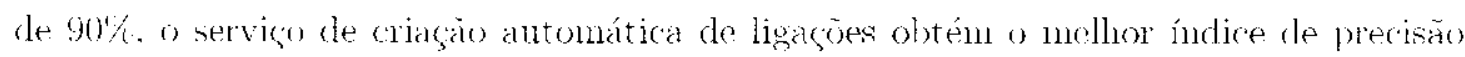
rom a mener perria de ligatsoes redevantes.

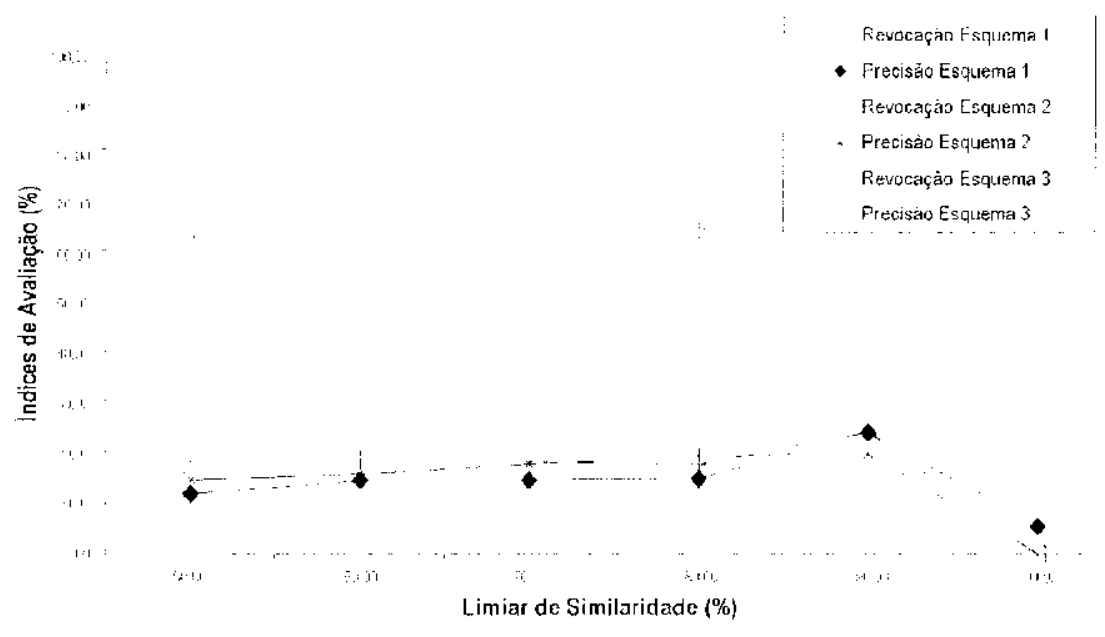

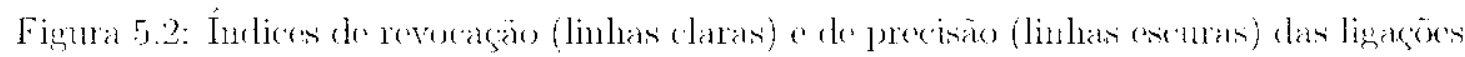

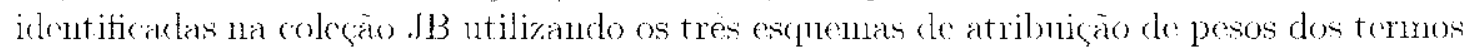

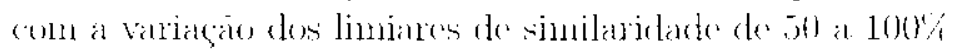

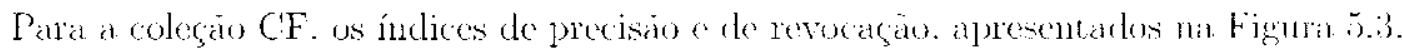

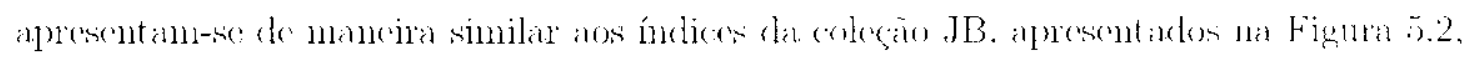
parm liniates de similaridade de 50 a $100 \%$.

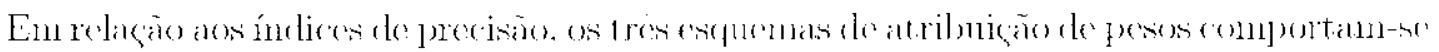

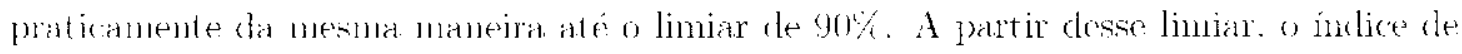

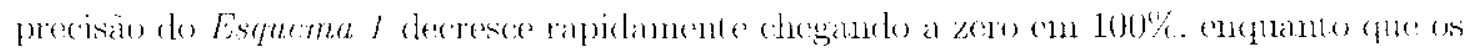

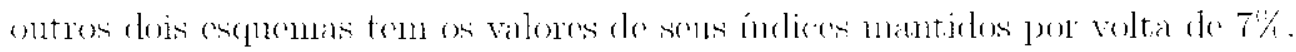

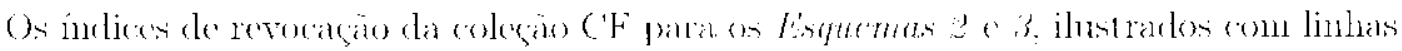

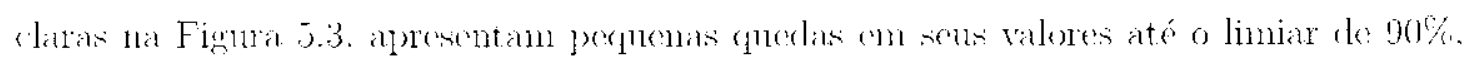

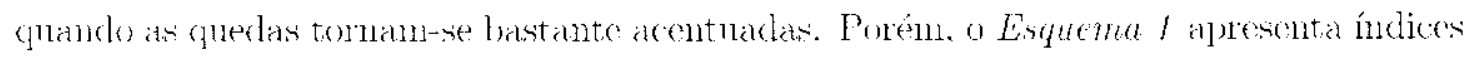

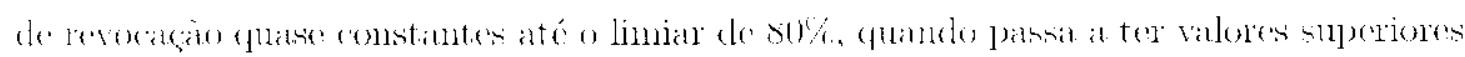

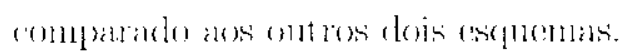


Como conchuido para a coleģa JB, us indices de precisaio e de revocaça da coleça C $\mathrm{C}$

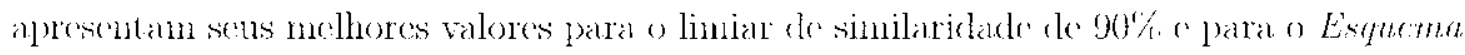

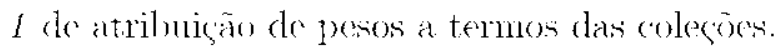

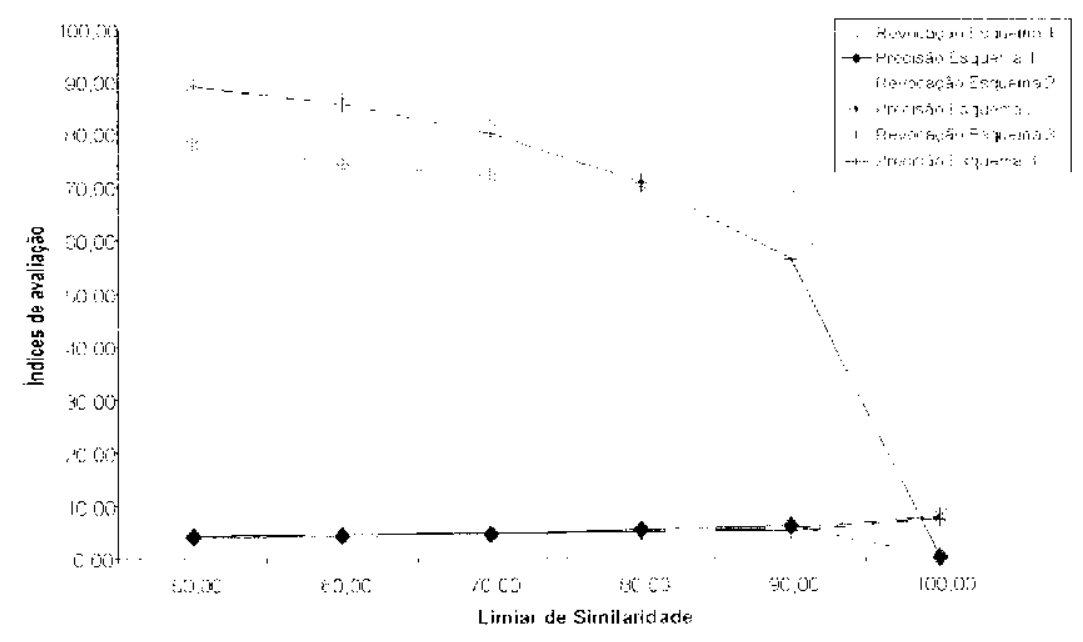

Fignra 5.3: Indices de revocagno (linhas (laras) e de precisano (limhas escuras) das ligacoes

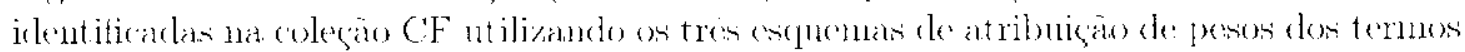
rom a variagán dos limiares de similaridade do 50 a $100 \%$

\subsection{Redução Baseada cm Distribuições Matemáticas}

No modelo vetorial. cada documento é representado por nun vetor numérice no qual

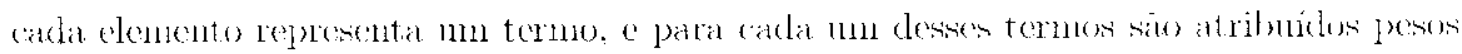

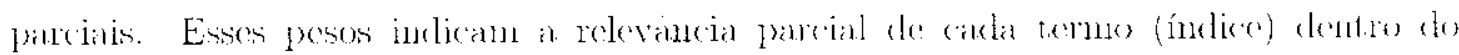
dox munento (Salton and Lesk. 1968). No cutanto. swes vetores sion momalmente grandes

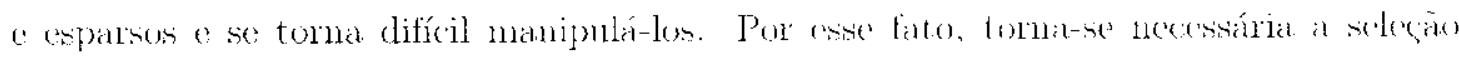

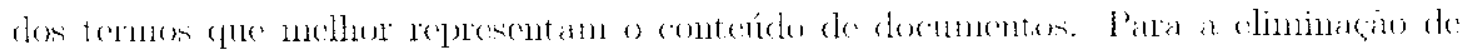

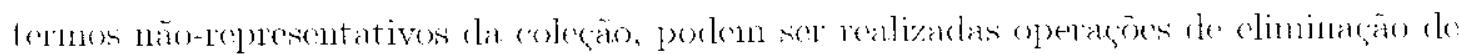

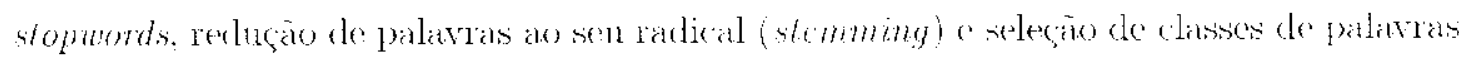

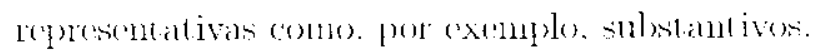

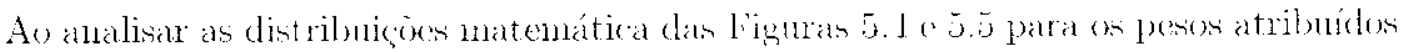

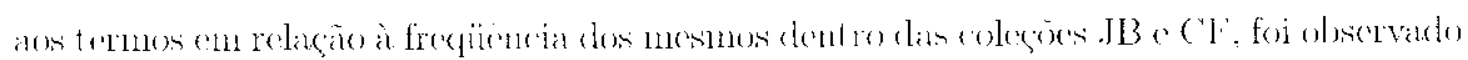


¿que os tres esquemas de atribuiçio de pesos. descritos na beça anterior, tem conporta-

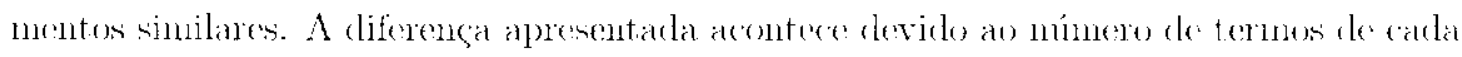

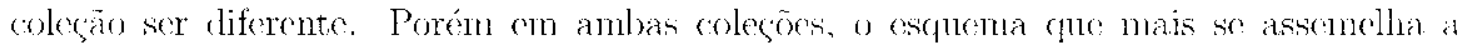
una distribuicano Weibull é o Ésquemu 1, apresentado no gráfico (a) de cada figura. uma

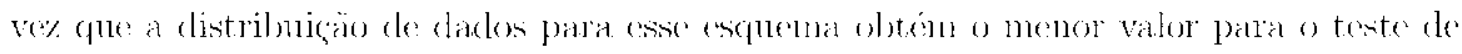
Anderson-Darling' (Stephens. 1974).

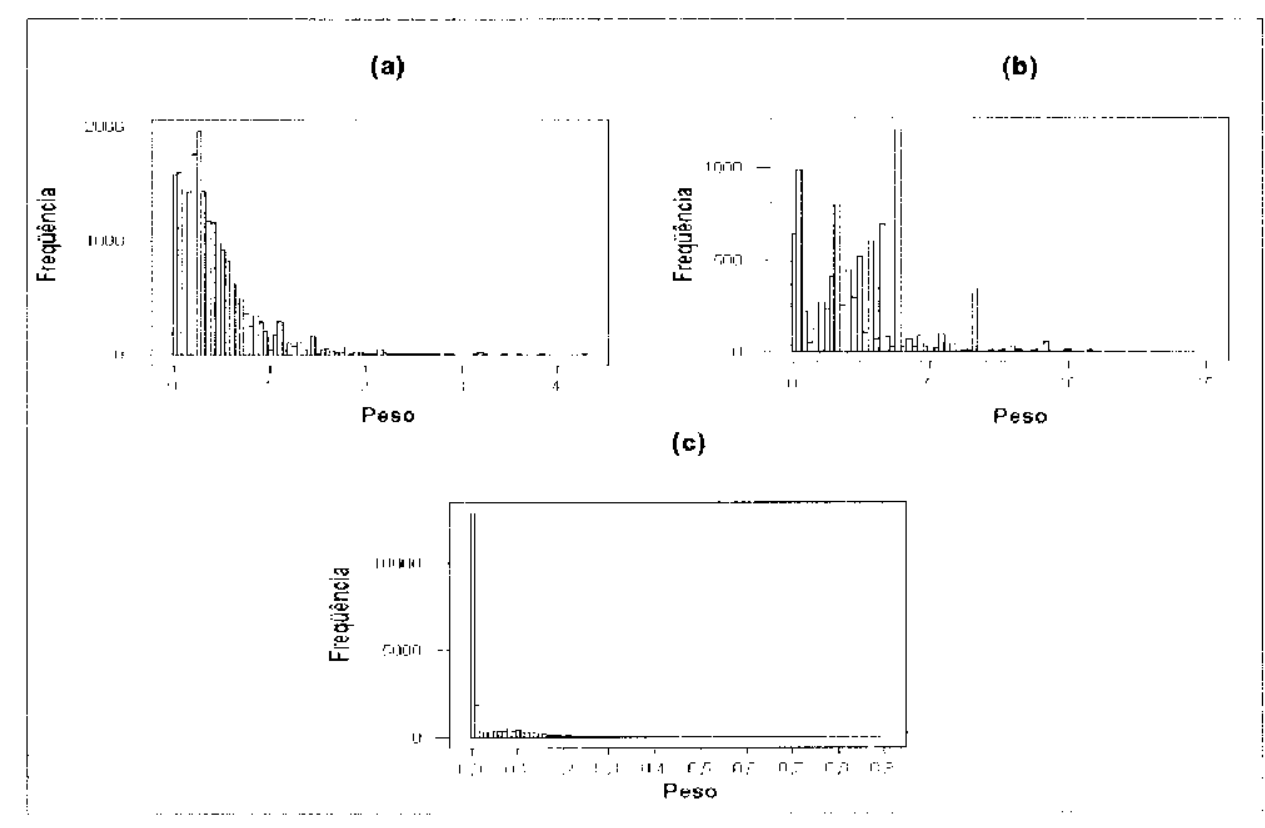

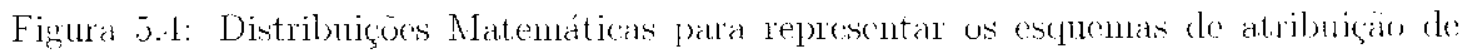

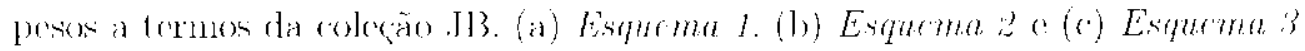

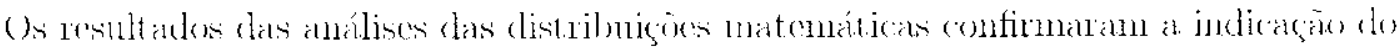

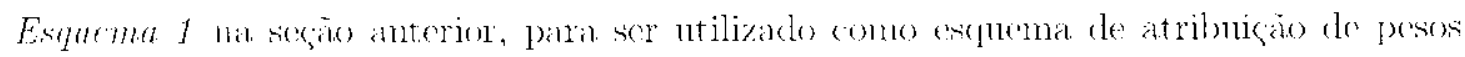

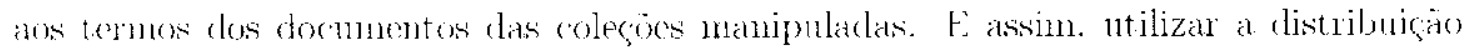

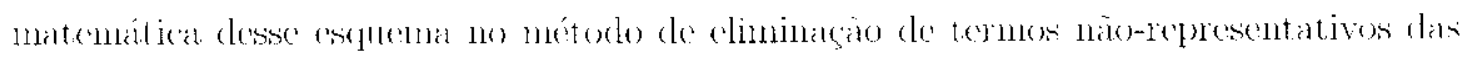
a)lecios.

\subsubsection{Procedimento}

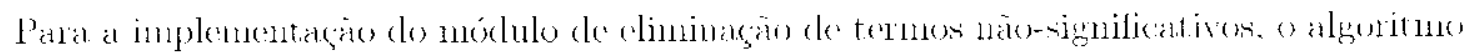

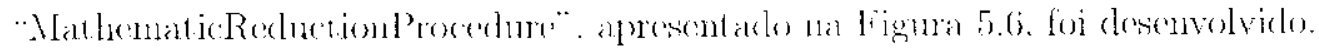

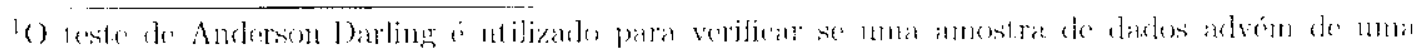

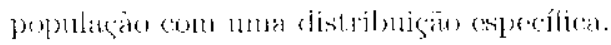


(a)

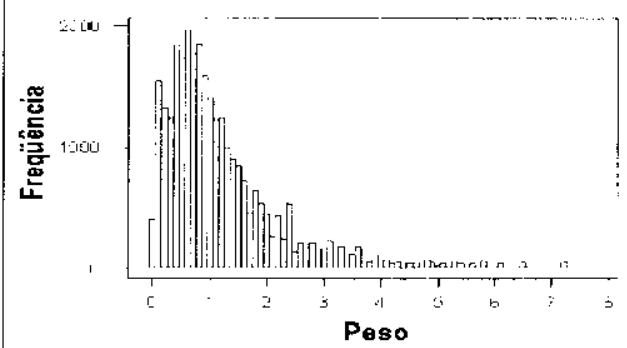

Peso (b)

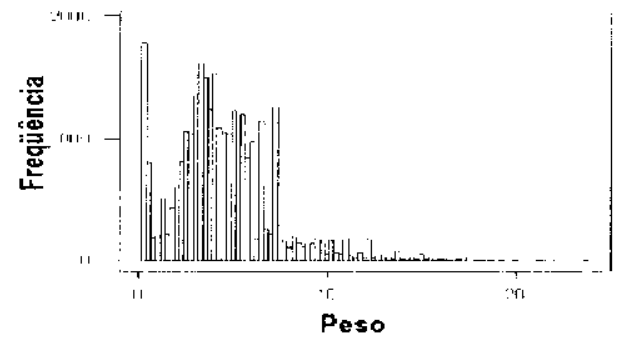

(c)

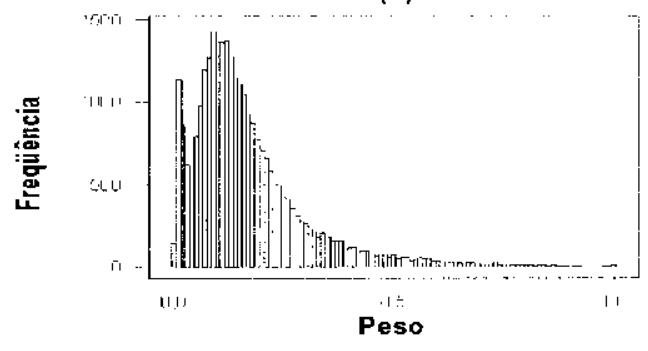

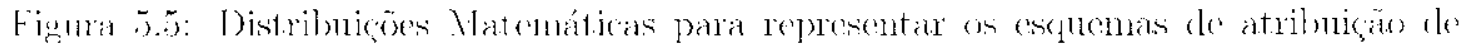

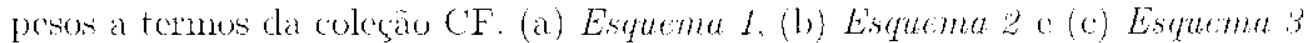

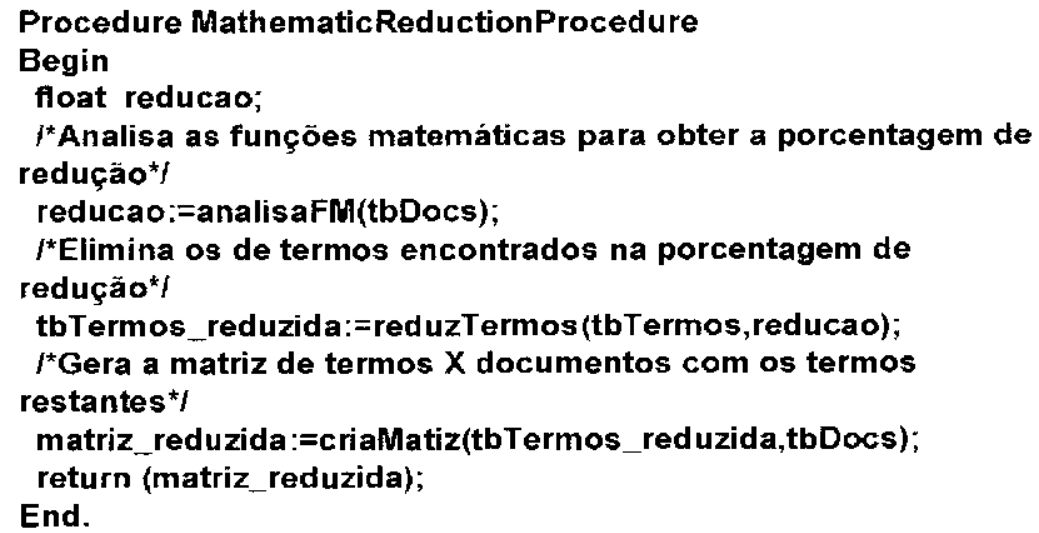

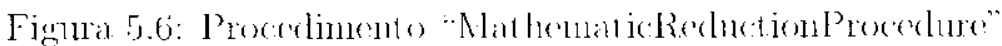

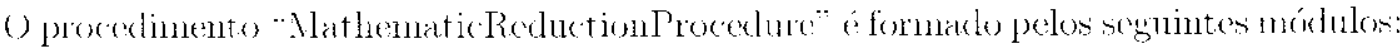

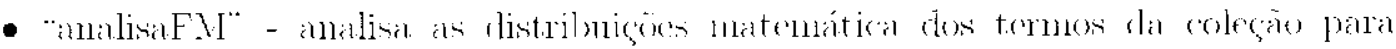

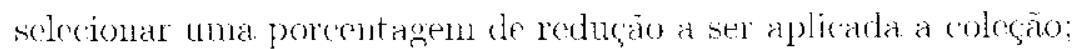

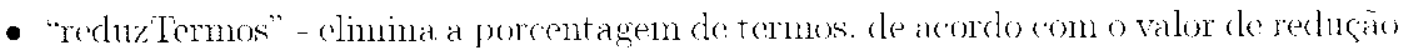
obticlo no processo anterior: 
- "criaMalriz" - gera a matriz de termos por docunentos utilizando os termos restan-

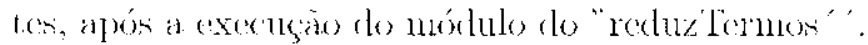

Com o intuito de demonstrar a utilidade do método de redução de vetores. isto é,

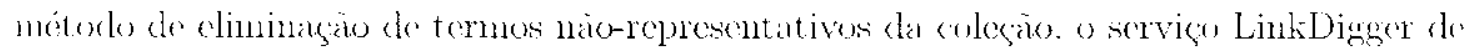

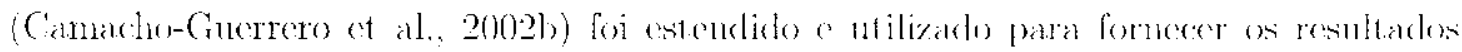
apresentados a seguir.

\subsubsection{Resultados}

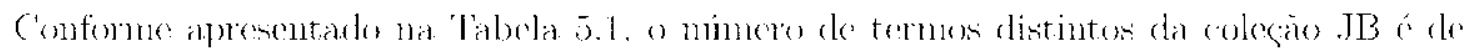
4789. Ao ntilizar o Esquema 1 para atribuican de pesose $90 \%$ de limiar cle sinilaridade.

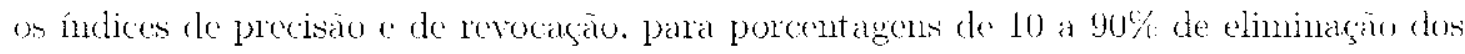

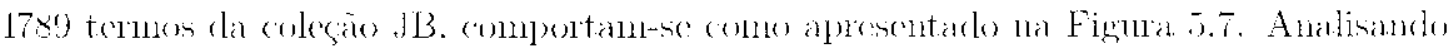

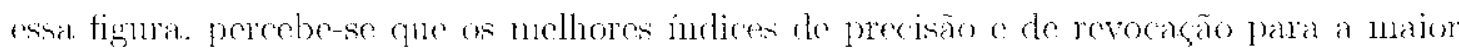

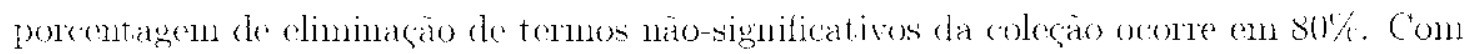

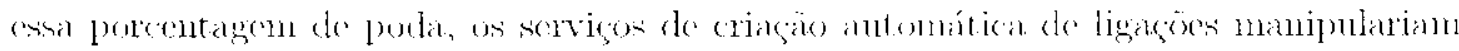

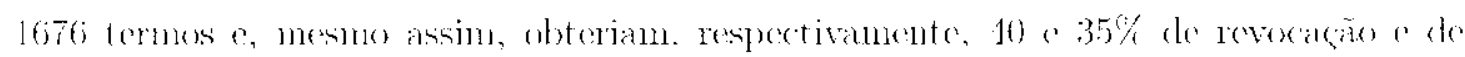
precisito.

Para exemplificar o desempenho das invest iganges apresentadin neste trabalho. perde-se

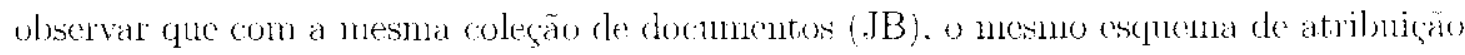

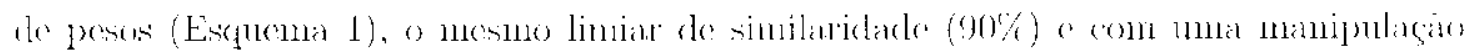

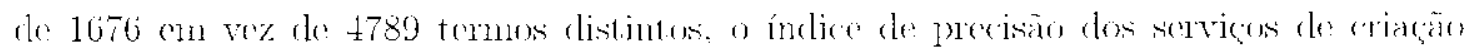

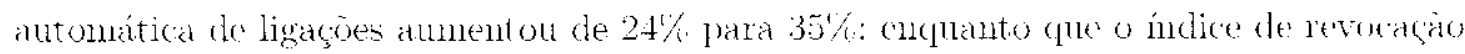

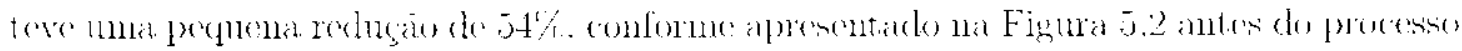
dre porlit. para $40 \%$.

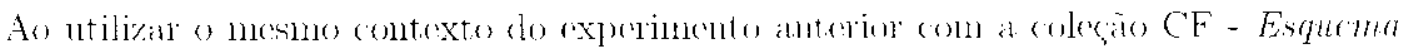

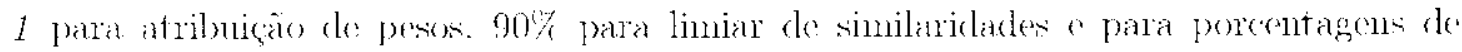

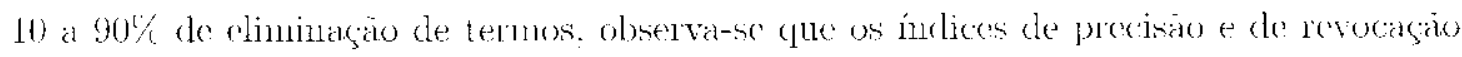

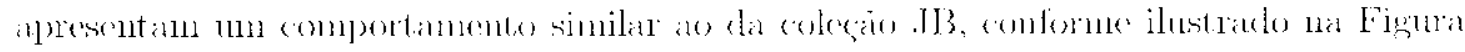

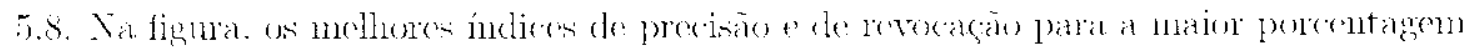

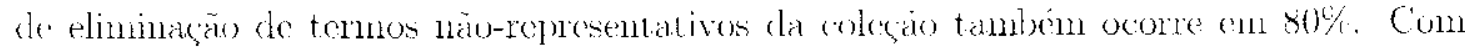

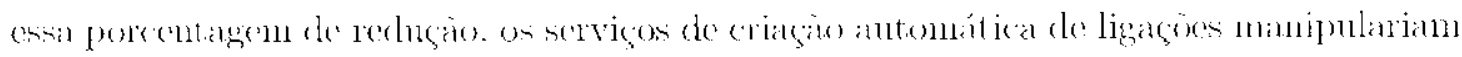

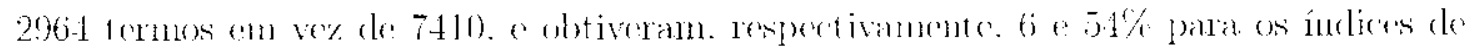

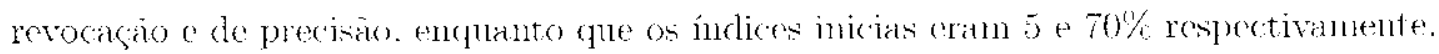




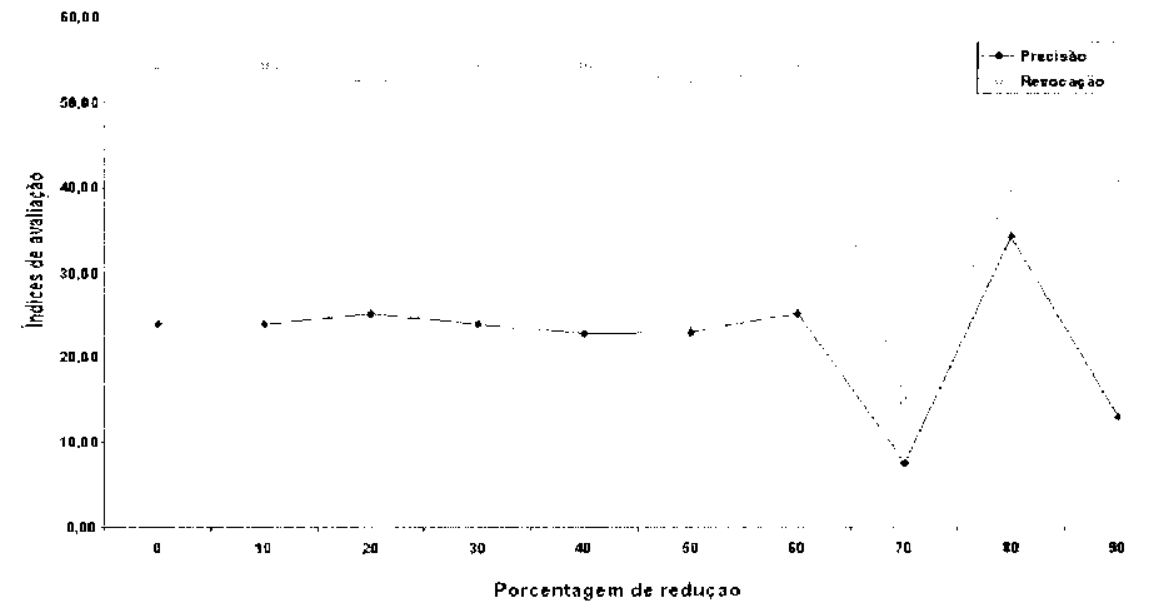

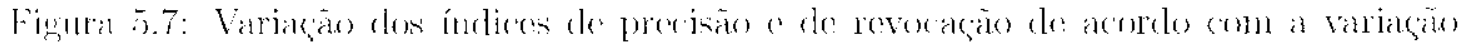
da porentagem de termos elininados da coleçäo JB cke docunentos. Nesse experinento

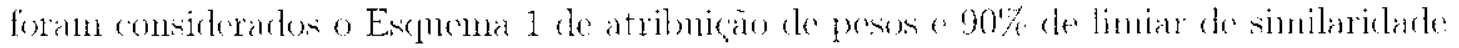

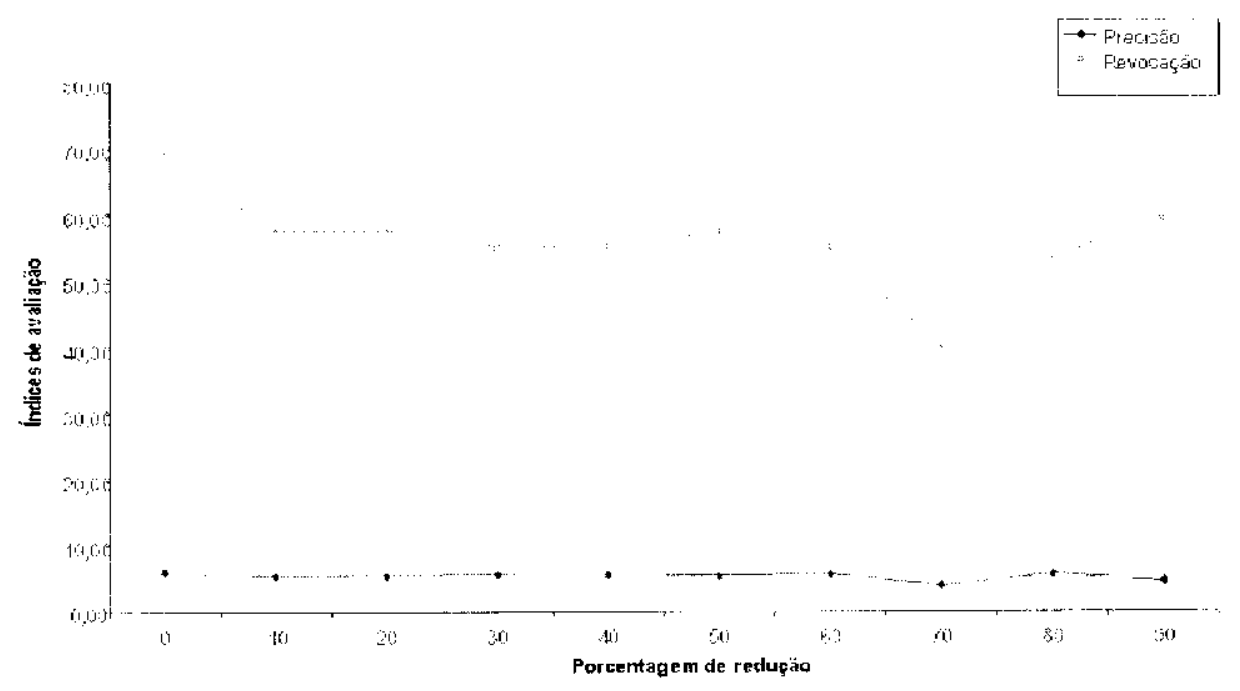

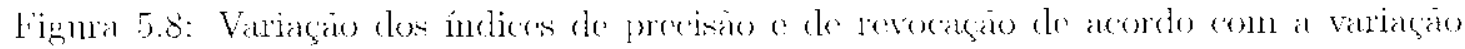

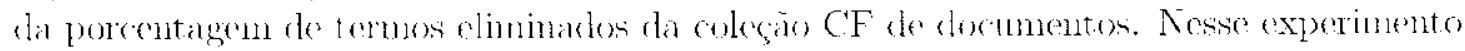

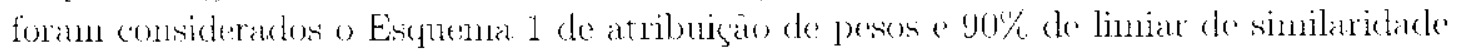




\subsection{Inclusão de Feedback de Usuários}

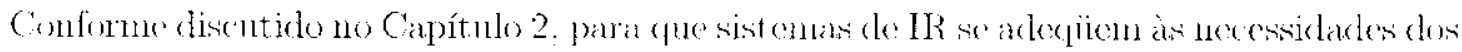

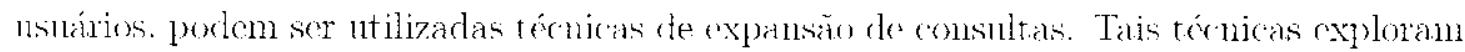

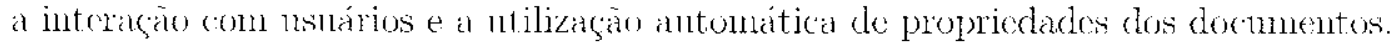

No sentido de adequar on serviços de criaço antomática do ligaços às expertativas

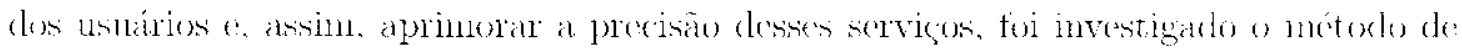

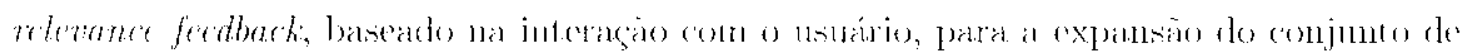
ligacioss relevantes geracliss (Nacedo et al.. 2002a).

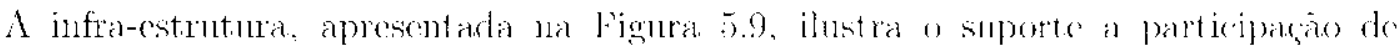

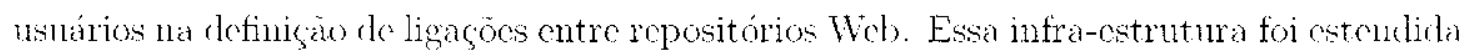

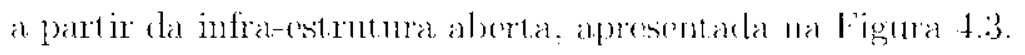

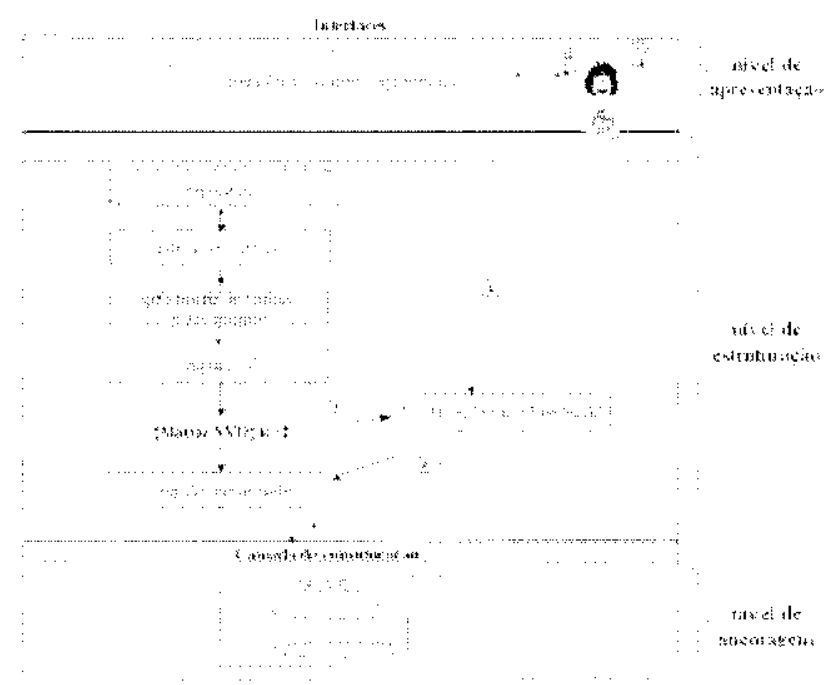

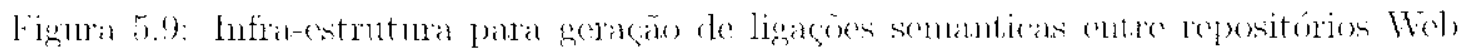

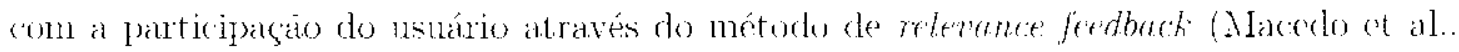
$2(1)(2)$

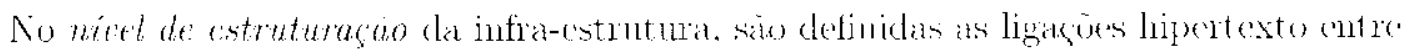

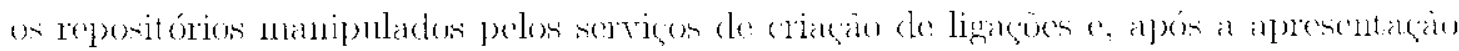

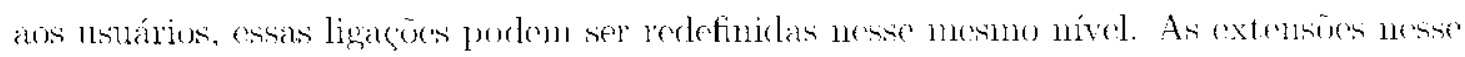

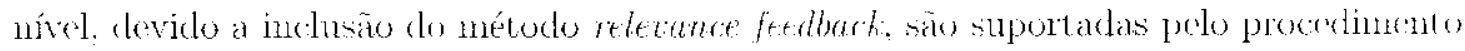

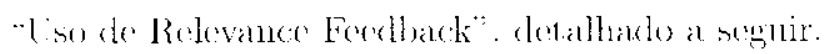

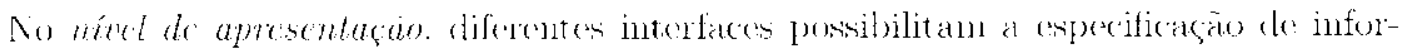


maģoes para a incicializaçăo do serviço e a apresentaça de resultados com possibilidade de interaçà de mistários.

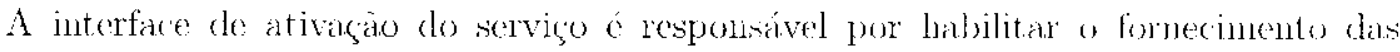

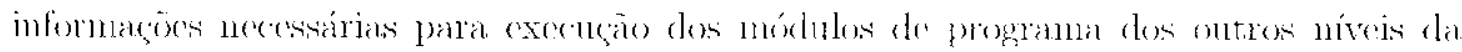
infra-estrutura. Já a interface de apresentagano de resultados mostra as informacôes advindas do nued de armaztmumento e permite que uslários indicquem, dentro do conjunto

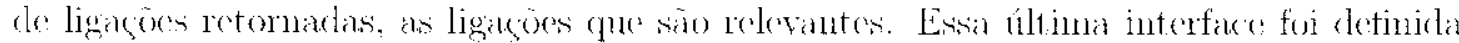

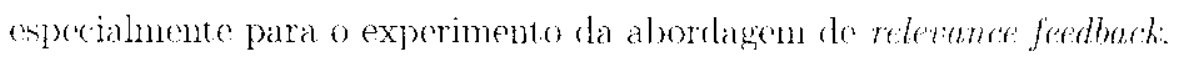

\subsubsection{Procedimento}

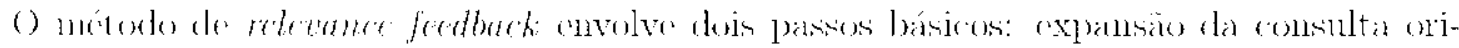

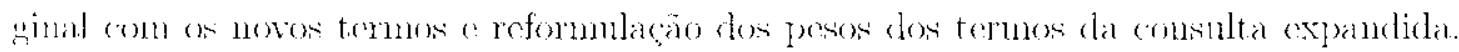
Para a inplementaçăo desse método. o procedimento "Cso de Relevance Fredback" foi desemvolvides.

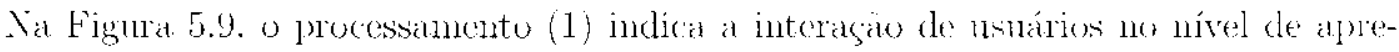

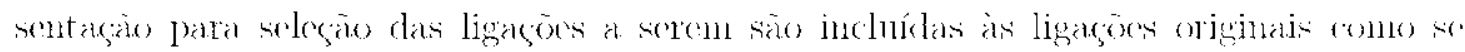

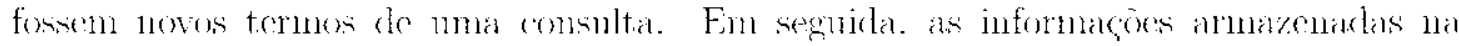
matriz semantica sào recaleulatas incluindo as novas informages (processanentu (2))

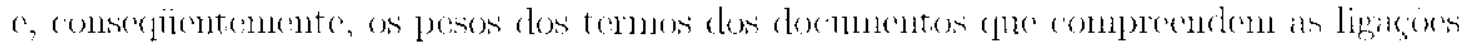

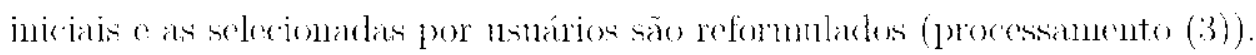

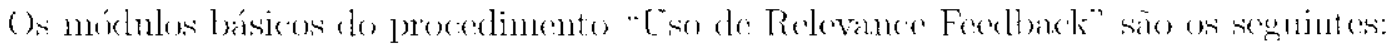

- "orrregamatriz" - busca a matriz do similaridades semânulicas gerada pelo proce-

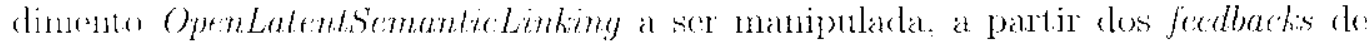
usuriácios:

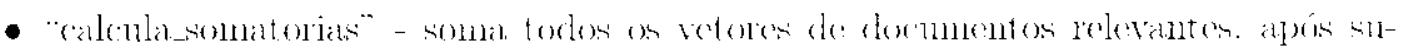

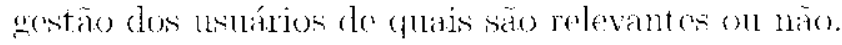

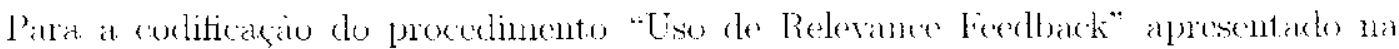

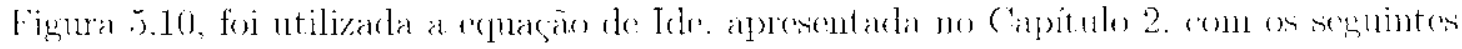
valores para as variáveis de ajuste $n=0.5,3=0.70 \%=0.1$. Na equacäo de Ide as

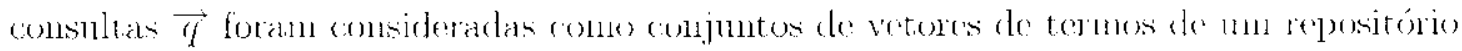




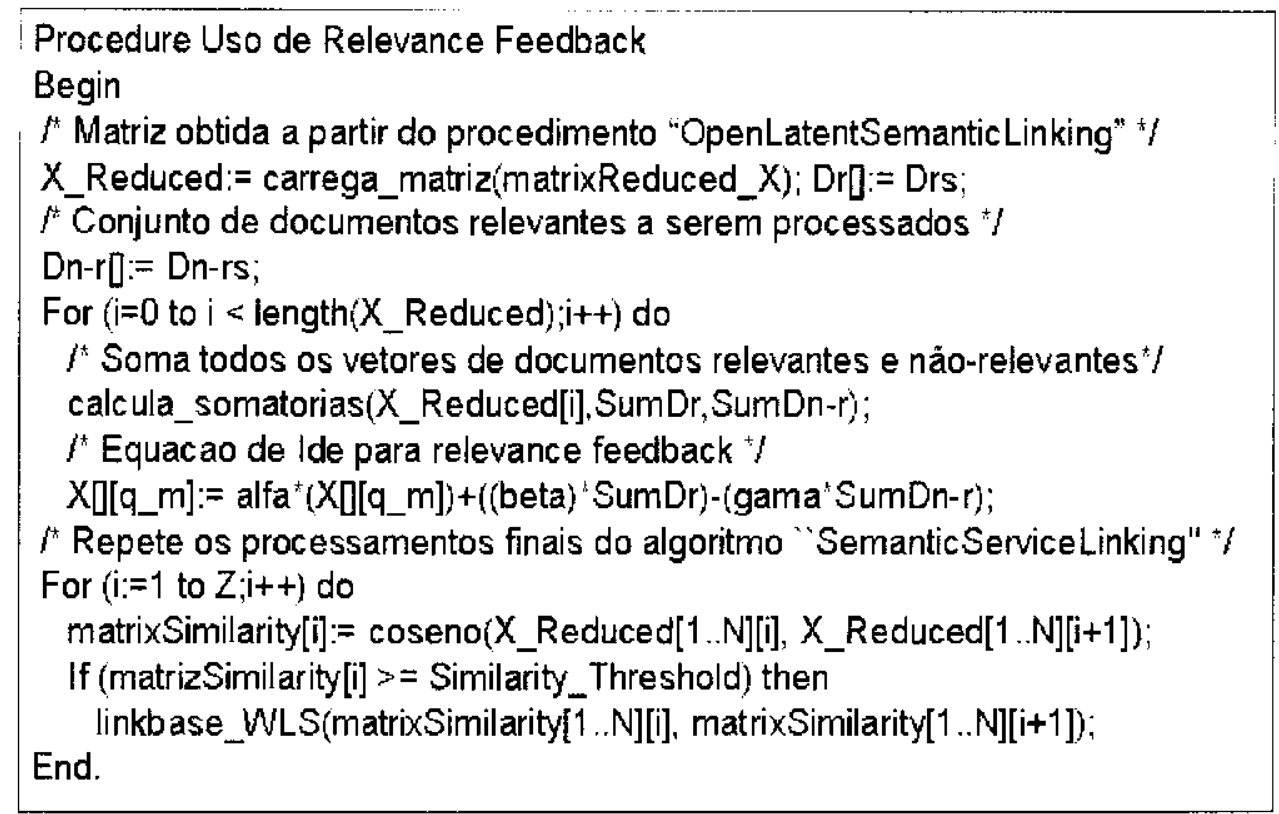

Fignra 5.10: Procedimento "Liso de Redenane Feedbath"

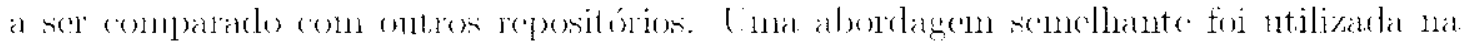

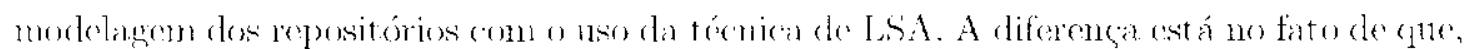
para modelar os repositórios para gerar ligaçoes usando LSA, todas as informagoen dos

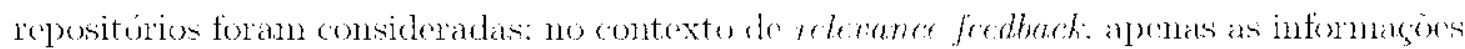

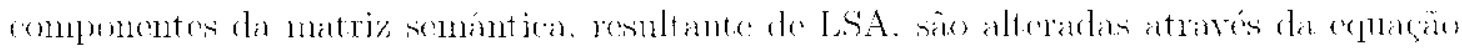
de Irle pois nsa matriz representa a estrutura somaintica da coleçäo.

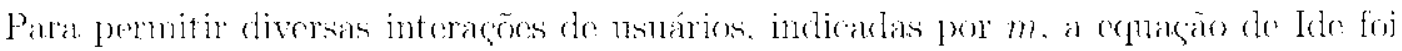
ajustada, conforme apresentado la Equaça 5.2.

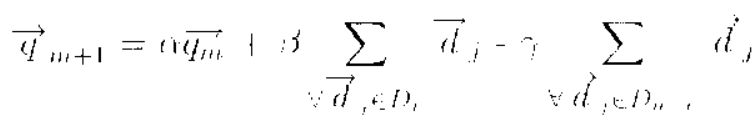

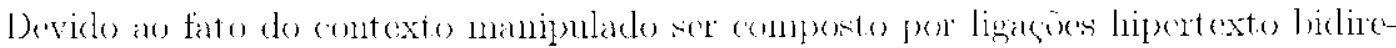

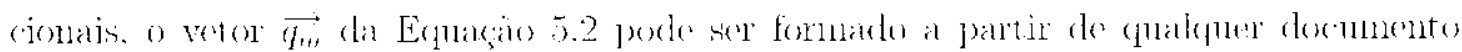

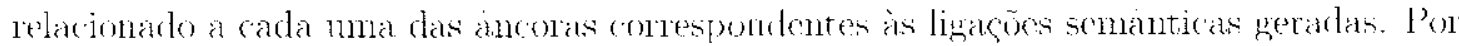

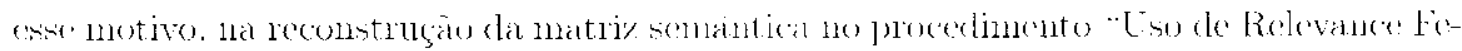

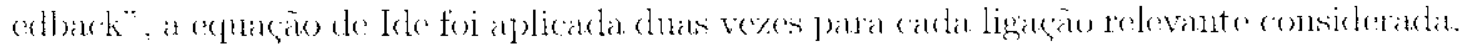

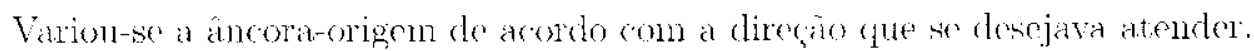


() serviço Linkifigger de (Canacho-Guerero et al., 20021) foi adaptado para pemitir

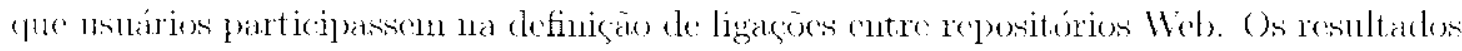
desses experinentos säo reportados a seguir.

\subsubsection{Resultados}

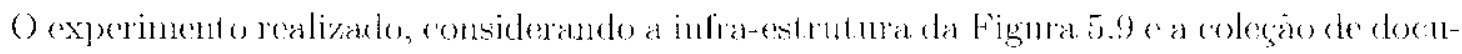

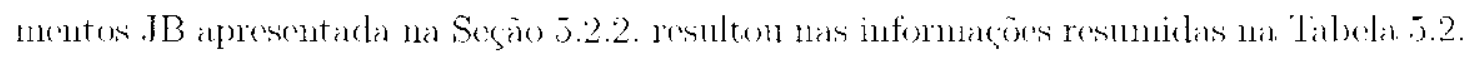

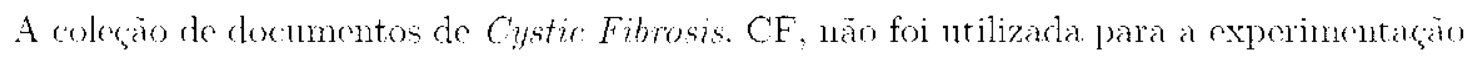

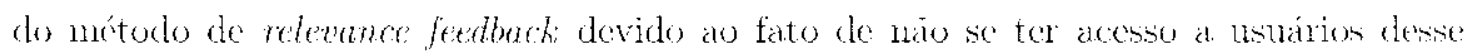

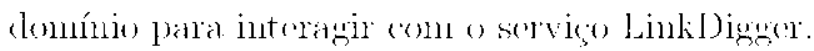

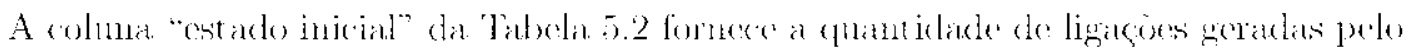

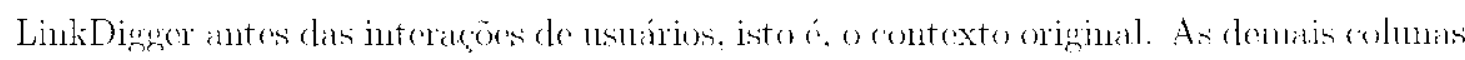

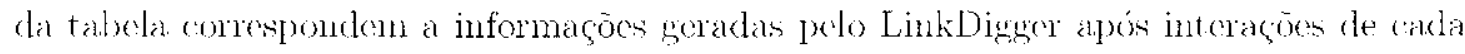

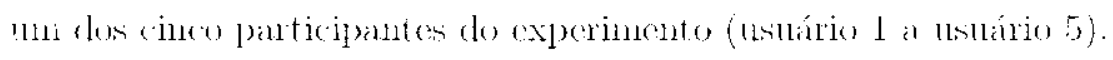

Tabela 5.2: Informacios obtidas a part ir do experimento com LinkDigger considerando remonce ferdloret:

\begin{tabular}{|c|c|c|c|c|c|c|}
\hline Variáveis de avaliação & estado inicial & $\begin{array}{l}\text { usuário } \\
1\end{array}$ & $\begin{array}{l}\text { usuário } \\
2\end{array}$ & $\begin{array}{l}\text { usuário } \\
3\end{array}$ & $\begin{array}{l}\text { usuário } \\
4\end{array}$ & $\begin{array}{l}\text { usuário } \\
5\end{array}$ \\
\hline $\begin{array}{l}\text { (1) Qtde de ligações } \\
\text { marcadas como rele- } \\
\text { vantes na interação do } \\
\text { usuário }\end{array}$ & 0 & 5 & 12 & 7 & 8 & 4 \\
\hline $\begin{array}{l}\text { (2) Qtde de ligações } \\
\text { relevantes e não re- } \\
\text { levantes geradas pelo } \\
\text { LinkDigger }(A)\end{array}$ & 44 & 37 & 12 & 16 & 12 & 9 \\
\hline $\begin{array}{l}\text { (3) Qtde de ligações } \\
\text { relevantes geradas pelo } \\
\text { LinkDigger ( } R a \text { ) }\end{array}$ & 8 & 5 & 7 & 6 & 7 & 2 \\
\hline $\begin{array}{l}\text { (4) Qtde de ligações re- } \\
\text { levantes }(K)\end{array}$ & 27 & 27 & 27 & 27 & 27 & 27 \\
\hline $\begin{array}{l}\text { (5) Índice de precisão - } \\
R \% / A(\%)\end{array}$ & 18,18 & 13,51 & 58,33 & 37,5 & 58,33 & 22,22 \\
\hline $\begin{array}{l}\text { (6) Índice de revocação } \\
R \text { ii } / R(\%)\end{array}$ & 29,63 & 18,51 & 25,92 & 22,22 & 25,92 & 7,40 \\
\hline
\end{tabular}

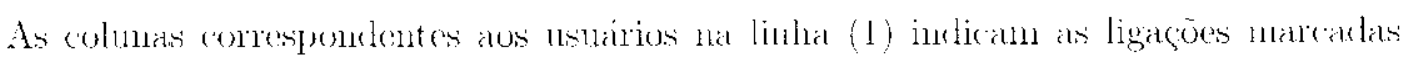


como relsantes por carla usuário das 44 ligagés geralas pelo LinkDigger após a princira

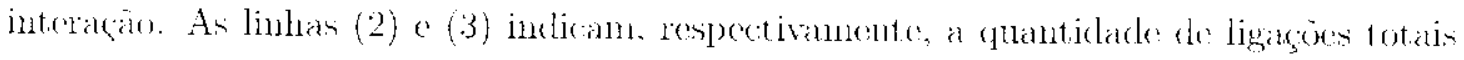

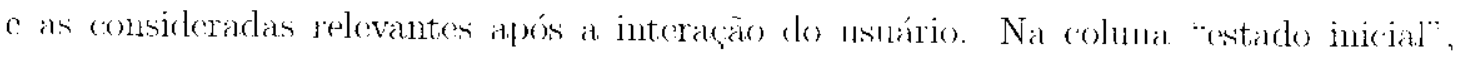
os valores 44 e 8 nas limhas (2) o (3) rorrespondem as quantidades de ligaçnes totais o

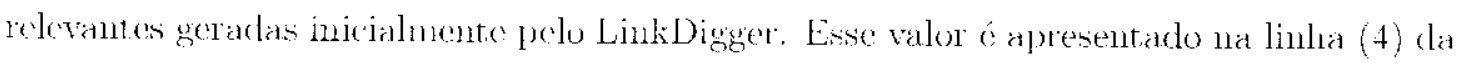

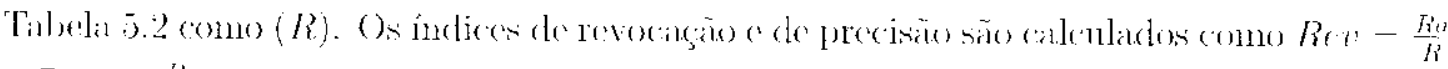
$\therefore$ Prer $={ }_{1}^{\text {hia }}$ e sàn apresentados, respectivamente, nas linhas (5) e (6) da tabelan.

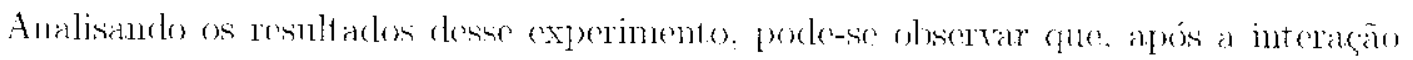

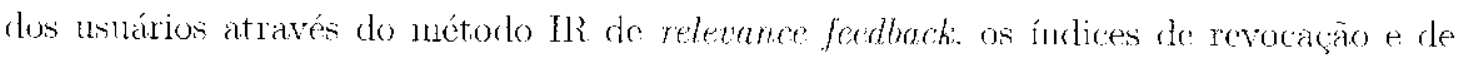

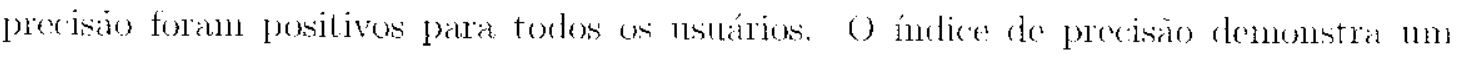

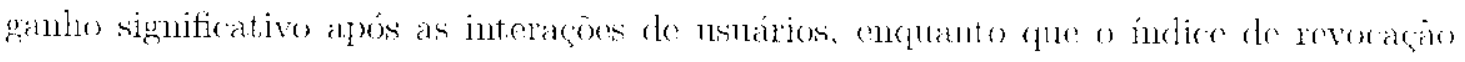
apresent a uma seqübucia de pequenas quedas de valores se comparados ao contexte inirial

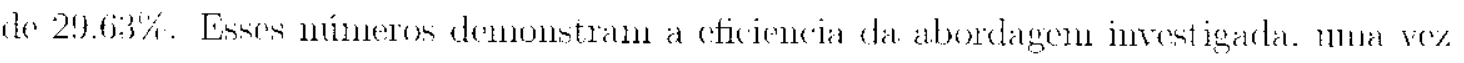

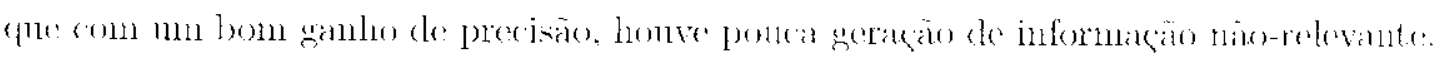

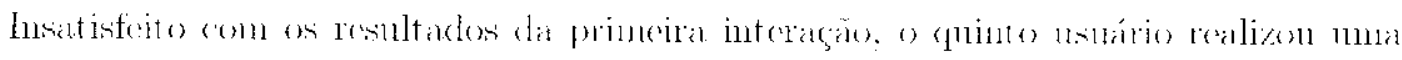

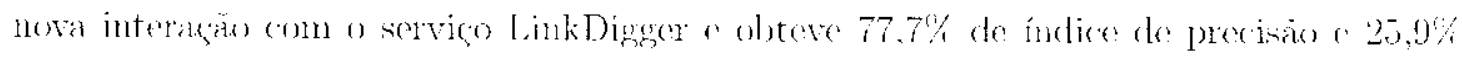

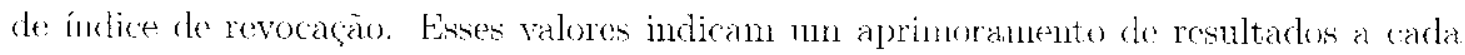

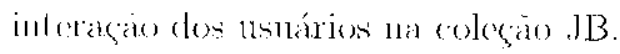

\subsection{Definição de um Serviço Configurável}

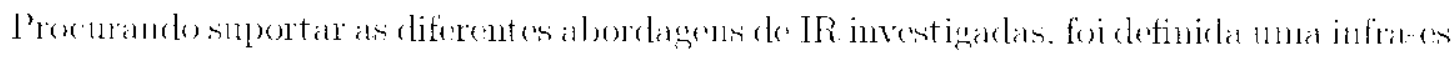

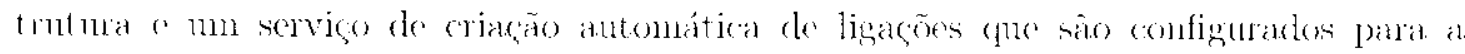

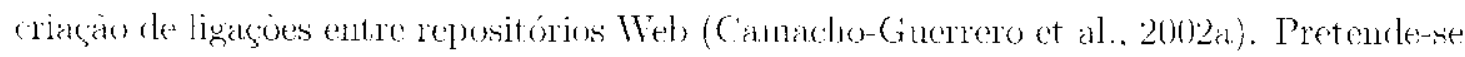

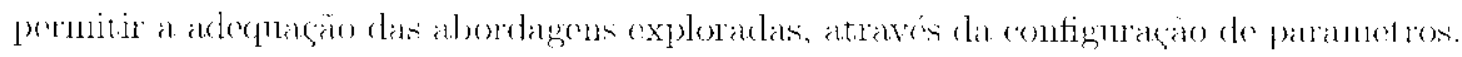

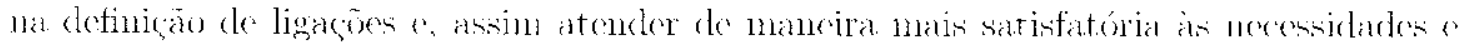
expectativals de nusurios.

A infra-estrutura do servico configurável é apresentarla na Figura 5.11 o detalharla a seguilir.

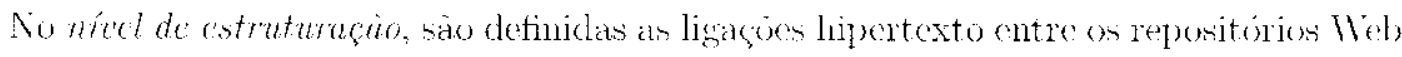

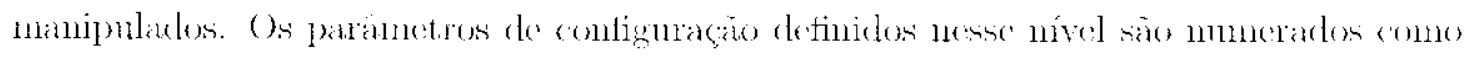

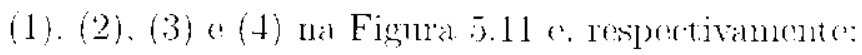




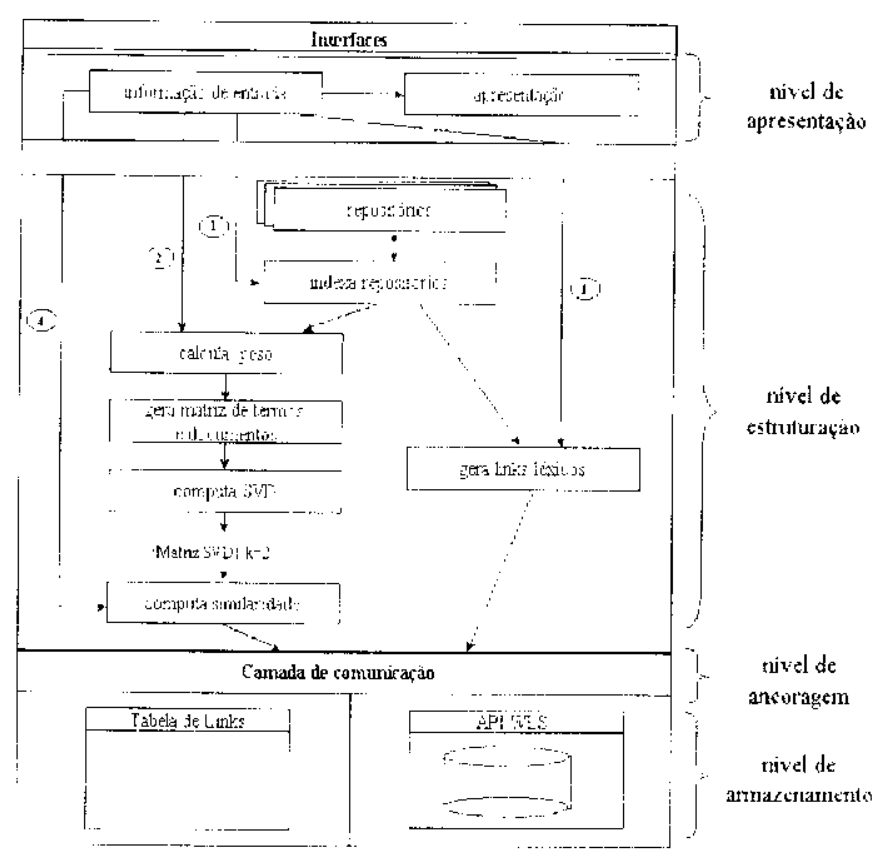

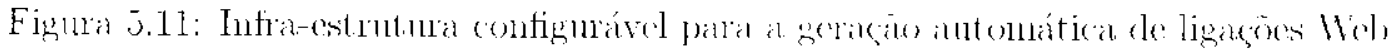

(1) afetam a definisgan dos repositórios a serem manipulados e a definiço dos paranetron

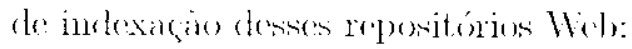

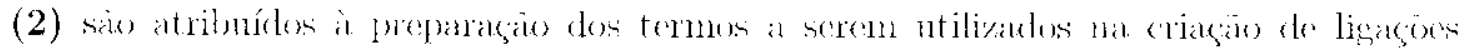

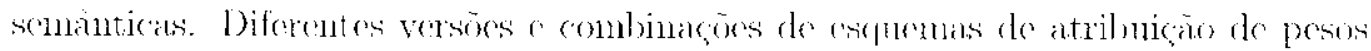
putom ser consibleralas:

(3) contextualizan a deliniça de ligacoes do tipo lexicais como, pur exemplo, peso

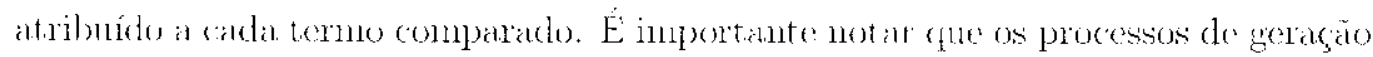

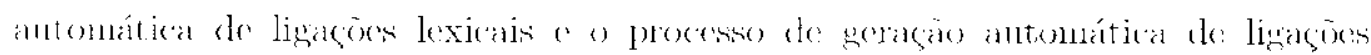
semaint icas näo săo exchusives:

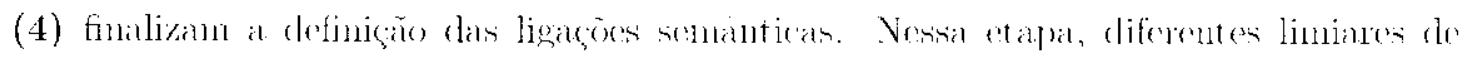
similatidades podem ser considerados. para deteruinar as ligacoes a serem anma-

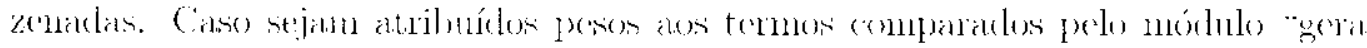

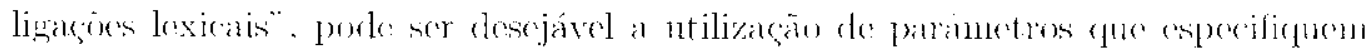
gratls de sinilarielades.

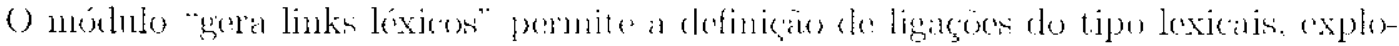

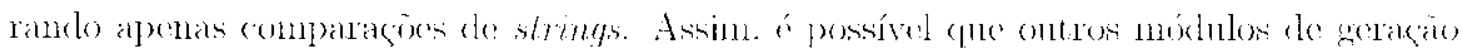


de difocutes tipos de ligagoes sejam adicionados à infratestrutura demonstrando a pro-

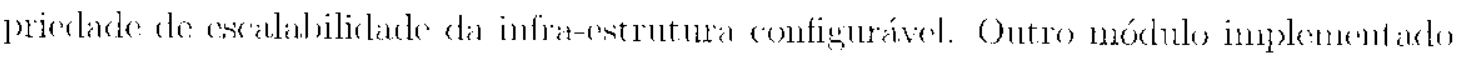

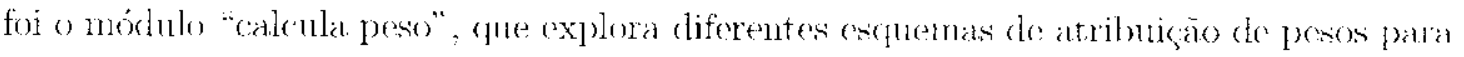
a rlefiniçäo de ligaços semanticas.

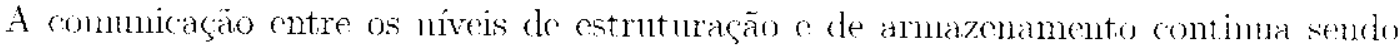
suportada por chamadas de funçós à API (Application Programming Interface) do WLS

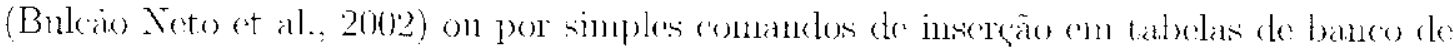

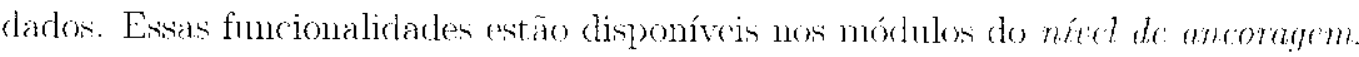

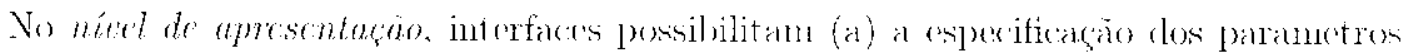
comfiguráves (habilita o fornecimento das informacones necessárias às funcionalidades e às

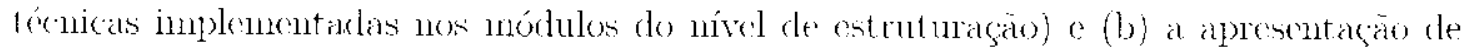

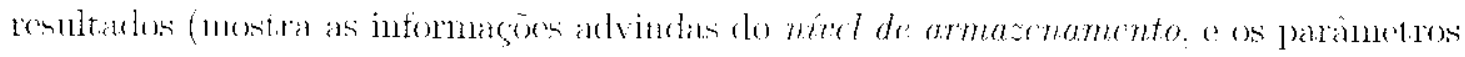
esperilicarlosi).

\subsubsection{Procedimento}

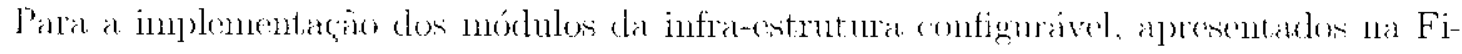
gura 5.11. " algoritmo codificado en "Flexibleservicetenling" da Figna 5.12 for desemvolvidu.

O) procedimento da Figura 5.12 executa os seguintes mórlulus:

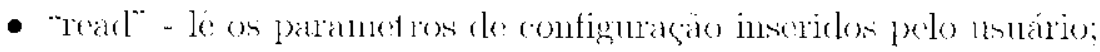

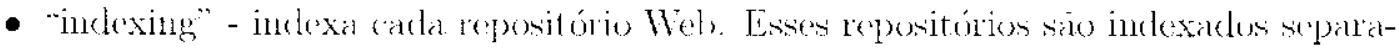

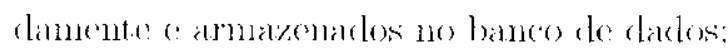

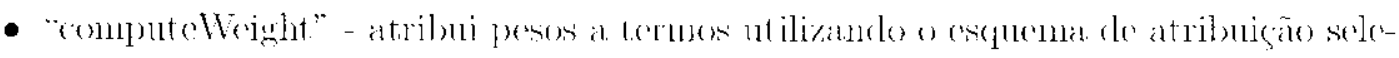
ciomelo:

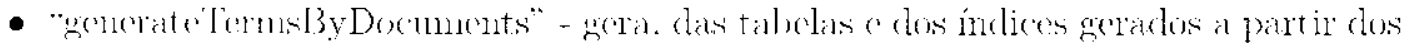
repositúrios, a matrix de termos por rlocunentos X:

- "computeSVD" - rlada a matrix X gerarla e o valor $k$ de redugão executa o análisco

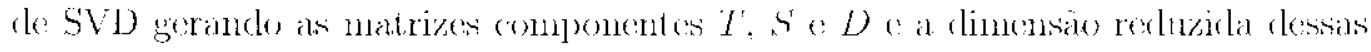
matrizes de acourlos com $h$; 


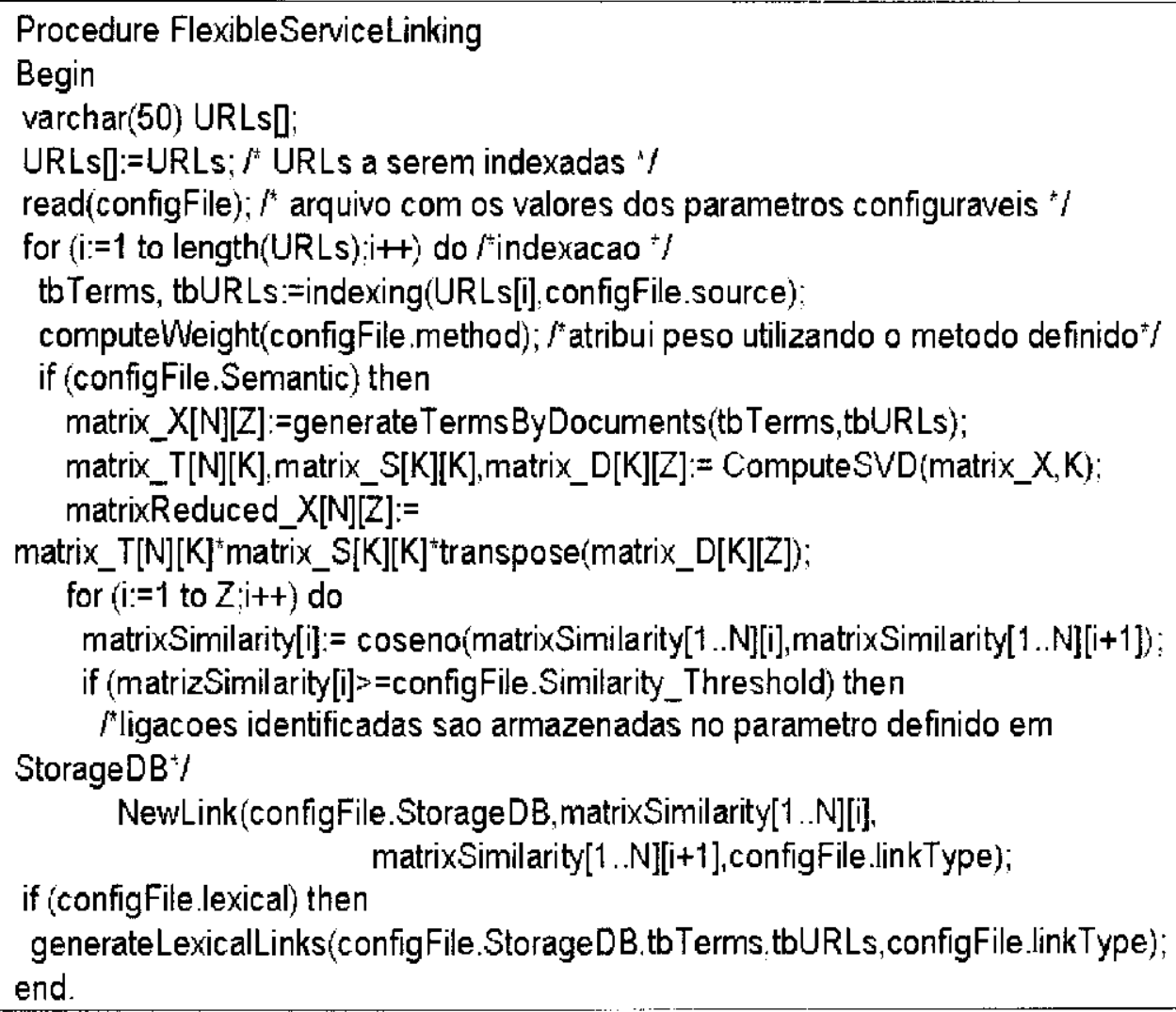

Figura 5.12: l'rexedinemo "HexibleserviecLinking"

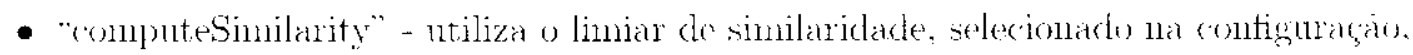

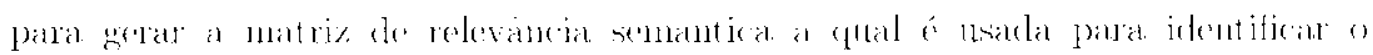

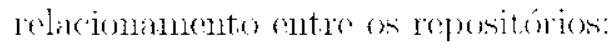

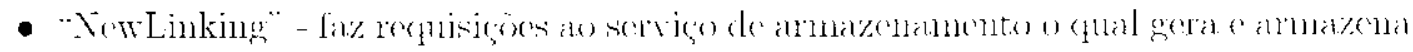

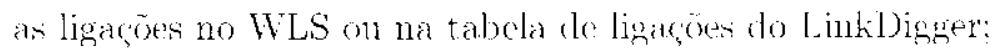

- "grmerateLexicalLinks" - dada as tabclas de temon e de docmuentos. gora ligacoen

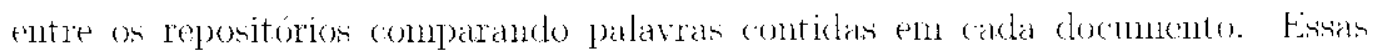

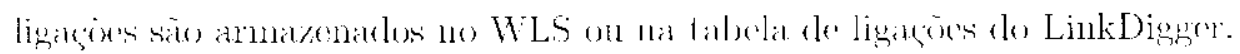

A infra-estrutura contiguravel foi implementada como extensio ao servico Web Link-

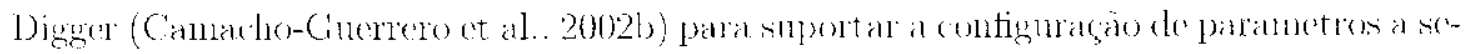

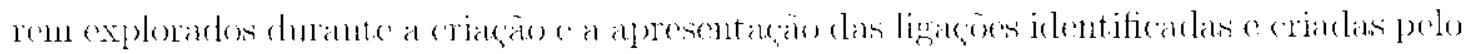

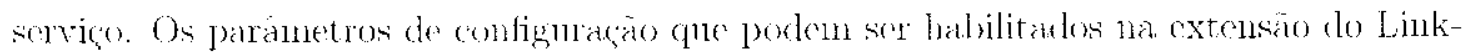

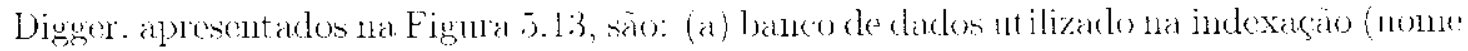




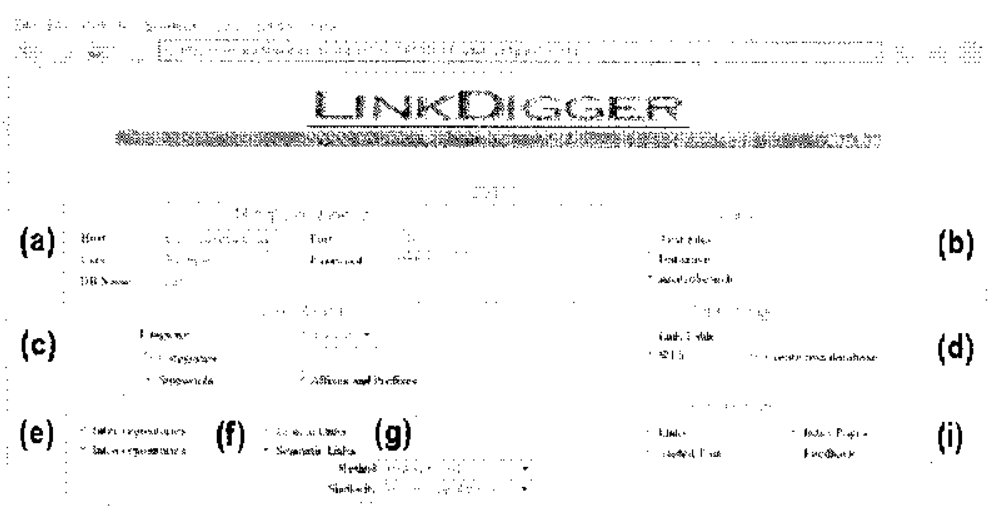

(h)

Figura 5.13: Interfare do LinkDigger para confignraço des parametros

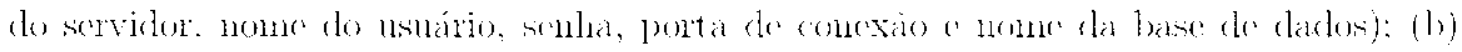

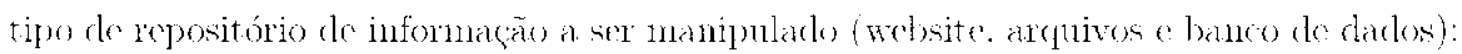
(c) engine responsável pela indexatgo (dicionários de stopuords. idioma. atixos/pretixos):

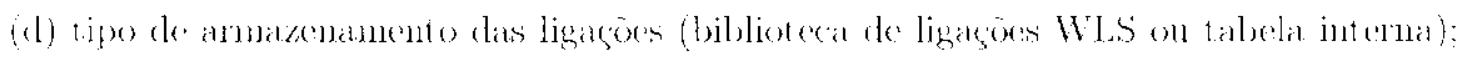

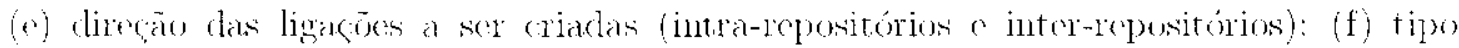
das ligacoes a serem criatas (léxico. semantion): lg) esquema do atriluniça de pesos a

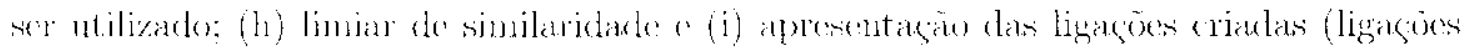

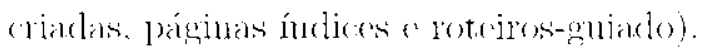

\subsection{Considerações Finais}

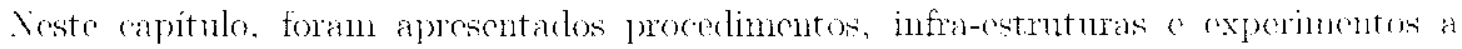
partir de investigacioes de abordagens de IR na tentativa de aprinomar a previsan dom

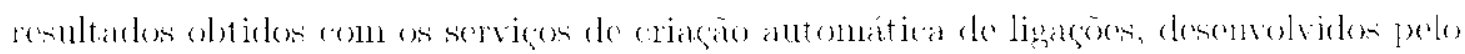

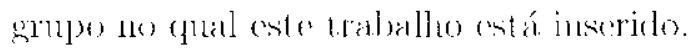

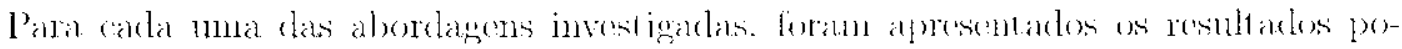

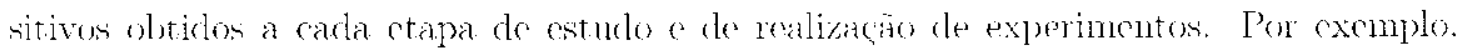

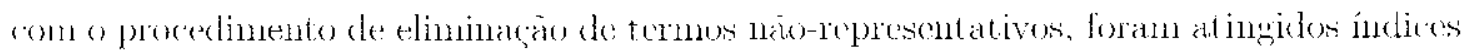

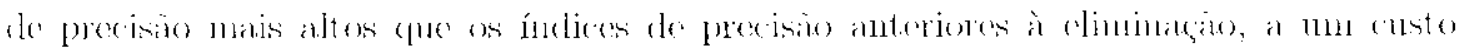




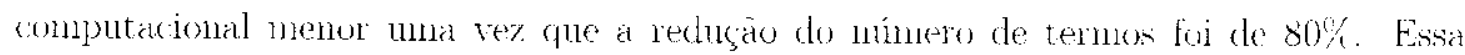

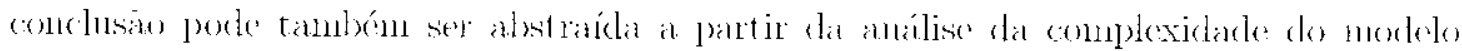

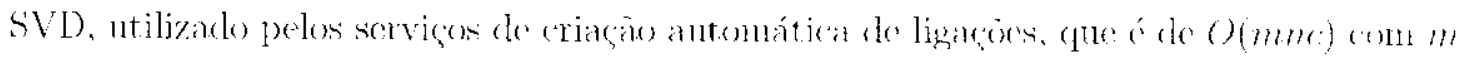

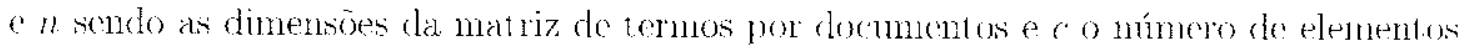
diferentes de zero con carla linha da mintriz.

Arredita-se que o desompenho dos serviços de criagrio antomática do ligagoen portes

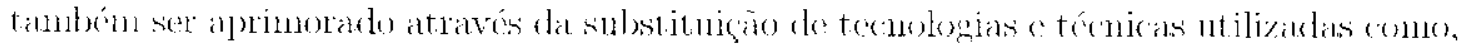

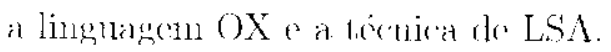




\section{Capítulo 6}

\section{Conclusões}

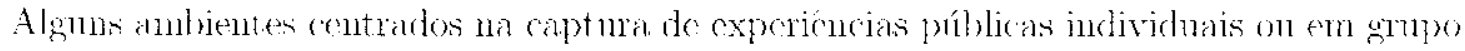

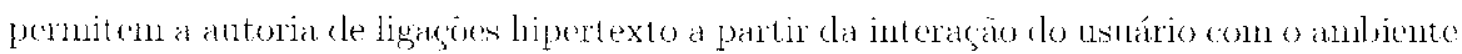

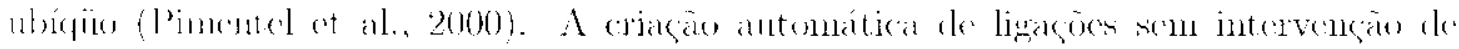

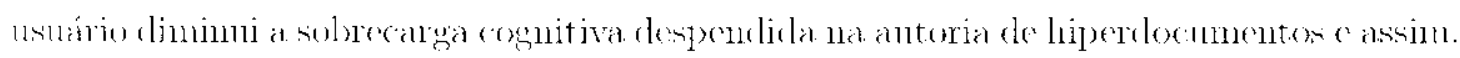
torna-se una importante ferramenta de hipermídin.

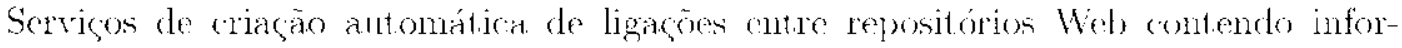

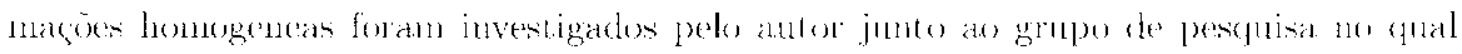

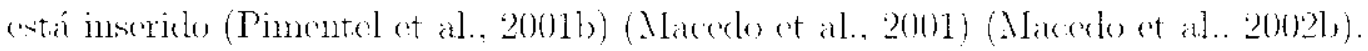

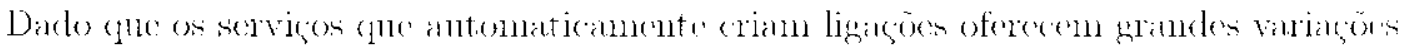

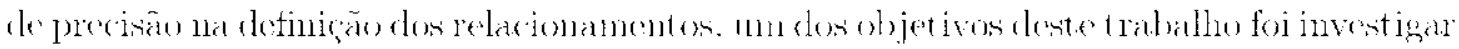

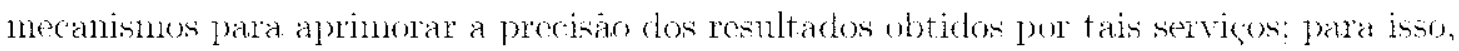

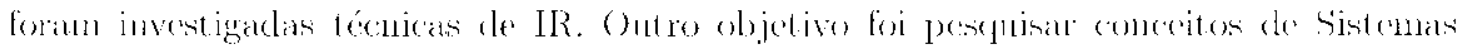

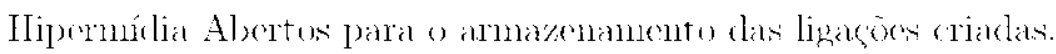

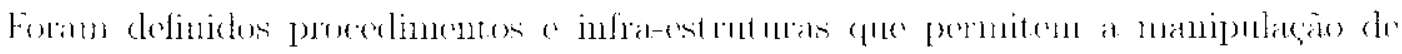

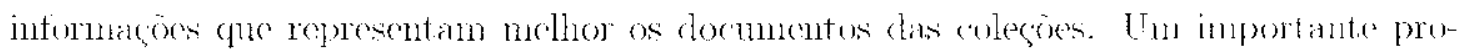

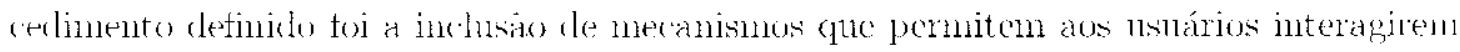

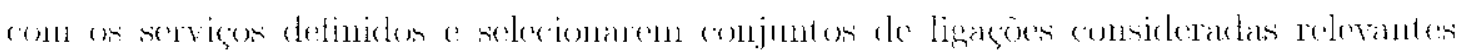

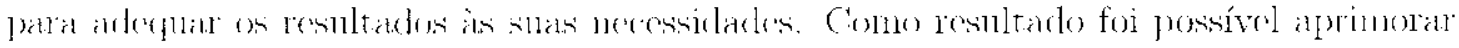

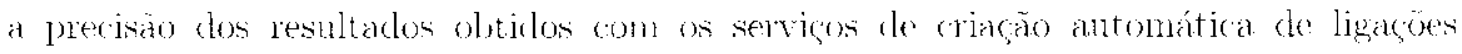
lipertextes.

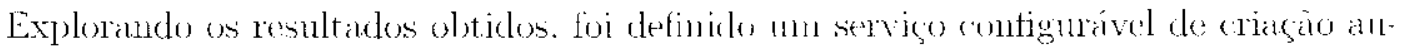




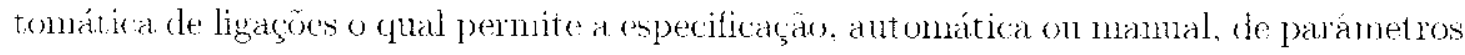

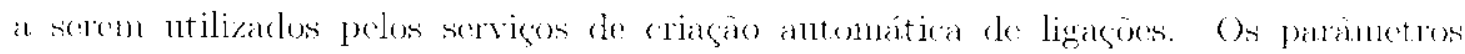

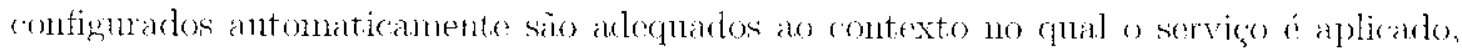
cuquanto que os parametros de configuraça manual permiten ajustes dos resultados sergumedo as expectativas dess noslários.

Os resultados obtidus com este 1.raballo ten contribuílo para o avanco das pescluisas

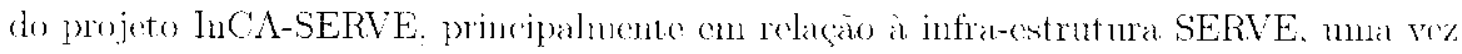

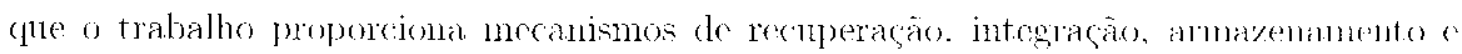
visualizaça de informaçoes contidas en repositórios Web.

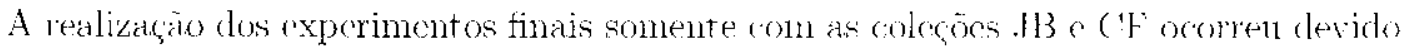

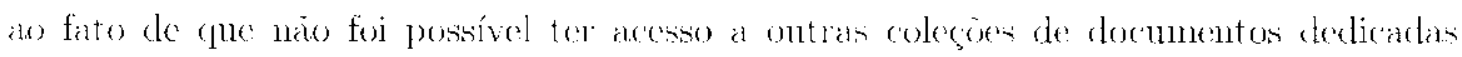

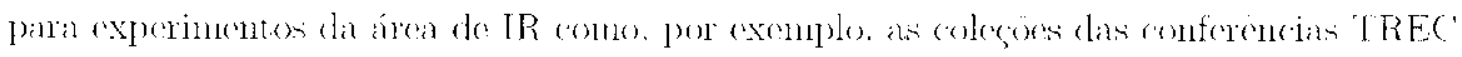
(Text RFtricval Conferenec) organizadas pelo NIST (National Institute of Standards

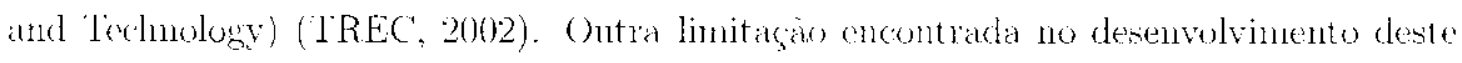

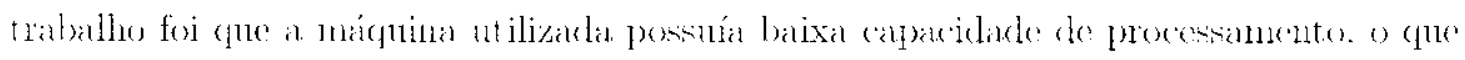

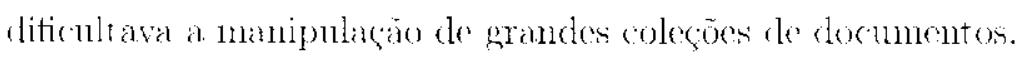

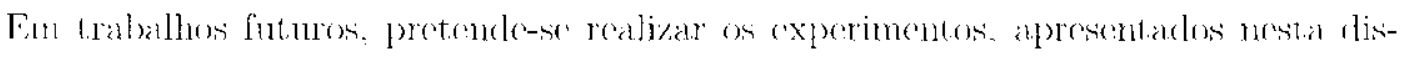
sertaçio. com coleçoes de docuncentos do tipo IREC. Alóm disso. tem sido planejados

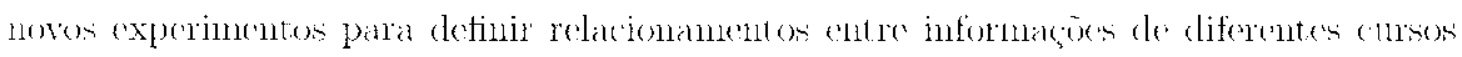

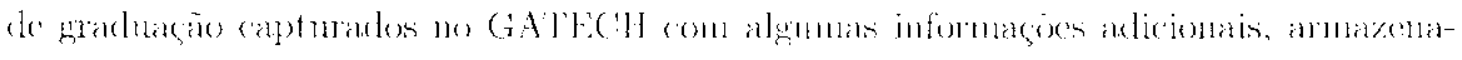
das nal Wob. sobre assmutos tratados nos cursos. Paralelanente aos testes com novas

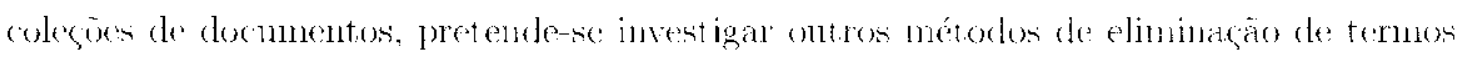

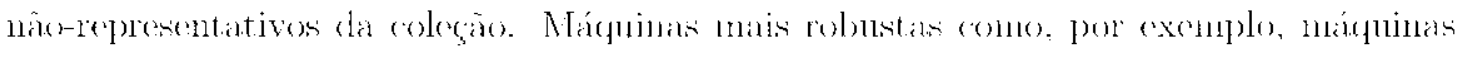

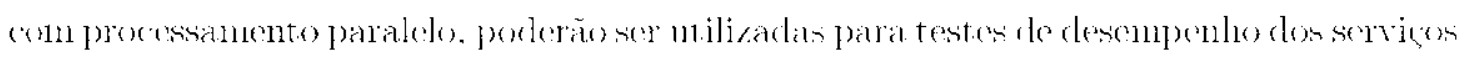
criados e, assim, possibilitar a verificagäo do tempo de respestate. 


\section{Bibliografia}

Alowd. G. (1999). Classrom 2000: an experience with the instrunentation of a living

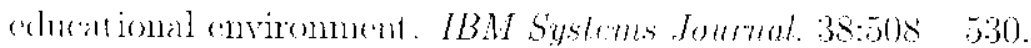

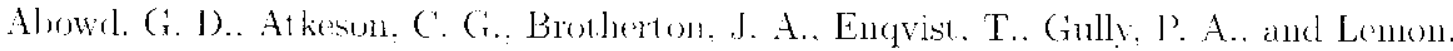

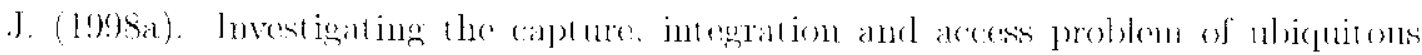

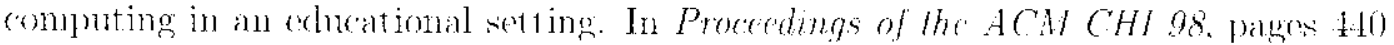
447.

Abowd. G. D., Brothertom, J. A., and Bhalodia. J. (19986)\}. Classrom 2000: A sistem

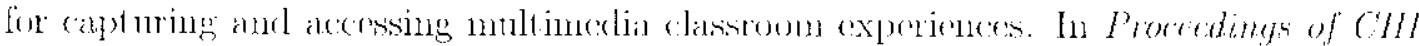
98 . pages $11 \cdot 19$.

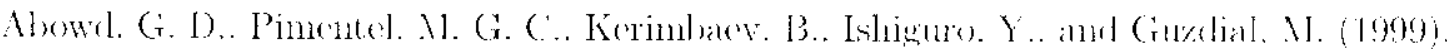
Anthoring discussion in lecture: an approach to collatboratively extending chastom

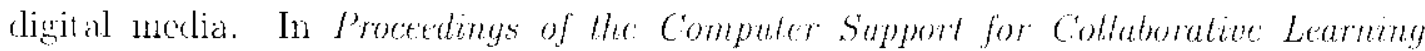
(CSCL) Comforener, pagers 11 . 19. Slandord Eniversity.

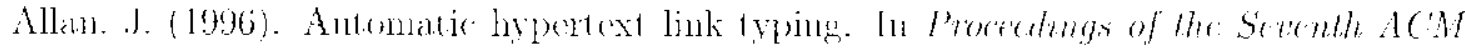

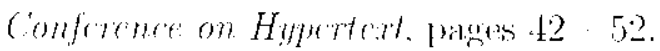

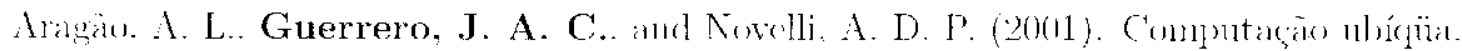
In ISIC - Somana Integrada de Computacao pago 8 . Campo Grande/AIS.

Baneza-Yates. R. and Ribeiro-Neto. B. (1999). Modem Information Retrienal. Addiwon Wesley: New Yurk. NY.

Bray. T.. Baoli. J., and Sperberg-No(neen. (. M. (1998). Extensible markup language (XML) 1.0. w3. renmmendill ion. http://www.w3.org/TR/REC-xm1.

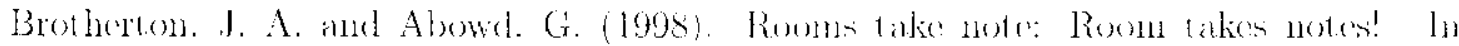

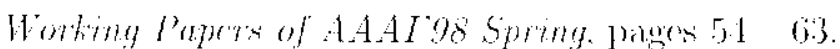


Brothertom, I. A., Bhaledia. J., and Alowel. G. D. (1998). Automated (alpture:

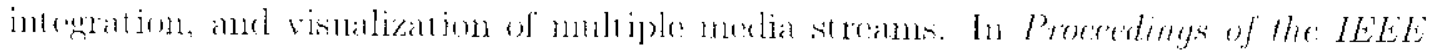

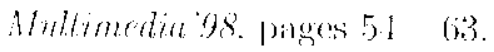

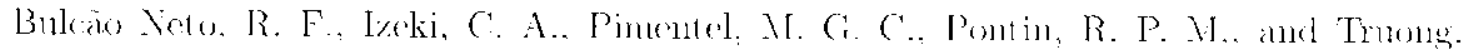
K. N. (2002). An open linking service supporting the ant horing of web documents. In Procedings of the ACM Dorment Engmenng Comfenente pages 66 73. Virginia. ISA. ACM Press.

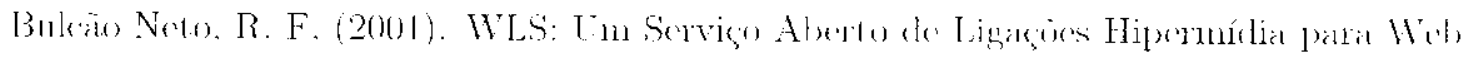

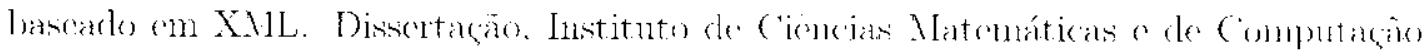
da CSP: Sáo Carlos/sP

Camacho-Guerrero, J. A. Jaredo, A. A. and Fortes. R. P. N. (2002a). Unia

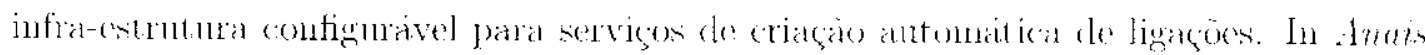

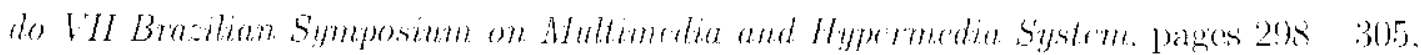
Fortaleza/C $\mathrm{F}$.

Camacho-Guerrero, J. A., I'imented. N. (r.. alk Bulrio Neto. R. F. (200)2b).

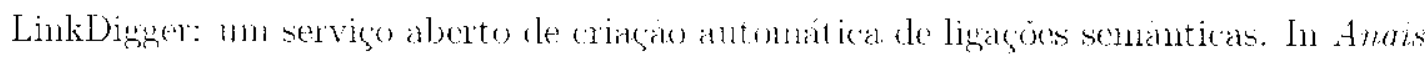

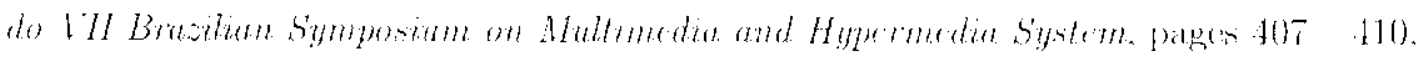
Fortalem/Ct:

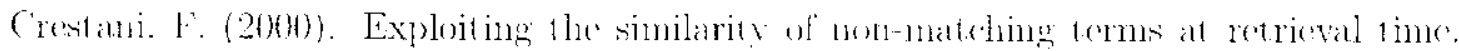
Toumul of Information Relritenl. 2:25 45.

Davis: H.. Lewis. A. anel Rirk, A. (1996). OHP: a draft proposial for a stantarel

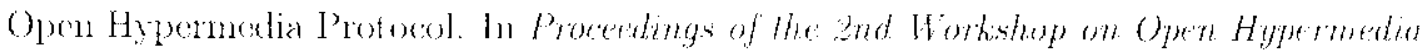

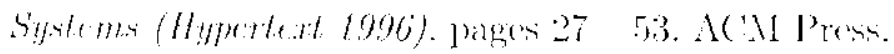

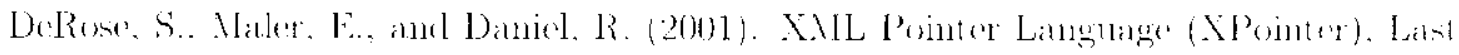
('all Working Dralt. online in Worlk Wirle Wro, http://www.w3.org/TR/xptr.

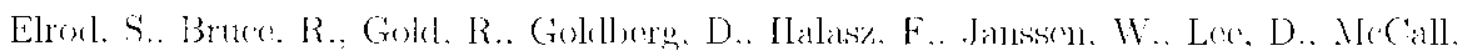
K.. Pederson. F. Pier. K., Tang. J.. and Wokt. B. (1992). Liveboard: a large

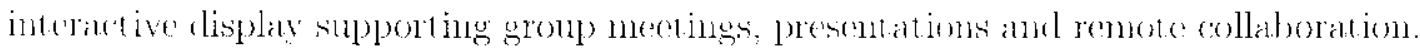

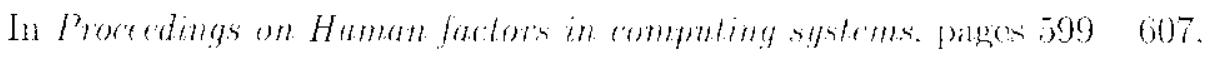

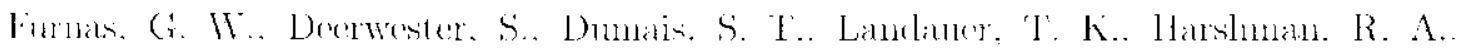

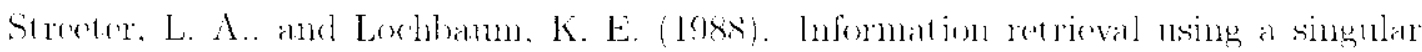

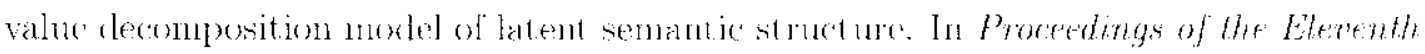




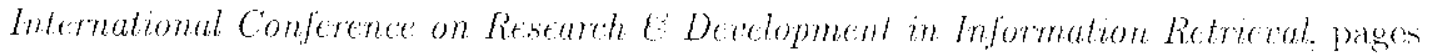
165.480.

Golovehinsky, G. (1997). What the query tokt the link: The integrations of hypertext and information retrieval. In Promerdings of the ACM Conformen on Hypertent $199 \%$ payes 3030.39.

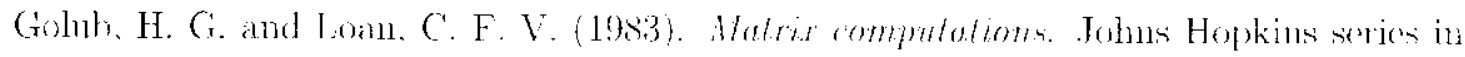
the mathematical sciences. Johns Hopkins Lniversity Press. 1a dition.

Green, s. (1999). Building hypertex links by computing semantic similarity. IEEE Transactions on Sinowhdge and Dala Engunceting. 11(5):71:3 730.

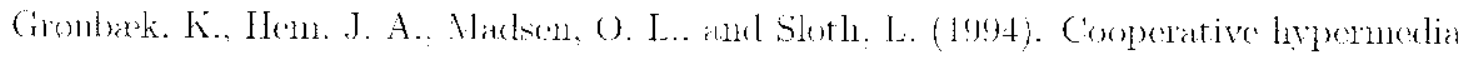

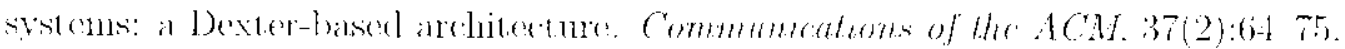

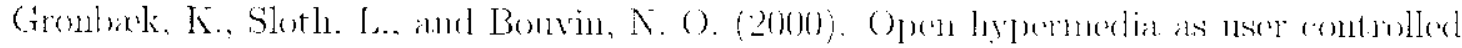

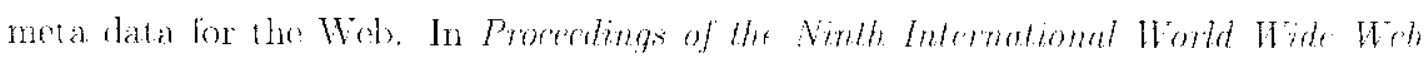

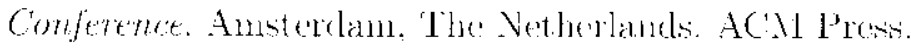

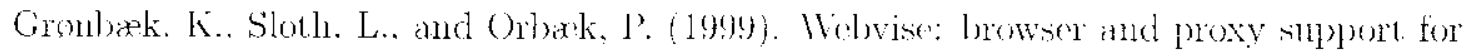

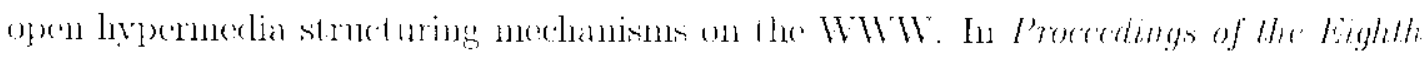

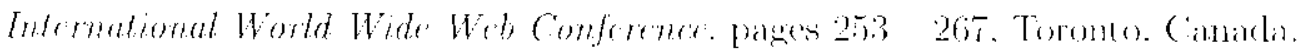

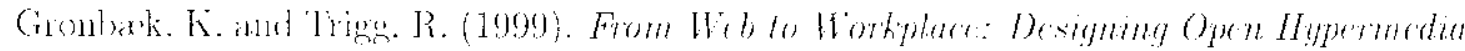

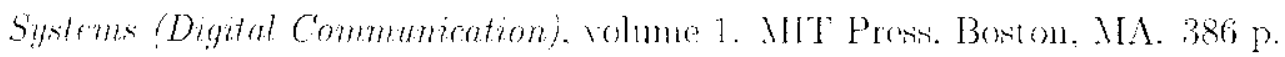

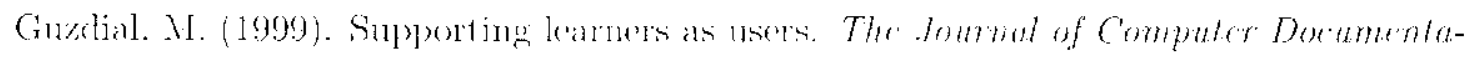
then: $23(2): 3 \cdot 13$.

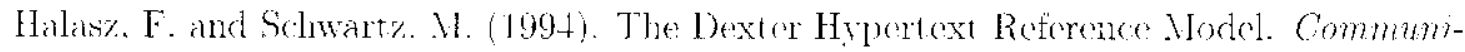
culions of the $40 \mathrm{~V} .37(2): 30) 39$.

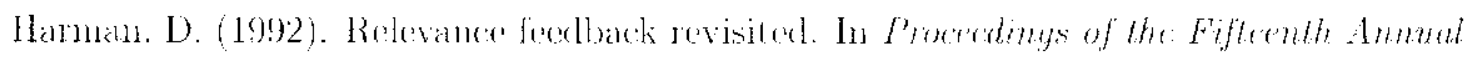

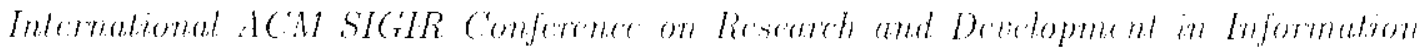
Retritutel pages $21 \quad 21$.

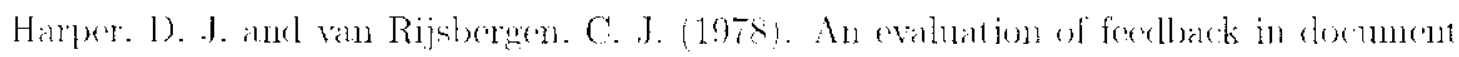

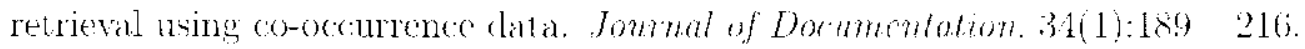

Henzinger: M. R. (2001). Hyporlink analysis for 1 he Woh. In IEEE Intemet Compulang. pages 1550 . 
Henzinger, M. R., Hevelom, A., Mitzemuather. M., and Najork, M. (1999). Measuring

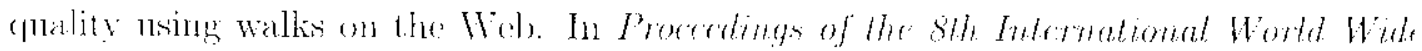

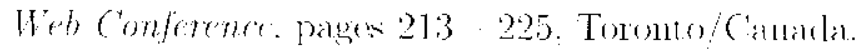

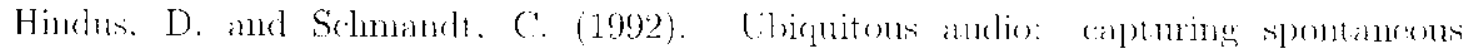

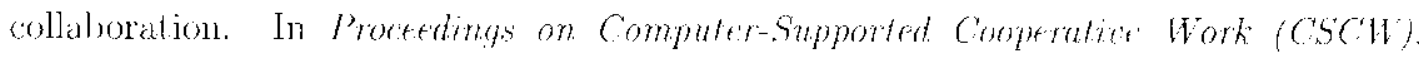
pagen $210 \quad 217$.

Ite. E. (1971). New experinnents in relevance foedlack. In Salton. G. oditor. The Smant Retrinal Syglem. pages 337 351. Prontice Hall.

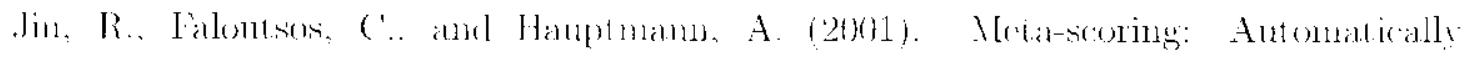

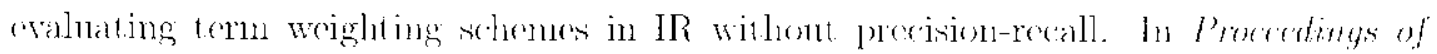
the 24 th Amunt Internulional ACM SICIR. pages : :3 X9.

Jome. K. S. (1972). A statistical interpretation of term specificity and its application in retrieval. Joumal of Docamentation. $28(1): 11$ - 21 .

Kaluan. J. Koivmen. M. l'rud1lommeanx, E., and Swick. R. R. (2)(k)1). Amoteal an

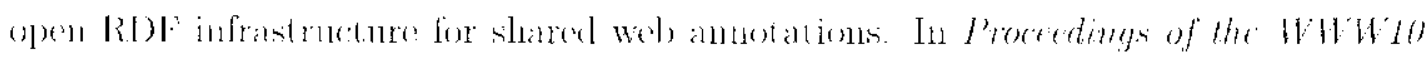
Intrational ('onfernere', Hong Kong.

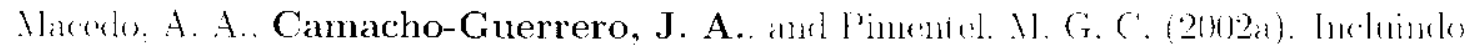

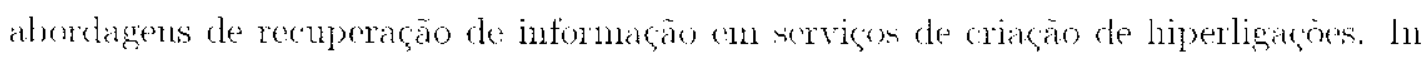

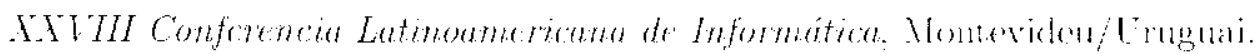

Materko. A. A. P'inentel, N. (i. (.. and Canacho-Guerrero, J. A. (20021)). Ani

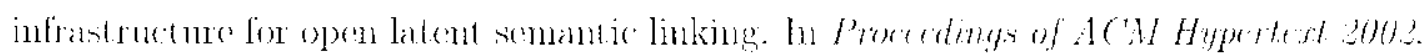

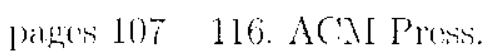

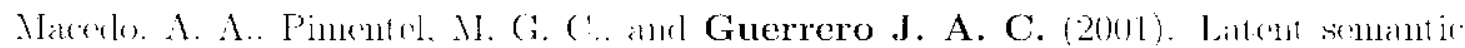
linking oxer homogenows repositoriss. In Procedings of the ACM Sympostum on

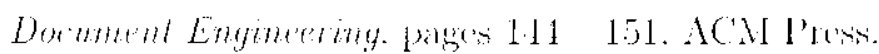

Malcon. K. C... Poltrock. S. E. and Schndeler. 1). (1991). Industrial strength hroermerlia:

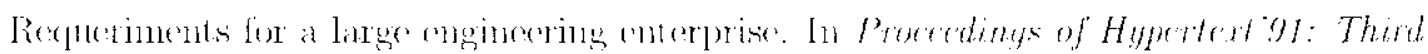
ACM Conference on Hyperten, panes 13 2 24. ACM Press.

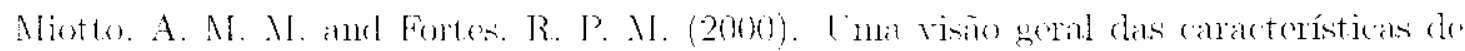

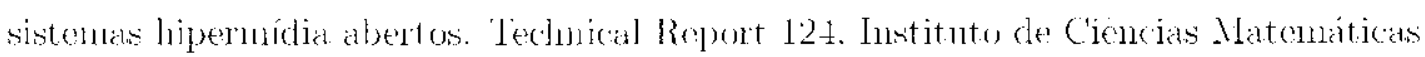

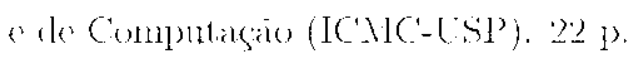


Mukhopadlya, S. aud Snith. B. (1999). Passive capture and strueturing of lextures. In

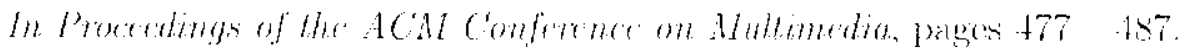

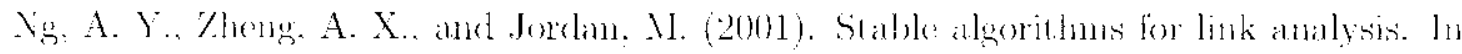
Proecedinge of SICIT ende page 9.

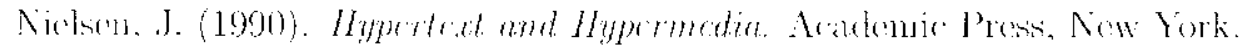

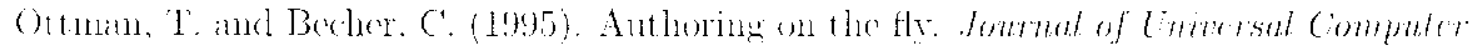
Srimer, $1(10): 7060717$.

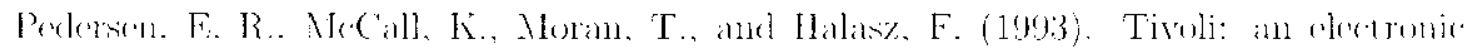
whitehoard for inlinmal workgroup mectings. In Procedongs on Human Fuetors in Compuling Systems pages 391 398.

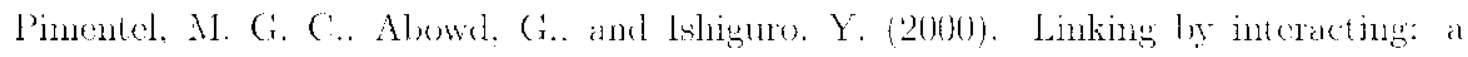

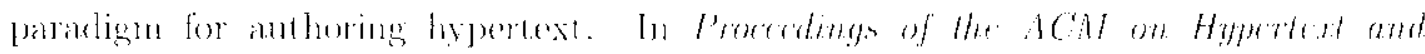
Hypermedan, pager 39 48, Sin Antonio-TX/LSA.

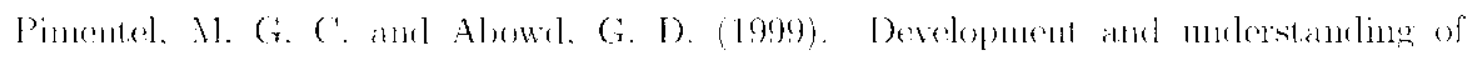

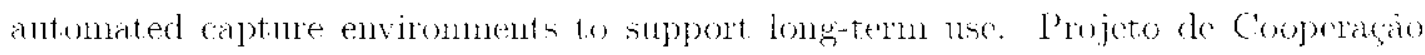

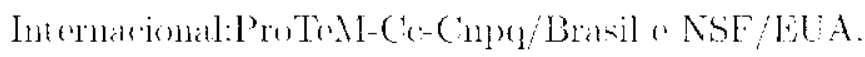

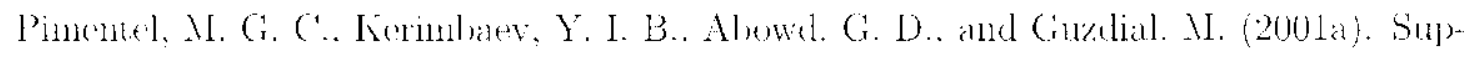

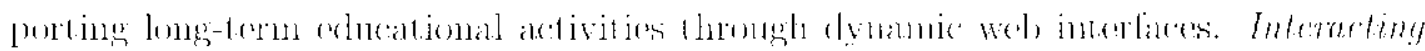
With Computers Joumal. 13:353 371.

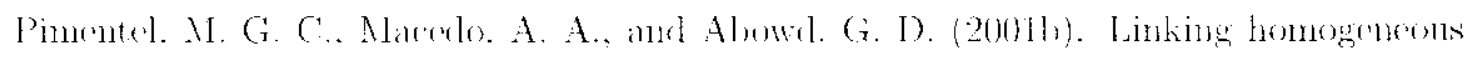

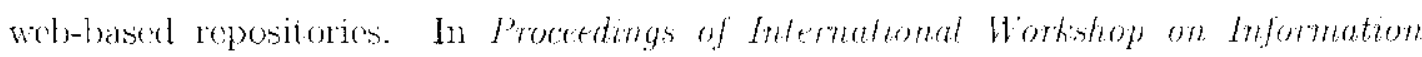

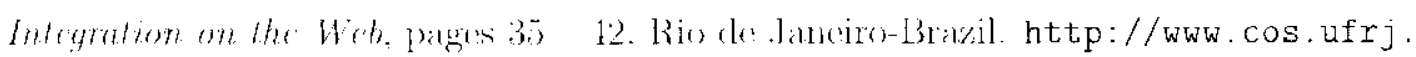
$\mathrm{br} /$ wiiw/schedule.html.

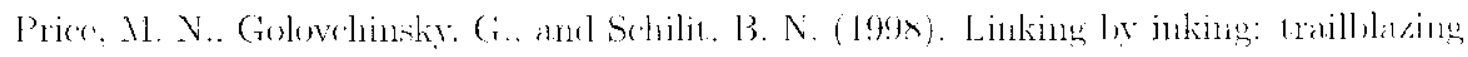

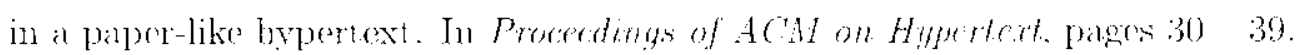

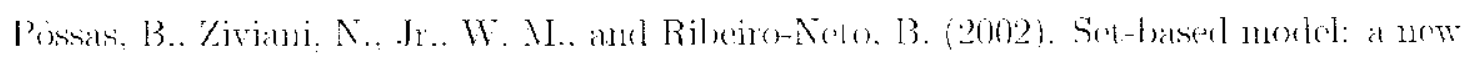

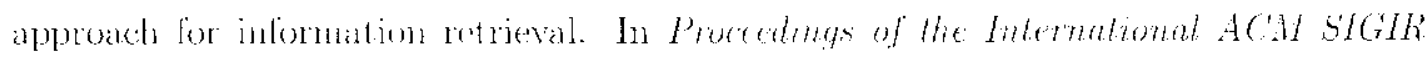

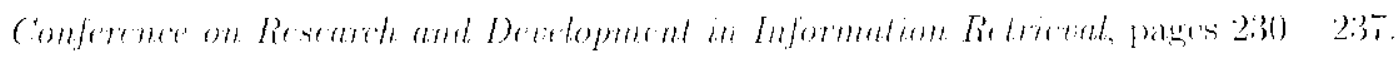

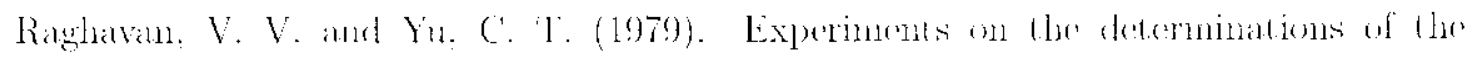

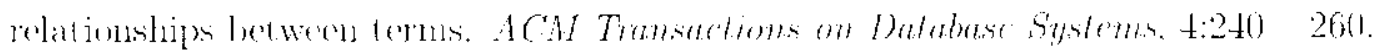


Robertson. S. and Jones. K. (1976). Relexance weighting of scalch toms. Joumal of the

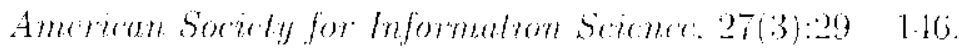

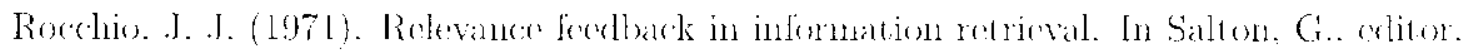

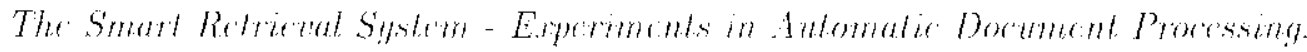

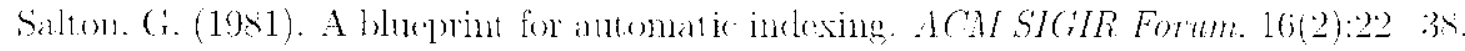

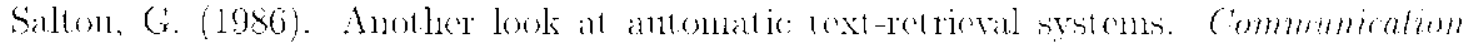
ACM 29. 7:648 6566.

Salten, G. and Allan. I. (1993). Solectivo toxt miliation and text trambersal. hu Proctedimgs of the ACM Confentene on Hyperted 199. pages $131 \quad 144$.

Saltom. G. and Bucklex ( $(1988)$. Ternu-weigh ing approuches in antomatic text ret rieval. Informalion Proctssing and Manugenent. 21(5):51:3 523.

Silton. G. and Lesk. M. (1968). Compuner avaluation of indexing and text procesing.

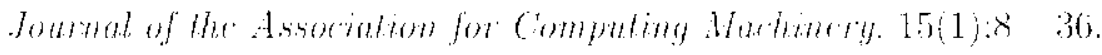

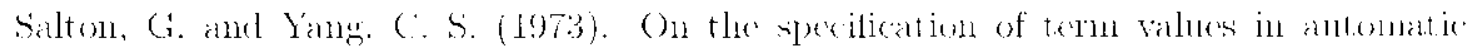

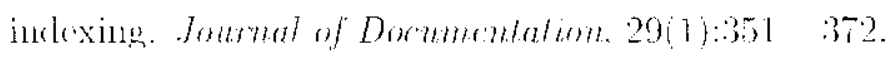

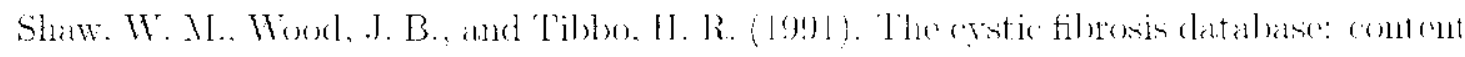

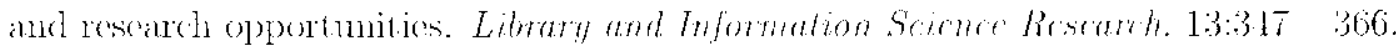

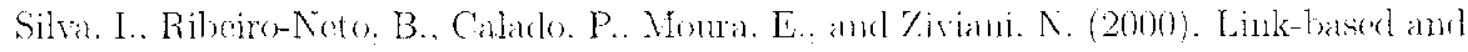

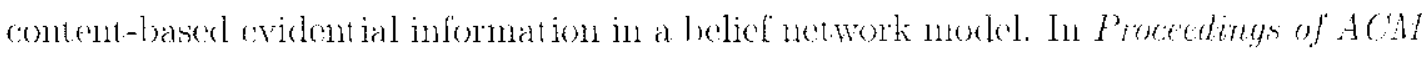

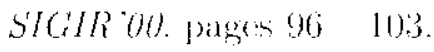

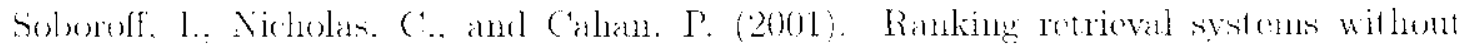

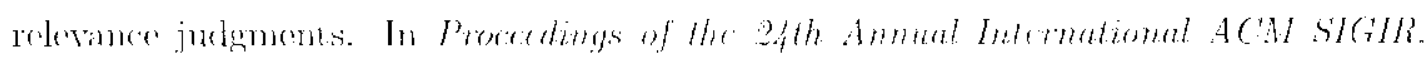
bages $66 \quad 73$.

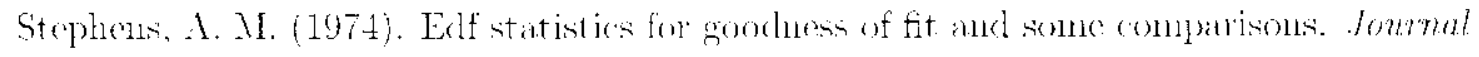
of the Antrian shatistial Assomiation. 69:730 733 .

Swan. R. and Allan. J. (1998). Aspect windews. 3-D visnalizations. and indirect

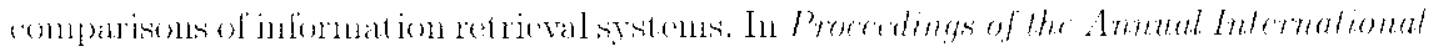

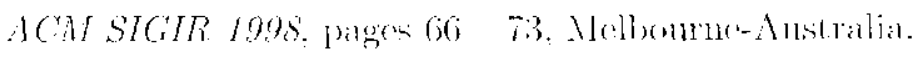


Tai, L. ('. (1996). Ardhitecture suppon for content-based hypermetiat. In l'rocedentes

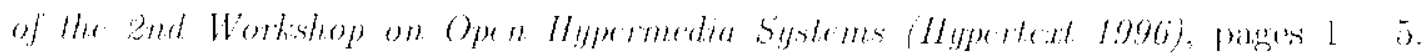
Wathingtom D.C.. CSA. ACXI Press.

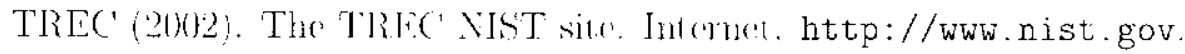

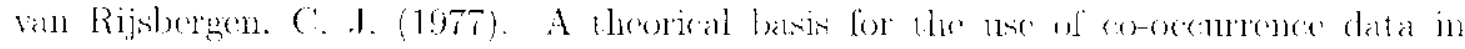
informat ism retrieval. Joumal of Documentation. 33(1):106 - 119. 